\title{
Further Analysis of Drivers Licensed with Medical Conditions in Utah
}

2 
This publication is distributed by the U.S. Department of Transportation, National Highway Traffic Safety Administration, in the interest of information exchange. The opinions, findings and conclusions expressed in this publication are those of the author(s) and not necessarily those of the Department of Transportation or the National Highway Traffic Safety Administration. The United States Government assumes no liability for its content or use thereof. If trade or manufacturer's names or products are mentioned, it is because they are considered essential to the object of the publication and should not be construed as an endorsement. The United States Government does not endorse products or manufacturers. 


\section{Technical Report Documentation Page}

\begin{tabular}{|c|c|c|c|}
\hline $\begin{array}{l}\text { 1. Repor No. } \\
\text { DOT HS } 809211\end{array}$ & 2. Government Accession No. & \multicolumn{2}{|c|}{ 3. Recipients's Catalog No. } \\
\hline \multirow{2}{*}{\multicolumn{2}{|c|}{$\begin{array}{l}\text { 4. Title and Subtitle } \\
\text { Further Analysis of Drivers Licensed with Medical } \\
\text { Conditions in Utah }\end{array}$}} & \multicolumn{2}{|c|}{$\begin{array}{l}\text { 5. Report Date } \\
\text { March, } 2001\end{array}$} \\
\hline & & \multicolumn{2}{|c|}{ 6. Performing Organization Code } \\
\hline \multicolumn{2}{|c|}{$\begin{array}{l}\text { 7. Author(s) D.D. Vernon, E. Diller, L. Cook, } \\
\text { J. Reading, and J. M. Dean }\end{array}$} & \multicolumn{2}{|c|}{ 8. Performing Organization Report No. } \\
\hline \multirow{2}{*}{\multicolumn{2}{|c|}{$\begin{array}{l}\text { 9. Performing Organization Name and Address } \\
\text { Utah CODES } \\
410 \text { Chipeta Way, Suite } 222 \\
\text { Salt Lake City, UT } 84108 \\
\end{array}$}} & \multicolumn{2}{|c|}{ 10. Work Unit No. (TRAIS)n code } \\
\hline & & \multicolumn{2}{|c|}{$\begin{array}{l}\text { 11. Contract of Grant No. } \\
\text { DTNH22-96-H-59017 Modification } 0004\end{array}$} \\
\hline \multirow{2}{*}{\multicolumn{2}{|c|}{$\begin{array}{l}\text { 12. Sponsoring Agency Name and Address } \\
\text { U.S. Department of Transportation } \\
\text { National Highway Traffic Safety Administration } \\
400 \text { Seventh Street, SW } \\
\text { Washington, DC } 20590\end{array}$}} & \multicolumn{2}{|c|}{$\begin{array}{l}\text { 13. Type of Report and Period Covered } \\
\text { NHTSA Technical Report, } 1992-1996\end{array}$} \\
\hline & & \multicolumn{2}{|c|}{ 14. Sponsoring Agency Code } \\
\hline \multicolumn{4}{|l|}{ 15. Supplementary Notes } \\
\hline \multicolumn{4}{|c|}{$\begin{array}{l}\text { 16. Abstract } \\
\text { The Utah Driver License Division has implemented a program since } 1979 \text { that restricts drivers with medical conditions } \\
\text { by functional ability category (medical condition) by assigning them a functional ability level. This study compares the } \\
\text { citation, all crash, and at-fault crash rates (per eligible licensed days) of medical conditions drivers at each functional ability } \\
\text { level, by category, to the rates of comparison drivers matched on age group, gender and county of residence over a five } \\
\text { year period. Analyses were performed separately for drivers reporting single medical conditions and those reporting } 2 \text { or } \\
\text { more medical conditions. Probabilistic linkage was used to link data from different databases in order to determine the } \\
\text { crash, at fault crash and citation rates by functional ability level classification at the time of occurrence. Corresponding } \\
\text { relative risks and confidence intervals were calculated. } \\
\text { Overall, for most functional ability categories, drivers in the medical conditions program had higher crash and at-fault } \\
\text { crash rates compared to their corresponding comparison groups, occurring at the numerically lowest (least restricted) } \\
\text { functional ability levels. The relative risk (odds ratios) were generally fairly modest, in the } 1.5-2.5 \text { range. For drivers with } \\
\text { multiple medical conditions, the functional ability levels were collapsed into two groups, unrestricted and restricted driving } \\
\text { privileges. Of the combinations of medical conditions analyzed, roughly half had higher risk of crashes and at fault-crashes } \\
\text { than comparison drivers; unrestricted and restricted drivers did not appear to differ materially. Further evaluation of the } \\
\text { medical conditions program, taking into account true exposure rates (miles driven), may be warranted. }\end{array}$} \\
\hline \multicolumn{2}{|c|}{$\begin{array}{l}\text { 17. Key words functional motor ability, medical } \\
\text { conditions, drivers, crash, citation, diabetes, epilepsy, } \\
\text { cardiovascular, pulmonary, alcohol, } \\
\text { vision, elderly, probabilistic linkage, CODES }\end{array}$} & \multicolumn{2}{|c|}{$\begin{array}{l}\text { 18. Distribution Statement } \\
\text { Document is available to the public through the National } \\
\text { Technical Information Service, } \\
\text { Springfield, VA } 22161\end{array}$} \\
\hline $\begin{array}{l}\text { 19. Security Classif. (of this report) } \\
\text { Unclassified }\end{array}$ & $\begin{array}{l}\text { 20. Security Classif. (of this page) } \\
\text { Unclassified }\end{array}$ & 21. No of Pages & 22. Price \\
\hline
\end{tabular}

Form DOT F1700.7 (8-72)

Reproduction of completed page authorized 


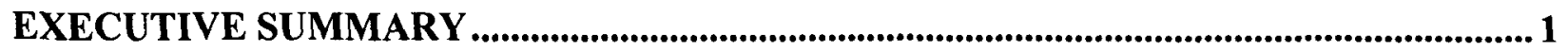

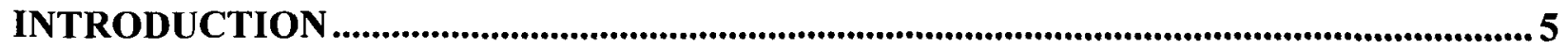

State of Utah Functional Ability in DRIVING: Guidelines and Standards for

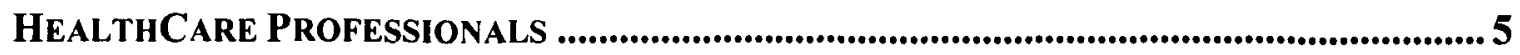

The Utah Crash OUtCome Data Evaluation System ................................................ 7

Evaluating the Existing Programof Licensing Drivers with Medical Conditions IN UTAH 8

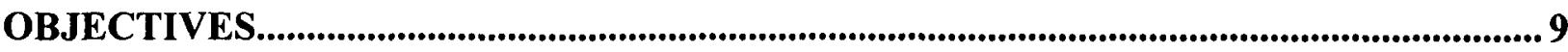

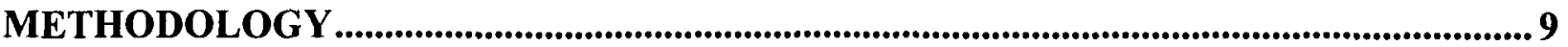

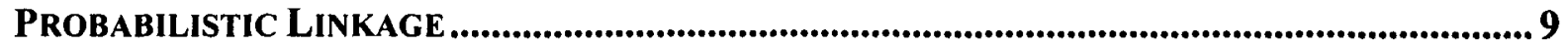

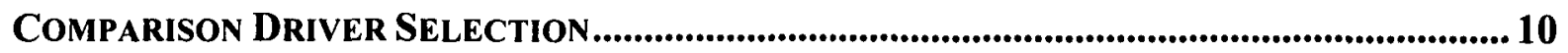

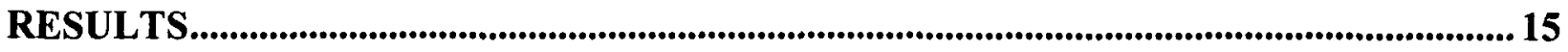

Diabetes Mellitus and Other Metabolic Conditions ........................................... 24

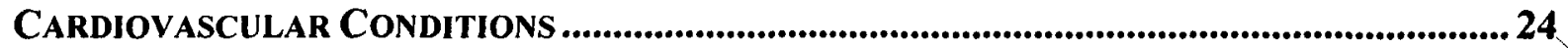

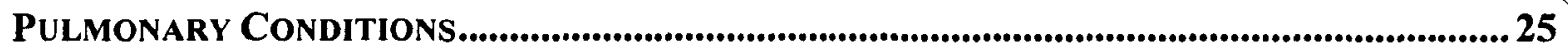

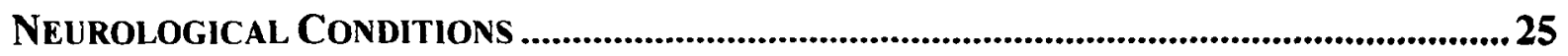

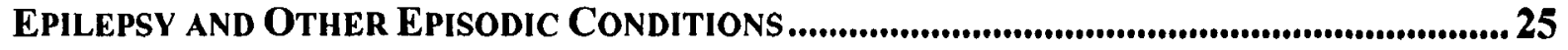

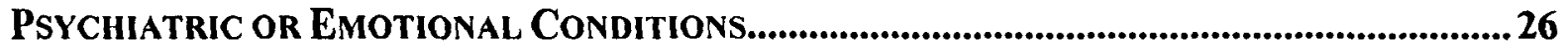

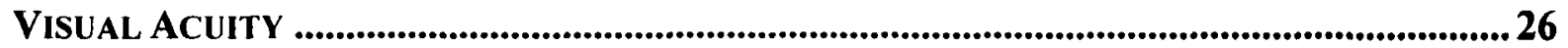

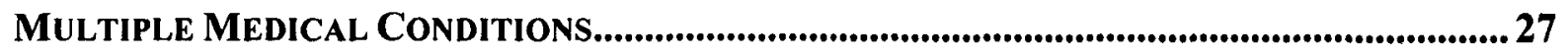

All Drivers Licensed in Multiple FunCtional ABility CATEGORIES........................ 35

DiabETES MELLITUS PLUS CARdIOVASCULAR CONDITIONS.............................................. 35

Diabetes MEllitus Plus Pulmonary Conditions ..................................................... 35

DiabETES MELlituS PluS NEUROLOGICAL CONDITIONS ................................................. 36

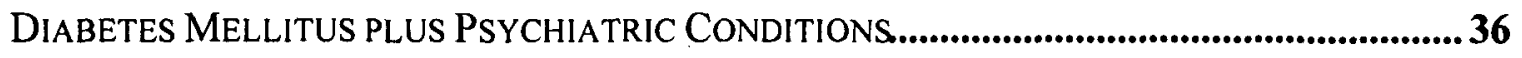

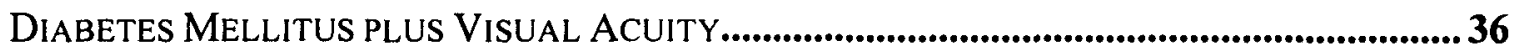

CARDIOVASCULAR PLUS PULMONARY CONDITIONS......................................................... 36

CaRdiovasculaR PlUS NEUROLOGICAL CONDITIONS.................................................... 37

CARDIOVASCULAR PLUS PSYCHIATRIC CONDITIONS.......................................................37

CARDIOVASCULAR PLUS VISUAL ACUITY ...................................................................... 37

CARDIOVASCULAR PLUS MUSCULOSKELETAL CONDITIONS................................................... 38

NEUROLOGICAL PLUS MUSCULOSKELETAL CONDITIONS...................................................... 38

NEUROLOGICAL PLUS FUNCTIONAL MOTOR CONDITIONS................................................... 38

MuSCULOSKELETAL PlUS FunCTIONAL MOTOR CONDITIONS............................................39

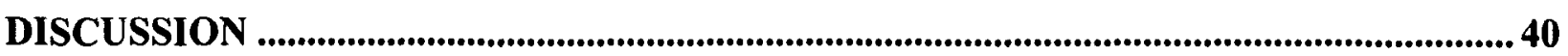

CONCLUSIONS AND RECOMMENDATIONS .................................................................. 43

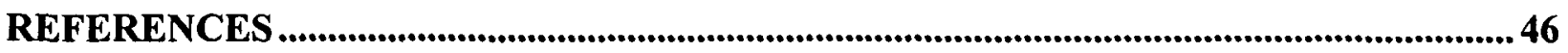

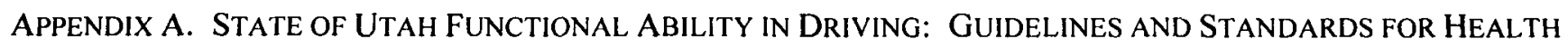
CARE PROFESSIONALS

APPENDiX B. General SCREening Questionnaire and Health Care Professional Forms

APPENDIX C. EXECUTIVE SUMMARY FROM FIRST REPORT 


\section{Executive Summary}

NOTE: This project is a continuation of Evaluating Drivers Licensed with Medical Conditions in Utah, 1992-1996, which was completed in June 1999 (DOT HS 809 023, available from the National Technical Information Service, Springfield, Virginia 22161). In order that this report be comprehensible as a stand-alone document, some of the introductory and explanatory materials from that report are repeated here.

The Utah Driver License Division operates a specialized licensing program for drivers who have medical conditions. The program was developed by the Division under the guidance of the Utah Medical Advisory Board, a group of physician advisors. The intent of the board was to create a program that improved public safety while imposing on drivers the fewest possible restrictions consistent with that goal. The program guidelines describe the physical, mental and emotional capabilities appropriate for various types of driving and thus determine license eligibility. The major function of the program is to identify drivers whose ability to drive may be impaired by their medical conditions, and then to control the impact of these limitations on traffic safety. This is accomplished by means of regulating how and when they may legally drive (that is, the imposition of restrictions on their driving privileges). Restrictions on licenses may include speed, area and/or time of day limitations. The program is based on self-reporting of medical conditions by applicants for driver's licenses. Drivers are first categorized by their specific medical conditions (termed functional ability categories by the program) and then by their ability to drive [termed functional ability level (1-12)]. The imposition of a restriction, and the kind of restriction, is indicated by the functional ability level. Drivers who are licensed with medical conditions may receive a full unrestricted or restricted license depending on their functional ability level.

The functional ability or medical condition categories include:

1. diabetes mellitus and other metabolic conditions

2. cardiovascular conditions

3. pulmonary conditions

4. neurological conditions

5. epilepsy and other episodic conditions

6. learning/memory/communications

7. psychiatric or emotional conditions

8. alcohol and other drugs

9. visual acuity

10. musculoskeletal abnormalities/chronic medical debilities

11. functional motor ability

12. hearing

The Utah Crash Outcome Data Evaluation System project (CODES) was funded to evaluate the effect of the existing medical condition licensing program on public safety. The project was funded by the National Highway Traffic Safety Administration (NHTSA), with the support of the Utah Driver License Division in the Utah Department of Public Safety, and the Utah Department of Transportation. 
In order to measure the effectiveness of this public safety program, we compared the citation, total crash and at-fault crash rates of drivers licensed with medical conditions to those of similar drivers matched on age group, gender and county of residence. Comparison drivers were obtained randomly from the general driving population and rates of adverse driving events were examined over a five-year period, 1992-1996. A two-to-one matching strategy was used. Sampling was performed with replacement.

Analyses were conducted for each functional ability category (medical condition) by each functional ability level. Analyses for drivers licensed with two medical conditions were conducted separately, by restriction status. We used probabilistic linkage to link data elements relating to the same driver from several different databases in order to combine the elements needed for the study (i.e., crash, violation and driver license databases). Many subgroups contained very small numbers of drivers; analysis was reported only when the number of subjects was sufficiently large to allow for meaningful analysis.

The rates of citation, crashes and at-fault crashes, expressed as events per 10,000 licensed days, varied between the populations and events of interest. No functional ability category appeared to be at greater risk for citations; some levels in the two largest categories, diabetes and cardiovascular, actually had lower rates of citations (for levels 3, and 3-4 respectively) than controls. For several medical conditions, there were significantly higher rates of crashes and atfault crashes than for controls, mostly for functional ability levels 3-5. Crash rates were significantly higher than controls for diabetes (levels $3 \& 4$ ), cardiovascular (level 5), neurological (levels 3-5), epilepsy (level 3-6), psychiatric (levels 3-6), and visual acuity (levels 3-6 and level 8). For at-fault crashes, rates were significantly higher than control for diabetes (levels 3-5), pulmonary (level 3), neurological (levels 3-5), epilepsy (levels 3-6), psychiatric (levels 3-6), and visual acuity (levels 3-6 and level 8). The magnitude of increased frequency for these groups was generally moderate, with odds ratios typically in the 1.5-2.5 range. For a few functional ability categories, crash and at-fault crash rates were higher than comparison drivers at the highest functional ability levels (that is, the most restricted); however the actual number of crash events in these subgroups was very small. Of note, several functional ability categories were so small (memory and communications disorders; alcohol and other drugs) that analysis of each functional ability level for them was not meaningful and was not done.

Drivers who were licensed in more than one functional ability category (reported more than one medical condition) during the study period were considered separately for the most common combinations of conditions. Only two-way combinations were analyzed, since there were few drivers reporting three or more separate medical conditions. Also, many of the possible combinations contained so few subjects that analysis was not meaningful and is not reported. Again because of small subgroup numbers, the functional ability levels were collapsed into two groups, restricted and unrestricted drivers. First, unrestricted drivers (functional ability levels 3 5 ) were analyzed. No combination had higher rates of citations than controls, while two combinations (diabetes+cardiovascular, and cardiovascular+neurological) actually had lower rates than controls. Crash rates were lower than controls for one group (diabetes+cardiovascular) and higher than controls for several others: diabetes+neurological, diabetes+psychiatric, diabetes+vison, neurological+musculoskeletal, neurological+functional motor, and musculoskeletal+functional motor. The magnitude of difference was moderate, with odds ratios 
being in the range 1.5-2.3 for the most part. Rates of at-fault crashes for unrestricted drivers with two medical conditions were higher than controls for diabetes+cardiovascular, diabetes+neurological, diabetes+psychiatric, diabetes+vison, neurological+musculoskeletal, and musculoskeletal+functional motor. Odds ratios ranged from 1.4 to 3.0. For this multiple medical conditions group, numbers of crash and at-fault crash events were low, 30-100 except for the largest combination group diabetes+cardiovascular.

Then, the multiple medical conditions group was analyzed for restricted drivers (functional ability level 6-11). No combination had higher citation rates than controls, while one group (cardiovascular+neurological) had lower rates. Crash rates were higher than control for 4 groups: diabetes+cardiovascular, neurological+musculoskeletal, nerulogical + functional motor, and musculoskeletal+functional motor. Odds ratios were 2.0-2.4 and numbers of crash events was low, 11-17. At-fault crash rates were higher than control for 6 groups:

diabetes+cardiovascular, diabetes+visual acuity, cardiovascular+visual acuity, neurological+musculoskeletal, musculoskeletal+functional motor, and musculoskeletal+functional motor. Odds ratios were 2.6-3.3, and the numbers of events were again low, 8-12 for each group.

The results of this study provide contextual information on the effects of the medical conditions licensing program on public safety. When analyzed by specific medical condition and functional ability level, medical conditions drivers overall had sporadically elevated rates of crashes and atfault crashes compared with control drivers. For specific conditions, elevations in adverse driving events, if they occurred, were in the numerically lowest functional ability levels (that is, levels where driving privileges were least restricted). For the subset of drivers with multiple medical conditions, several specific combinations of medical conditions were associated with higher rates of crashes and at-fault crashes compared with controls. For most of these multiple conditions groups, absolute numbers of both drivers and adverse events were very low.

As with any injury control intervention, evaluation is an essential component of the program in order to identify areas of increased risk and to provide feedback to the administering agency. The aim of this research was to evaluate the rates of adverse driving events by individual functional ability levels in order to determine if there were distinct levels for which risk increases or decreases, and to describe the effects of co-existing medical conditions. Some subgroups of medical conditions drivers did appear to have increased rates of crashes and at-fault crashes compared with controls. Almost all of these subgroups were in numerically low functional ability levels, such that their driving privileges were not restricted. The differences in rates were generally of modest magnitudes, and conceivably could be deemed acceptable. The increase in crash and at-fault crash rates might be addressed by changing the functional ability levels to restrict the driving privileges of currently unrestricted drivers. Such a change would have to be broad, covering all or nearly all of the medical conditions categories, since the increase in rates was seen in most of the categories. Further, it is not known that such a change in the program would affect the rates of crashes and at-fault crashes for these drivers. For the drivers with multiple medical conditions, there were groups with increased rates of crashes and at-fault crashes in both restricted and unrestricted functional ability levels. The absolute numbers of crashes, however, were so small that program alterations specifically to address this may not be worth considering. 


\section{Introduction}

NOTE: This project is a continuation of Evaluating Drivers Licensed with Medical Conditions in Utah, 1992-1996, which was completed in June 1999 (DOT HS 809 023, available from the National Technical Information Service, Springfield, Virginia 22161). In order that this report be comprehensible as a stand-alone document, some of the introductory and explanatory materials from that report are repeated here. The Executive Summary from the first report is included here as Appendix C.

\section{State of Utah Functional Ability in Driving: Guidelines and Standards for Health Care Professionals}

Driver license agencies, as regulatory entities, have the responsibility of developing and enforcing policies that protect public safety, while balancing the risks of licensing drivers who have physical or mental impairments. Utah is not unique in the development and implementation of a licensing program for drivers with medical conditions; most states have specific policies related to physical and mental function and driving (1). The rationale for such programs is that certain diseases or conditions could impair driving ability and, therefore, drivers with medical conditions should be subject to a more rigorous screening process so that they do not jeopardize others on the roads (2). Any such program, however, must be applied in a careful and reasonable fashion; note that it is unlawful for any State or local government under the Americans with Disabilities Act to discriminate against a qualified person with disabilities on the basis of those disabilities.

Because of the demographic shift in the age of our population (3), and the higher prevalence of chronic medical conditions in elderly persons, it is increasingly important to evaluate the effects of these existing programs and to assure that they are protective of public safety as is their intent. The number of drivers in these programs will only increase in future years and modifications resulting from such analyses, can provide future benefit.

The Utah Driver License Division implemented a program in 1979 to license drivers with medical conditions. In 1981, the Utah Driver License Division Medical Advisory Board (a physician advisory group) redesigned the written standards of the program that describe the physical, mental and emotional capabilities appropriate for various types of driving. The intent of the board was to create a program that improved public safety while imposing on drivers the fewest possible restrictions consistent with that goal.

The program uses a general questionnaire to screen all license applicants within the state to identify medical conditions related to the applicant's physical, mental and emotional health. Applicants who report a medical condition when completing the questionnaire are placed into one (or more) of twelve broad categories of medical diagnoses. These are termed functional ability categories by the program and are listed in Table 1. In this report, the terms functional ability category and medical condition are used interchangeably to refer to these 12 categories: 
Table 1: Functional ability categories

1. diabetes mellitus and other metabolic conditions

2. cardiovascular conditions

3. pulmonary conditions

4. neurological conditions

5. epilepsy and other episodic conditions

6. learning/memory/communications

7. psychiatric or emotional conditions

8. alcohol and other drugs

9. visual acuity

10. musculoskeletal abnormalities/chronic medical debilities

11. functional motor ability

12. hearing

Applicants identifying themselves on the questionnaire as having a medical condition are evaluated for the potential impact of their medical condition on their ability to drive a motor vehicle. Based upon the results of the questionnaire, an applicant may have a driver license immediately issued, or the applicant may be required to complete a more extensive health history form. An applicant identified as having a medical condition may be required to provide documentation by a health care provider to verify his or her functional ability level before a license will be issued. Applicants are then rated on their ability to drive by being placed into one of 12 classifications. These are termed by the program, somewhat confusingly, as functional ability levels. Scaling is done by a medical professional according to detailed guidelines provided by the program. A copy of the State of Utah Functional Ability in Driving: Guidelines and Standards for Health Care Professionals is located in Appendix A. Copies of the general screening questionnaire and the corresponding forms that are completed by health care professionals are located in Appendix B. The functional ability level assignment signifies various constraints and restrictions on driver license privileges. Driving privileges are increasingly more restricted at numerically higher levels. Depending upon the functional ability category (medical condition) and functional ability level $(1-12)$, an applicant who has a medical condition may receive full (unrestricted) or restricted driving privileges, or the license application may be denied. Specifics of restrictions for a given functional ability level are not totally consistent between different functional ability categories (medical conditions). However, the restrictions associated with functional ability levels can roughly be summarized as described in Table 2. 
Table 2. Relationship of Functional Ability Profiles to Driving Risk/Responsibility or Limitation

\begin{tabular}{|c|c|}
\hline $\begin{array}{l}\text { Functional Ability } \\
\text { Profile Level }\end{array}$ & $\begin{array}{c}\text { Driving Risk/Responsibility, License Class or } \\
\text { Limitations }\end{array}$ \\
\hline $1-2$ & $\begin{array}{l}\text { Irrelevant for private drivers. } 1 \text { is used for commercial } \\
\text { drivers and } 2 \text { is for drivers with a history of a medical } \\
\text { problem which is now resolved. No restrictions on driving } \\
\text { privileges or licensing periods. }\end{array}$ \\
\hline 3-5 & $\begin{array}{l}\text { No restrictions on driving privileges; licensing periods are } \\
\text { shortened. }\end{array}$ \\
\hline 6 & Driving with speed limitations \\
\hline 7 & Driving with speed and area limitations \\
\hline 8 & Driving with speed, area and time of day limitations \\
\hline 9 & $\begin{array}{l}\text { Driving accompanied by licensed driver with limitations of } \\
\text { speed and/or area and/or time of day limitations as } \\
\text { recommended by health care professional }\end{array}$ \\
\hline 10 & $\begin{array}{l}\text { Special driving limitations recommended by health care } \\
\text { professional not covered above }\end{array}$ \\
\hline 11 & $\begin{array}{l}\text { Under evaluation - may or may not drive, according to } \\
\text { circumstances as determined by director, with medical } \\
\text { advice as appropriate }\end{array}$ \\
\hline 12 & No driving \\
\hline
\end{tabular}

The major product of this program, then, is the imposition of driving restrictions on individuals who have medical conditions and whose medical conditions, after evaluation, appear to adversely affect the ability to drive a motor vehicle. The restrictions are applied by placement in functional ability levels. (Applicants who disagree with the level assigned by their health care provider may contest the level and have it reviewed by the Utah Driver License Medical Advisory Board.)

\section{The Utah Crash Outcome Data Evaluation System}

The Utah Crash Outcome Data Evaluation System (CODES) was created in 1992 at the University of Utah School of Medicine through a successful competitive funding application from the National Highway Traffic Safety Administration (NHTSA). Utah was one of the initial seven CODES states that used probabilistic linking techniques to link computerized data from motor vehicle crashes with those from several health care related data sets including emergency medical services and hospital inpatient and emergency department databases. The initial objective of CODES was to measure the effectiveness of safety belts and motorcycle helmets (4). Since its creation, Utah CODES has linked and analyzed state crash, ambulance, hospital inpatient and outpatient data in part or entirely for the years $1991-1997$.

Utah CODES has become an integral partner with the Utah Department of Public Safety, the Utah Department of Health and the Utah Department of Transportation in injury control efforts related to traffic safety in the state. Analysis of the linked data sets has identified the medical and 
resulting financial outcomes for injuries caused by crashes. Utah specific data have been used to analyze the effects of pending legislative issues and to support changes that would be of benefit to public health and safety (e.g., implementation of a primary seatbelt law and graduated licensing program for teens). Because program staff have the capability and experience in probabilistic linkage and analytical techniques, Utah CODES possessed expertise to perform the necessary linkages in order to evaluate the existing program of licensing drivers with medical conditions.

\section{Evaluating the Existing Program of Licensing Drivers with Medical Conditions in Utah}

Several agencies approached Utah CODES about evaluating the medical conditions licensing program in the state. According to the Department of Public Safety, the program is controversial; many drivers feel the program is unwarranted while others feel the standards set forth are so lenient as to compromise public safety. Utah's medical conditions program and the associated guidelines have been regarded as one of the more effective such programs in the country. Ufortunately research in this area is sparse. Consequently, both the Utah Medical Advisory Board and the Utah Driver License Division were interested in evaluating the effects of the program. Because of the applicability of the research to public policy, Utah CODES was funded to evaluate the effect of the existing system. The project was funded by NHTSA with the support of the Utah Driver License Division in the Utah Department of Public Safety and the Utah Department of Transportation. 


\section{OBJECTIVES}

The purpose of the study was to compare the crash and citation rates of drivers with medical conditions to drivers without medical conditions. We sought to analyze each functional ability level for each functional ability category (medical conditions) for the study period $1992-1996$. Some functional ability categories were excluded from analysis entirely, however, because they contained too few drivers for analysis by each functional ability level. Also, some specific functional ability levels for other functional ability categories were excluded because of very small numbers. Analyses for drivers licensed with multiple medical conditions were performed separately, by restriction status.

\section{METHODOLOGY}

\section{Probabilistic Linkage}

Data used in this analysis existed in several disparate databases available to Utah CODES. Probabilistic linkage was used to link data elements from these databases in order to combine the relevant data elements needed for such a study. Probabilistic linkage is an iterative tool which can overcome inaccuracies or differences in the separate databases (e.g., incorrect, missing or duplicate data, typographical errors, changes in surnames, etc.) which exact matching cannot; it is amply described elsewhere $(6,7)$. Data linkages were performed using Automatch Software® and are described below:

\section{Crash to Utah Master Driver License File}

Variables from the Utah Department of Transportation Crash Files were linked to variables from the Utah Master Driver License File for the years 1992-1996. Fields used to link these two files included the license state of the crash driver, name (last, first, middle initial), sex, date of birth, and driver license number. The medical condition database was provided in a relational file to the Utah Master Driver License File.

The crash file identified 397,849 Utah licensed drivers as having had a crash during the study period. The Utah Master Driver License File contained 1,750,918 drivers license records. Of the Utah licensed drivers in crashes, 384,311 (97\%) drivers were successfully matched to the corresponding driver license records. A copy of the match file is located in Appendix C.

\section{Utah Death Certificate Database to Utah Master Driver License File}

Probabilistic linkage was used to identify persons who held valid driver licenses and died either during the study period, or in the five years previous to the study period. This linkage was performed because drivers licensed with medical conditions were thought to have a higher mortality rate than the general population of drivers and deaths would effect the eligible number of driving days. Variables used to link these two files included name (last, first, middle), city, state, residential zip code, sex, date of birth, and social security number. 
The death certificate database was subset to include persons ages sixteen years and over (i.e., persons eligible for a driver license). Thus, the resulting data set contained 100,248 death certificates for the years 1986-96 that were linked to $1,750,918$ drivers license records from the 1997 Utah Driver License Master File. Of these, 59,709 (59.6\%) were successfully matched.! This matching procedure allowed a date of death variable to be created for drivers who died during the study period. By creating this variable, drivers who held valid driver licenses when they died could be excluded at the date of death (since deceased persons cannot drive even though their license is still valid) and allowed the replacement of comparison drivers who died prior to the study start date. ${ }^{2}$ This procedure was performed in order to minimize misclassification bias of the number of days a driver was eligible to drive in the study. A copy of the match file is located in Appendix C.

\section{Comparison Driver Selection}

Ideally, crash and citation rates should be related to exposure, expressed as events per mile driven and controlled for risk factors that affect the likelihood of the event occurring. For example, if two drivers have the same number of crashes per year but one drives only half as much as the other, the rates are the same per unit time but two-fold higher when comparing driving distances. Additionally, factors such as weather, road surface, traffic conditions and speed limit may affect crash risk. Likewise, local law enforcement patterns in areas where drivers frequently drive affect the risk of citation. Unfortunately, true exposure data is not available. There is no reliable information on the number of miles driven by individuals with medical conditions.

'The following checks confirmed these results:

1. Check of Linkage Strategy and Other State's Experiences

Linkage strategy was reviewed internally by Utah CODES staff and externally by Mike McGlincy of Matchware, Inc. A similar linkage using Los Angeles County drivers and voters, matched at around $60 \%$.

2. Manual Check of Subset

Death certificates contain a code for cause of death. One such code is driver in a crash (Ecodes $8100,8110, \ldots 8190)$ ). 628 individuals were so identified, and 593 were found to be successfully linked (94\%). The remaining 35 individuals were looked up in the crash files. 17 of these drivers were from out of state and therefore, did not have a Utah license. 12 drivers did not have a license number in the crash file, although the state was identified as Utah. This would leave a linkage rate of $593 / 599$ (99\%). 4 drivers had license numbers that did not match to the DMV file (e.g., possible data entry errors). The remaining 2 individuals had a Utah drivers license and were found in the DMV data. For these two drivers, social security numbers did not match on 7 and 9 digits respectively.

${ }^{2}$ Overall, drivers with medical conditions did not have a higher mortality rate during the study period than those selected comparisons. Of the 68,769 drivers with medical conditions who renewed their licenses after 1/1/92, $3,810(5.5 \%)$ matched to the death certificate file. Two comparison driver records were selected for each medical condition driver. Of those records, 10,372 (7.5\%) of the selected comparison records linked to the death certificate file. However, it is important to note that comparison drivers did not have to renew after $1 / 1 / 92$ to be included in the study. This was because their driver licenses are valid for 4 or 5 years depending upon the date of issue, as opposed to the shorter periods for drivers licensed with medical conditions. When limiting the linkage results to those comparison drivers who renewed their driver licenses after $1 / 1 / 92$, the percentage of drivers linking to the death certificate file was $3.2 \%(3,975 / 122,863)$. 
This concept of exposure is important when comparing the crash and citation rates of different populations, particularly in the older persons or persons who have medical conditions that may affect driving. During the study period, drivers who reported medical conditions in Utah were much different than the general population of drivers. Figure 1 illustrates the differences in ages between the medical condition drivers by restriction status and the rest of the driving population. Note that the medical conditions driving population is much older than the general driving population overall, and that restricted drivers tend to be older than unrestricted drivers licensed with medical conditions. In addition to age, other characteristics of drivers with medical conditions may affect their driving habits. It has been shown that chronically ill drivers who are not confident in their driving ability limit the amount they drive, or limit their driving to times or conditions when they feel comfortable to drive $(8,9)$. For example, persons who do not see well at night may schedule trips during daylight hours. These factors meant that a direct comparison of medical conditions program drivers with the entire population of Utah drivers would probably not be valid.

While ideally a study to evaluate the medical conditions program would consider exposure and these other factors, such data were not available. Because collecting these data would have been cost prohibitive, we determined that the best method to approximate these factors would be to match drivers with medical conditions to a representative comparison group. We reasoned that drivers of similar age and location are likely to drive similar amounts, so that age- and locationmatching would be a reasonable proxy for true exposure rates.

A case-control methodology was therefore chosen for this study. For each driver with a medical condition, two drivers without medical conditions from the same age group, gender and county of residence were selected for comparison. For this study, only drivers without medical conditions were eligible to be chosen as a comparison driver. This category excludes all drivers with medical conditions and drivers with incomplete information in the master driver license file. 
Figure 1. Percentage of Drivers Reporting Medical Conditions by Restriction Status Compared to Drivers Not Reporting Medical Conditions By Age, Utah 1992 - 1996

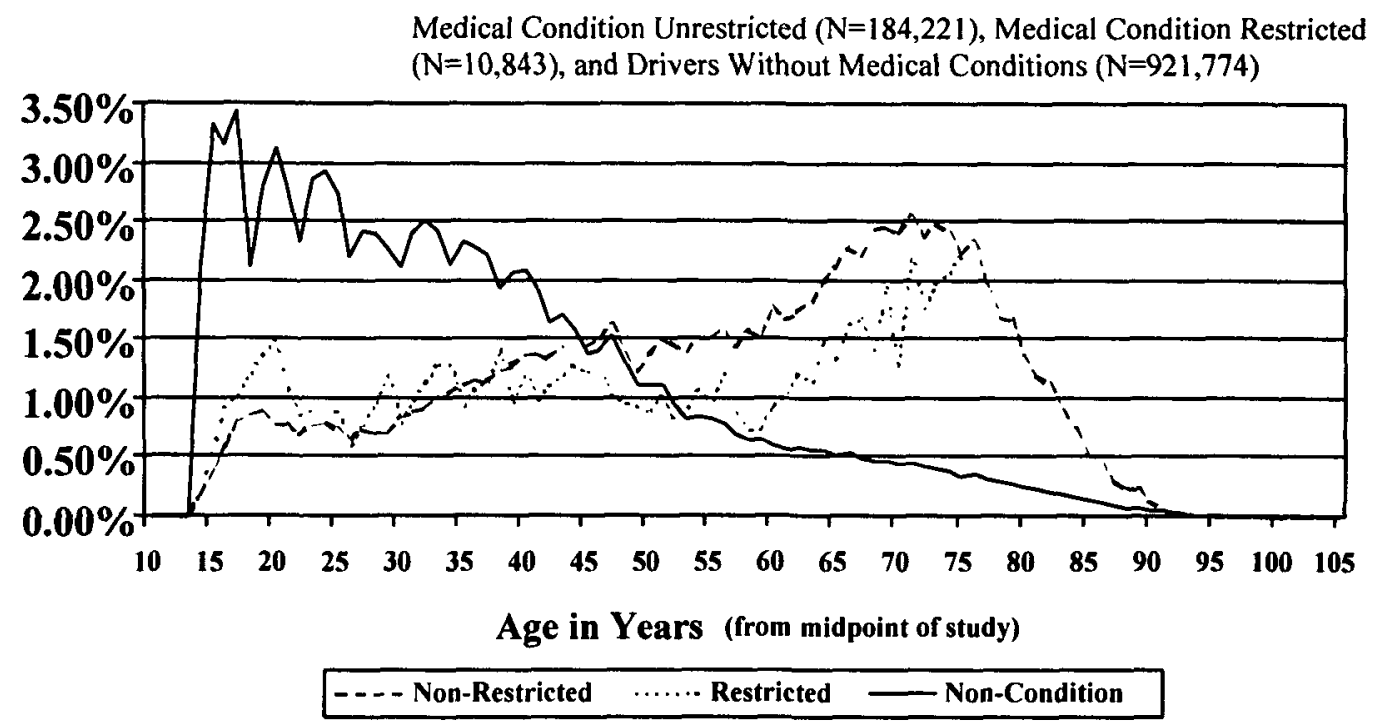

Drivers in the medical conditions program were subdivided by functional ability category (that is, medical conditions categories) (Table 1). The category "hearing" was excluded from analysis since this category was only used for commercial drivers. Drivers in each functional ability category were further subset by functional ability level (Table 2). If a driver with a medical condition fluctuated between functional ability levels over time, he or she was counted in each level for the appropriate time period. The same comparison drivers were used for each medical condition driver who fluctuated for functional ability level. Comparison drivers were followed for the duration if they held a valid driver license during the study period. Drivers listed in multiple functional ability categories were analyzed separately by restriction status. These groupings were further separated into categories by age group, county of residence and gender. Age groups included years 10-14, 15-19, 20-24, 25-29, 30-39, 40-49, 50-59, 60-69, 70-79, 80 and older. Driver's age was calculated at the midpoint of the study period using the date of birth available in the Master Driver License File. We included the age group 10-14 in order to capture new drivers entering the study near the endpoint (1995-1996).

Comparison drivers were selected randomly from all licensed drivers not in the medical conditions program from the 1997 master file. Commercial drivers who were licensed at functional ability level 1 (no history of disease/condition) were not included in the population from which a comparison driver could be selected. Similarly, drivers licensed at functional ability level 2 (past history of disease/condition but licenses are issued the same as the general driving population) were excluded. For each driver with a medical condition, two comparison drivers fitting the grouping criteria (age group, county of residence and gender) were chosen at random from the Utah Master Driver License File. Sampling for comparison drivers was performed with replacement, meaning that each possible comparison driver was eligible to be selected even if that driver was chosen previously to be a comparison. This method was used 
because there were too few drivers in some groupings to select two unique comparison drivers for each medical condition driver from the same age group, sex and county of residence.

The results of probabilistic linkage were used to determine the number of eligible licensed driving days by functional ability level; and the number of crashes, at-fault crashes and citations occurring at that functional ability level for each driver. Drivers with medical conditions who fluctuated between functional ability levels had the corresponding number of days at each level assigned. As mentioned previously, drivers who died during the study period had their corresponding number of eligible driving days adjusted so that the date of death was included but the following days excluded. Similarly, if a chosen driver had his or her driving privileges suspended because of citations or crashes, they were not excluded from the study; the number of eligible license days was adjusted to reflect the suspension. ${ }^{3}$

Comparison drivers were followed for the duration of the study $(1992-1996)$ by their eligible number of driving days (the number of days they held a valid driver license) during the study period. The number of days used for these groups was higher than the number of days for drivers with medical conditions because the licensing periods are much shorter for drivers who have medical conditions (shorter licensing periods are built into the medical conditions driver program). For example, if a driver with a medical condition was in the database for 1 year of the study period, he or she would be counted for 365 days. However, his or her corresponding driver would have been followed from $1992-1996$, or 1,825 days. This was done in order to simplify the matching process and minimize the computer time used to generate the comparison drivers. The eligible number of driving days for both drivers with medical conditions and their comparisons reflects the data of the Utah Driver License Division. The same two comparison drivers were used for drivers whose functional ability level fluctuated. Events and eligible license days for these comparison drivers were counted at each functional ability level status.

Crashes were considered to be "at fault" if a driver received a citation for the crash or was marked as having contributed to the crash. Only crashes and citations that occurred during the period of time the driver was licensed were considered. Events (citation or crash) were corresponded to the driver's record, and restriction status. Citation, crash and at fault crash rates per eligible licensed driving day were calculated separately for restricted and unrestricted drivers with medical conditions and their corresponding drivers for each functional ability category. These data were then used to estimate the relative risk for each medical condition category, allowing a comparison of the crash or citation risk of drivers licensed with medical conditions to similar drivers licensed without medical conditions from the general driving population. The relative risk approximates a Chi-Square distribution with one degree of freedom. Using this distribution, we calculated a $95 \%$ confidence interval for the estimate of relative risk (10). Relative risk describes the influence of a particular variable on the likelihood of an outcome. For instance, drivers in the visual acuity group at functional ability level 3 have a relative risk for

\footnotetext{
${ }^{3}$ The inclusion criteria of selected comparison drivers were chosen similarly to drivers with medical conditions in order to minimize bias. These drivers reflect a random sample of drivers from the general driving population with similar characteristics (age group, gender and county of residence) as those drivers with medical conditions. We did not select comparison drivers who were licensed for the whole study period as this would bias the sample towards those with "good driving records." Similarly, we did not exclude drivers who died during the study period because drivers with medical conditions were not chosen this way. Both condition and comparison drivers who died were counted for the time of the study period they were alive and licensed as drivers.
} 
crashes of 1.407 ; this means that they were 1.407 times as likely to be in a crash as were members of the control group.

The second part of the project was an analysis of drivers with more than one medical diagnosis or medical condition. These drivers were therefore put into more than one functional ability category, and were assigned a functional ability level for each. Only a minority of drivers was listed in more than one functional ability category, and only a few of the possible combinations of functional ability categories occurred often enough to allow for meaningful analysis. Only two-way combinations of functional ability categories (drivers reporting two medical conditions) occurred with sufficient frequency to allow for meaningful analysis, although there were small numbers of drivers with 3 or more medical conditions (as many as 7). Also, the numbers of drivers with two medical conditions was too small to allow for analysis by individual functional ability level. Therefore, the functional ability levels were collapsed into unrestricted (functional ability levels 3-5) and restricted (levels 6-11) groups. 


\section{RESULTS}

During 1992-1996, there were a total of 68,770 drivers in the medical conditions program excluding drivers in functional ability level 1 (commercial drivers) and level 2 (drivers whose medical condition has resolved). The majority of drivers $(54,825,79.7 \%)$ were licensed in a single functional ability category (one medical condition). The remaining drivers $(13,832$, $20.1 \%$ ) were licensed in two or more functional ability categories (that is, reported 2 or more medical conditions) during the study period. Most of the drivers reporting multiple conditions were licensed in two functional ability categories; however, the number per licensed driver ranged from one to seven categories during the study period. This is shown in Table 3.

Table 3. Number of Functional Ability Categories Reported by Drivers with Medical Conditions in Utah, 1992 - 1995

\begin{tabular}{|c|r|r|}
\hline Number of Categories & Count & Percent \\
\hline 1 & 54,825 & $79.9 \%$ \\
\hline 2 & 10,595 & $15.4 \%$ \\
\hline 3 & 2,403 & $3.5 \%$ \\
\hline 4 & 653 & $0.9 \%$ \\
\hline 5 & 146 & $0.2 \%$ \\
\hline 6 & 28 & $0.0 \%$ \\
\hline 7 & 7 & $0.0 \%$ \\
\hline Total & 68,770 & $100.0 \%$ \\
\hline
\end{tabular}


Table 4 shows the two way categorical combinations for drivers who were licensed in multiple functional ability categories. Note that drivers may appear more than one time, depending upon the number of functional ability categories reported. The most common 2-way combinations of functional ability categories were "cardiovascular and diabetes," "cardiovascular and vision," and "cardiovascular and pulmonary." As noted, only 2-way combinations were considered.

Table 4. Two Way Combinations of Drivers Licensed in Multiple Functional Ability Categories, Utah Driver License Division, 1992- 1995

\begin{tabular}{|c|c|c|c|c|c|c|c|c|c|c|}
\hline & 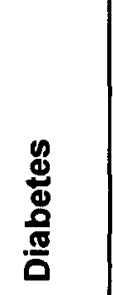 & 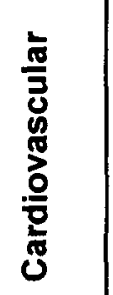 & $\begin{array}{l}\frac{Z}{\pi} \\
\frac{\pi}{0} \\
o \\
\underline{\bar{z}} \\
0\end{array}$ & $\begin{array}{l}\overline{\bar{J}} \\
\bar{g} \\
\frac{0}{0} \\
\frac{0}{3} \\
2\end{array}$ & $\begin{array}{l}\text { के } \\
\frac{0}{0} \\
\text { 흔 }\end{array}$ & 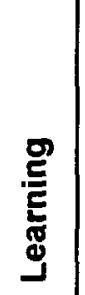 & 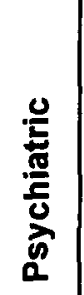 & $\begin{array}{l}\overline{0} \\
\overline{0} \\
\bar{\delta} \\
\bar{x}\end{array}$ & $\frac{5}{5}$ & 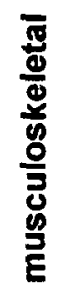 \\
\hline Cardiovascular & 5,436 & & & & & & & & & \\
\hline Pulmonary & 717 & 1,796 & & & & & & & & \\
\hline \begin{tabular}{|l|} 
Neurological \\
\end{tabular} & 614 & 941 & 223 & & & & & & & \\
\hline Epilepsy & 173 & 280 & 89 & 369 & & & & & & \\
\hline Learning & 102 & 197 & 48 & 380 & 117 & & & & & \\
\hline Psychiatric & 497 & 853 & 299 & 243 & 168 & 228 & & & & \\
\hline Alcohol & 81 & 98 & 57 & 61 & 52 & 38 & 269 & & & \\
\hline Vision & 1,359 & 1,933 & 372 & 315 & 100 & 92 & 176 & 25 & & \\
\hline musculoskeletal & 401 & 574 & 205 & 547 & 80 & 127 & 194 & 53 & 180 & \\
\hline Functional Motor & 241 & 330 & 94 & 637 & 72 & 150 & 118 & 38 & 140 & 780 \\
\hline
\end{tabular}


Figure 2 shows the percentages of drivers who were licensed in multiple functional ability categories, by each functional ability category. Over half of these drivers with multiple conditions were in the respective "cardiovascular" and "diabetes and other metabolic conditions" functional ability categories.

\section{Figure 2. Drivers Licensed in Multiple Functional Ability Categories, Percentage by Category $N=31,970$ cate gories for 18,832 drivers}

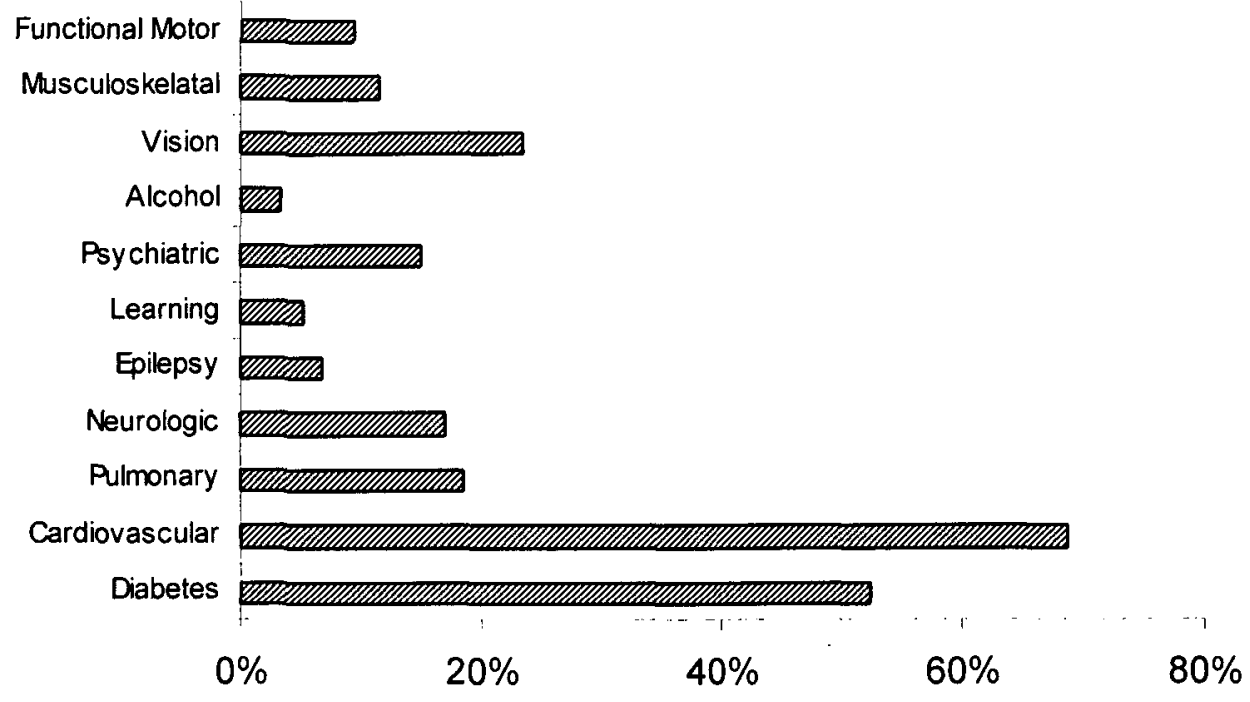

Analyses performed for drivers who reported single medical conditions are presented in Tables 5-7. For each functional ability category, rates of citations, crashes, and at-fault crashes are presented, broken out for each functional ability level. Rates are compared to age- and locationmatched controls, and odds ratios generated. Analyses are omitted for subgroups that contained too few subjects or events to allow for meaningful analysis. 
Table 5. Relative Risk for Citations, Single Functional Ability Category and Corresponding Comparison Groups, by Functional Ability Level

\begin{tabular}{|c|c|c|c|c|c|c|c|c|c|c|c|c|c|}
\hline \multirow[t]{2}{*}{ Condition } & \multirow[t]{2}{*}{ Level } & \multicolumn{4}{|c|}{ Medical Conditions } & \multicolumn{4}{|c|}{ Control Group } & \multicolumn{4}{|c|}{ Rate Ratio } \\
\hline & & Divers & Citations & \# Days & Rate & Drivers & Citations & \# Days & Rate & Ratio & L 95\% & U 95\% & Significance \\
\hline \multirow[t]{9}{*}{ Diabetes } & 3 & 5,121 & 501 & $3,246,531$ & 1.543 & 9,956 & 3,003 & $16,002,739$ & 1.877 & 0.822 & 0.75 & 0.90 & *\# \\
\hline & 4 & 6,924 & 1,959 & $6,388,418$ & 3.067 & 13,576 & 5,941 & $20,812,910$ & 2.854 & 1.074 & 1.02 & 1.13 & \\
\hline & 5 & 801 & 140 & 316,278 & 4.427 & 1,588 & 719 & $2,400,555$ & 2.995 & 1.478 & 1.23 & 1.77 & ॠ \\
\hline & 6 & 192 & 12 & 25,235 & 4.755 & 379 & 174 & 549,517 & 3.166 & 1.502 & 0.84 & 2.68 & \\
\hline & 7 & 144 & 4 & 11,916 & 3.357 & 287 & 134 & 434,634 & 3.083 & 1.089 & 0.40 & 2.94 & \\
\hline & 8 & 11 & 1 & 847 & 11.806 & 22 & 14 & 36,551 & 3.830 & 3.082 & 0.45 & 21.14 & \\
\hline & 9 & 6 & 1 & 455 & 21.978 & 12 & 4 & 15,397 & 2.598 & 8.460 & 1.36 & 52.44 & * \\
\hline & 10 & 18 & 0 & 6,627 & 0.000 & 36 & 17 & 50,640 & 3.357 & Zero Rate & & & \\
\hline & 11 & 33 & 6 & 9,119 & 6.580 & 66 & 32 & 93,870 & 3.409 & 1.930 & 0.82 & 4.55 & \\
\hline \multirow[t]{9}{*}{ Cardiovascular } & 3 & 16,192 & 1,175 & $9,342,197$ & 1.258 & 29,918 & 8,212 & $50,582,274$ & 1.623 & 0.775 & 0.73 & 0.82 & $\star \star$ \\
\hline & 4 & 4,271 & 217 & $2,021,556$ & 1.073 & 8,201 & 1,963 & $13,126,357$ & 1.495 & 0.718 & 0.62 & 0.83 & $\star \star \star$ \\
\hline & 5 & 982 & 36 & 255,469 & 1.409 & 1,926 & 445 & $2,991,355$ & 1.488 & 0.947 & 0.67 & 1.33 & \\
\hline & 6 & 138 & 0 & 14,079 & 0.000 & 270 & 81 & 414,798 & 1.953 & 0.000 & & & \\
\hline & 7 & 10 & 0 & 878 & 0.000 & 20 & 15 & 29,323 & 5.115 & Zero Rate & & & \\
\hline & 8 & 6 & 0 & 1,253 & 0.000 & 12 & 1 & 18,385 & 0.544 & Zero Rate & & & \\
\hline & 9 & 1 & 0 & 128 & 0.000 & 2 & 0 & 2,997 & 0.000 & Zero Rate & & & \\
\hline & 10 & 3 & 0 & 1,222 & 0.000 & 6 & 4 & 8,418 & 4.752 & Zero Rate & & & \\
\hline & 11 & 11 & 8 & 5,369 & 14.900 & 22 & 11 & 35,036 & 3.140 & 4.746 & 2.08 & 10.83 & * \\
\hline \multirow[t]{7}{*}{ Pulmonary } & 3 & 2,055 & 338 & $1,283,858$ & 2.633 & 4,058 & 1,706 & $6,083,179$ & 2.804 & 0.939 & 0.84 & 1.05 & \\
\hline & 4 & 760 & 63 & 363,022 & 1.735 & 1,498 & 488 & $2,336,598$ & 2.089 & 0.831 & 0.64 & 1.08 & \\
\hline & 5 & 612 & 37 & 306,710 & 1.206 & 1,212 & 295 & $1,883,754$ & 1.566 & 0.770 & 0.55 & 1.08 & \\
\hline & 7 & 217 & 3 & 50,490 & 0.594 & 428 & 87 & 664,096 & 1.310 & 0.454 & 0.15 & 1.39 & \\
\hline & 9 & 20 & 0 & 3,850 & 0.000 & 40 & 10 & 67,371 & 1.484 & Zero Rate & & & \\
\hline & 10 & 14 & 0 & 2,691 & 0.000 & 28 & 6 & 47,373 & 1.267 & Zero Rate & & & \\
\hline & 11 & 8 & 1 & 733 & 13.643 & 16 & 5 & 25,487 & 1.962 & 6.954 & 1.10 & 43.97 & * \\
\hline \multirow[t]{8}{*}{ Neurological } & 3 & 510 & 57 & 281,984 & 2.021 & 1,010 & 355 & $1,556,600$ & 2.281 & 0.886 & 0.67 & 1.17 & \\
\hline & 4 & 402 & 45 & 206,311 & 2.181 & 797 & 287 & $1,241,932$ & 2.311 & 0.944 & 0.69 & 1.29 & \\
\hline & 5 & 318 & 36 & 165,579 & 2.174 & 627 & 211 & 963,848 & 2.189 & 0.993 & 0.70 & 1.41 & \\
\hline & 6 & 136 & 7 & 58,892 & 1.189 & 270 & 98 & 415,232 & 2.360 & 0.504 & 0.24 & 1.07 & \\
\hline & 7 & 60 & 3 & 21,018 & 1.427 & 119 & 26 & 190,673 & 1.364 & 1.047 & 0.32 & 3.45 & \\
\hline & 9 & 3 & 0 & 374 & 0.000 & 6 & 0 & 8,375 & 0.000 & Zero Rate & & & \\
\hline & 10 & 11 & 4 & 5,803 & 6.893 & 22 & 16 & 33,885 & 4.722 & 1.460 & 0.49 & 4.34 & \\
\hline & 11 & 9 & 1 & 5,595 & 1.787 & 18 & 5 & 24,214 & 2.065 & 0.866 & 0.10 & 7.40 & \\
\hline
\end{tabular}




\begin{tabular}{|c|c|c|c|c|c|c|c|c|c|c|c|c|c|}
\hline \multirow[t]{2}{*}{ Condition } & \multirow[t]{2}{*}{ Level } & \multicolumn{4}{|c|}{ Medical Conditions } & \multicolumn{4}{|c|}{ Control Group } & \multicolumn{4}{|c|}{ Rate Ratio } \\
\hline & & Divers & Citations & \# Days & Rate & Drivers & Citations & \# Days & Rate & Ratio & L 95\% & U 95\% & Significance \\
\hline \multirow[t]{8}{*}{ Epilepsy } & 3 & 564 & 138 & 322,206 & 4.283 & 1,111 & 689 & $1,677,433$ & 4.107 & 1.043 & 0.87 & 1.25 & \\
\hline & 4 & 2,307 & 829 & $2,103,023$ & 3.942 & 4,562 & 2,674 & $6,763,679$ & 3.953 & 0.997 & 0.92 & 1.08 & \\
\hline & 5 & 917 & 101 & 202,135 & 4.997 & 1,815 & 1,101 & $2,606,464$ & 4.224 & 1.183 & 0.97 & 1.45 & \\
\hline & 6 & 281 & 13 & 21,759 & 5.975 & 557 & 345 & 794,758 & 4.341 & 1.376 & 0.79 & 2.39 & \\
\hline & 7 & 317 & 11 & 26,087 & 4.217 & 626 & 388 & 899,850 & 4.312 & 0.978 & 0.54 & 1.78 & \\
\hline & 8 & 465 & 21 & 51,332 & 4.091 & 919 & 544 & $1,320,262$ & 4.120 & 0.993 & 0.64 & 1.54 & \\
\hline & 10 & 91 & 8 & 23,457 & 3.411 & 178 & 108 & 255,716 & 4.223 & 0.808 & 0.39 & 1.65 & \\
\hline & 11 & 98 & 9 & 27,345 & 3.291 & 193 & 85 & 295,129 & 2.880 & 1.143 & 0.58 & 2.27 & \\
\hline \multirow{7}{*}{ Psychiatric } & 3 & 6,219 & 1,648 & $4,528,381$ & 3.639 & 12,205 & 5,877 & $18,678,295$ & 3.146 & 1.157 & 1.10 & 1.22 & " \\
\hline & 4 & 1,730 & 370 & 668,171 & 5.538 & 3,424 & 1,680 & $5,080,122$ & 3.307 & 1.674 & 1.50 & 1.87 & * \\
\hline & 5 & 508 & 63 & 90,773 & 6.940 & 1,004 & 531 & $1,511,605$ & 3.513 & 1.976 & 1.53 & 2.55 & " \\
\hline & 6 & 207 & 14 & 31,172 & 4.491 & 409 & 241 & 623,137 & 3.868 & 1.161 & 0.68 & 1.99 & \\
\hline & 9 & 91 & 2 & 14,817 & 1.350 & 182 & 119 & 277,611 & 4.287 & 0.315 & 0.08 & 1.18 & \\
\hline & 10 & 17 & 3 & 4,507 & 6.656 & 34 & 24 & 52,107 & 4.606 & 1.445 & 0.44 & 4.77 & \\
\hline & 11 & 20 & 0 & 7,951 & 0.000 & 40 & 15 & 63,855 & 2.349 & Zero Rate & & & \\
\hline \multirow[t]{9}{*}{\begin{tabular}{|l} 
Vision \\
\end{tabular}} & 3 & 6,657 & 709 & $2,264,533$ & 3.131 & 12,814 & 4,397 & $19,078,918$ & 2.305 & 1.359 & 1.26 & 1.47 & * \\
\hline & 4 & 2,120 & 202 & 742,145 & 2.722 & 4,145 & 1,203 & $6,215,686$ & 1.935 & 1.406 & 1.21 & 1.63 & ॠ \\
\hline & 5 & 1,854 & 359 & $1,286,255$ & 2.791 & 3,622 & 1,064 & $5,495,635$ & 1.936 & 1.442 & 1.28 & 1.62 & 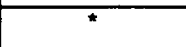 \\
\hline & 6 & 1,240 & 119 & 700,795 & 1.698 & 2,372 & 468 & $3,504,635$ & 1.335 & 1.272 & 1.04 & 1.55 & " \\
\hline & 7 & 146 & 5 & 46,826 & 1.068 & 289 & 39 & 438,558 & 0.889 & 1.201 & 0.47 & 3.04 & \\
\hline & 8 & 141 & 20 & 53,346 & 3.749 & 278 & 59 & 395,674 & 1.491 & 2.514 & 1.54 & 4.10 & " \\
\hline & 9 & 32 & 0 & 5,704 & 0.000 & 63 & 9 & 91,639 & 0.982 & Zero Rate & & & \\
\hline & 10 & 59 & 9 & 39,825 & 2.260 & 118 & 20 & 170,892 & 1.170 & 1.931 & 0.89 & 4.18 & \\
\hline & 11 & 44 & 4 & 26,004 & 1.538 & 87 & 18 & 120,303 & 1.496 & 1.028 & 0.35 & 3.04 & \\
\hline
\end{tabular}

Rates are expressed as citations per 10,000 license days.

* The confidence interval does not include 1.0. Therefore, the higher rate of the medical conditions group is statistically significant.

** indicates that the medical conditions group has a statistically significant lower rate. 
Table 6. Relative Risk for All Crashes, Single Functional Ability Category and Corresponding Comparison Groups, by Functional Ability Level

\begin{tabular}{|c|c|c|c|c|c|c|c|c|c|c|c|c|c|}
\hline \multirow[t]{2}{*}{ Condition } & \multirow[t]{2}{*}{ Level } & \multicolumn{4}{|c|}{ Medical Conditions } & \multicolumn{4}{|c|}{ Control Group } & \multicolumn{4}{|c|}{ Rate Ratio } \\
\hline & & Drivers & Crashes & \# Days & Rate & Drivers & Crashes & \# Days & Rate & Ratio & L 95\% & U 95\% & Significance \\
\hline \multirow[t]{9}{*}{ Diabetes } & 3 & 5,121 & 422 & $3,246,531$ & 1.300 & 9,956 & 1,770 & $16,002,739$ & 1.106 & 1.175 & 1.06 & 1.31 & * \\
\hline & 4 & 6,924 & 1,263 & $6,388,418$ & 1.977 & 13,576 & 2,837 & $20,812,910$ & 1.363 & 1.450 & 1.36 & 1.55 & * \\
\hline & 5 & 801 & 58 & 316,278 & 1.834 & 1,588 & 335 & $2,400,555$ & 1.396 & 1.314 & 1.00 & 1.73 & \\
\hline & 6 & 192 & 6 & 25,235 & 2.378 & 379 & 76 & 549,517 & 1.383 & 1.719 & 0.76 & 3.91 & \\
\hline & 7 & 144 & 3 & 11,916 & 2.518 & 287 & 69 & 434,634 & 1.588 & 1.586 & 0.50 & 4.99 & \\
\hline & 8 & 11 & 0 & 847 & 0.000 & 22 & 4 & 36,551 & 1.094 & Zero Rate & & & \\
\hline & 9 & 6 & 0 & 455 & 0.000 & 12 & 0 & 15,397 & 0.000 & Zero Rate & & & \\
\hline & 10 & 18 & 0 & 6,627 & 0.000 & 36 & 8 & 50,640 & 1.580 & Zero Rate & & & \\
\hline & 11 & 33 & 2 & 9,119 & 2.193 & 66 & $\overline{17}$ & 93,870 & 1.811 & 1.211 & 0.28 & 5.23 & \\
\hline \multirow[t]{9}{*}{ Cardiovascular } & 3 & 16,192 & 983 & $9,342,197$ & 1.052 & 29,918 & 5,142 & $50,582,274$ & 1.017 & 1.035 & 0.97 & 1.11 & \\
\hline & 4 & 4,271 & 183 & $2,021,556$ & 0.905 & 8,201 & 1,297 & $13,126,357$ & 0.988 & 0.916 & 0.78 & 1.07 & \\
\hline & 5 & 982 & 43 & 255,469 & 1.683 & 1,926 & 308 & $2,991,355$ & 1.030 & 1.635 & 1.19 & 2.24 & " \\
\hline & 6 & 138 & 0 & 14,079 & 0.000 & 270 & 39 & 414,798 & 0.940 & Zero Rate & & & \\
\hline & 7 & 10 & 0 & 878 & 0.000 & 20 & 5 & 29,323 & 1.705 & Zero Rate & & & \\
\hline & 8 & 6 & 0 & 1,253 & 0.000 & 12 & 3 & 18,385 & 1.632 & Zero Rate & & & \\
\hline & 9 & 1 & 0 & 128 & 0.000 & 2 & $\overline{0}$ & 2,997 & 0.000 & Zero Rate & & & \\
\hline & 10 & 3 & 0 & 1,222 & 0.000 & 6 & 1 & 8,418 & 1.188 & Zero Rate & & & \\
\hline & 11 & 11 & 3 & 5,369 & 5.588 & 22 & 2 & 35,036 & 0.571 & 9.788 & 2.29 & 41.86 & 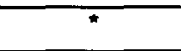 \\
\hline \multirow[t]{7}{*}{ Pulmonary } & 3 & 2,055 & 213 & $1,283,858$ & 1.659 & 4,058 & 798 & $6,083,179$ & 1.312 & 1.265 & 1.09 & 1.47 & * \\
\hline & 4 & 760 & 51 & 363,022 & 1.405 & 1,498 & 283 & $2,336,598$ & 1.211 & 1.160 & 0.86 & 1.56 & \\
\hline & 5 & 612 & 33 & 306,710 & 1.076 & 1,212 & 205 & $1,883,754$ & 1.088 & 0.989 & 0.68 & 1.43 & \\
\hline & 7 & 217 & 5 & 50,490 & 0.990 & 428 & 73 & 664,096 & 1.099 & 0.901 & 0.36 & 2.23 & \\
\hline & 9 & 20 & 0 & 3,850 & 0.000 & 40 & 5 & 67,371 & 0.742 & Zero Rate & & & \\
\hline & 10 & 14 & 0 & 2,691 & 0.000 & 28 & 6 & 47,373 & 1.267 & Zero Rate & & & \\
\hline & 11 & 8 & 1 & 733 & 13.643 & 16 & 4 & 25,487 & 1.569 & 8.693 & 1.41 & 53.45 & * \\
\hline \multirow[t]{8}{*}{\begin{tabular}{|l} 
Neuralgic \\
\end{tabular}} & 3 & 510 & 50 & 281,984 & 1.773 & 1,010 & 169 & $1,556,600$ & 1.086 & 1.633 & 1.20 & 2.23 & * \\
\hline & 4 & 402 & 42 & 206,311 & 2.036 & 797 & 133 & $1,241,932$ & 1.071 & 1.901 & 1.35 & 2.67 & * \\
\hline & 5 & 318 & 32 & 165,579 & 1.933 & 627 & 110 & 963,848 & 1.141 & 1.693 & 1.15 & 2.50 & ๘ \\
\hline & 6 & 136 & 9 & 58,892 & 1.528 & 270 & 57 & 415,232 & 1.373 & 1.113 & 0.55 & 2.25 & \\
\hline & 7 & 60 & 4 & 21,018 & 1.903 & 119 & 23 & 190,673 & 1.206 & 1.578 & 0.55 & 4.52 & \\
\hline & 9 & 3 & 0 & 374 & 0.000 & 6 & 0 & 8,375 & 0.000 & Zero Rate & & & \\
\hline & 10 & 11 & 2 & 5,803 & 3.447 & 22 & 6 & 33,885 & 1.771 & 1.946 & 0.40 & 9.37 & \\
\hline & 11 & 9 & 1 & 5,595 & 1.787 & 18 & 2 & 24,214 & 0.826 & 2.164 & 0.21 & 22.51 & \\
\hline
\end{tabular}




\begin{tabular}{|c|c|c|c|c|c|c|c|c|c|c|c|c|c|}
\hline \multirow[t]{2}{*}{ Condition } & \multirow[t]{2}{*}{ Level } & \multicolumn{4}{|c|}{ Medical Conditions } & \multicolumn{4}{|c|}{ Control Group } & \multicolumn{4}{|c|}{ Rate Ratio } \\
\hline & & Drivers & Crashes & \# Days & Rate & Drivers & Crashes & \# Days & Rate & Ratio & L95\% & U 95\% & Significance \\
\hline \multirow[t]{8}{*}{ Epilepsy } & 3 & 564 & 86 & 322,206 & 2.669 & 1,111 & 262 & $1,677,433$ & 1.562 & 1.709 & 1.34 & 2.17 & * \\
\hline & 4 & 2,307 & 563 & $2,103,023$ & 2.677 & 4,562 & 1,047 & $6,763,679$ & 1.548 & 1.729 & 1.56 & 1.91 & * \\
\hline & 5 & 917 & 59 & 202,135 & 2.919 & 1,815 & 451 & $2,606,464$ & 1.730 & 1.687 & 1.29 & 2.21 & * \\
\hline & 6 & 281 & 8 & 21,759 & 3.677 & 557 & 141 & 794,758 & 1.774 & 2.072 & 1.03 & 4.16 & * \\
\hline & 7 & 317 & 5 & 26,087 & 1.917 & 626 & 184 & 899,850 & 2.045 & 0.937 & 0.39 & 2.28 & \\
\hline & 8 & 465 & 15 & 51,332 & 2.922 & 919 & 240 & $1,320,262$ & 1.818 & 1.608 & 0.96 & 2.70 & \\
\hline & 10 & 91 & 8 & 23,457 & 3.411 & 178 & 45 & 255,716 & 1.760 & 1.938 & 0.93 & 4.06 & \\
\hline & 11 & 98 & 4 & 27,345 & 1.463 & 193 & 50 & 295,129 & 1.694 & 0.863 & 0.31 & 2.39 & \\
\hline \multirow[t]{7}{*}{ Psychiatric } & 3 & 6,219 & 985 & $4,528,381$ & 2.175 & 12,205 & 2,631 & $18,678,295$ & 1.409 & 1.544 & 1.44 & 1.66 & * \\
\hline & 4 & 1,730 & 167 & 668,171 & 2.499 & 3,424 & 752 & $5,080,122$ & 1.480 & 1.688 & 1.43 & 1.99 & * \\
\hline & 5 & 508 & 32 & 90,773 & 3.525 & 1,004 & 235 & $1,511,605$ & 1.555 & 2.268 & 1.58 & 3.25 & 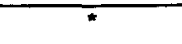 \\
\hline & 6 & 207 & 12 & 31,172 & 3.850 & 409 & 93 & 623,137 & 1.492 & 2.579 & 1.45 & 4.60 & * \\
\hline & 9 & 91 & 2 & 14,817 & 1.350 & 182 & 26 & 277,611 & 0.937 & 1.441 & 0.34 & 6.02 & \\
\hline & 10 & 17 & 1 & 4,507 & 2.219 & 34 & 8 & 52,107 & 1.535 & 1.445 & 0.18 & 11.42 & \\
\hline & 11 & 20 & 0 & 7,951 & 0.000 & 40 & 14 & 63,855 & 2.192 & Zero Rate & & & \\
\hline \multirow[t]{9}{*}{ Vision } & 3 & 6,657 & 416 & $2,264,533$ & 1.837 & 12,814 & 2,491 & $19,078,918$ & 1.306 & 1.407 & 1.27 & 1.56 & " \\
\hline & 4 & 2,120 & 132 & 742,145 & 1.779 & 4,145 & 733 & $6,215,686$ & 1.179 & 1.508 & 1.25 & 1.81 & * \\
\hline & 5 & 1,854 & 205 & $1,286,255$ & 1.594 & 3,622 & 655 & $5,495,635$ & 1.192 & 1.337 & 1.14 & 1.56 & " \\
\hline & 6 & 1,240 & 92 & 700,795 & 1.313 & 2,372 & 357 & $3,504,635$ & 1.019 & 1.289 & 1.03 & 1.62 & * \\
\hline & 7 & 146 & 6 & 46,826 & 1.281 & 289 & 47 & 438,558 & 1.072 & 1.196 & 0.51 & 2.79 & \\
\hline & 8 & 141 & 17 & 53,346 & 3.187 & 278 & 44 & 395,674 & 1.112 & 2.866 & 1.68 & 4.89 & 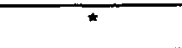 \\
\hline & 9 & 32 & 0 & 5,704 & 0.000 & 63 & 13 & 91,639 & 1.419 & Zero Rate & & & \\
\hline & 10 & 59 & 6 & 39,825 & 1.507 & 118 & 15 & 170,892 & 0.878 & 1.716 & 0.67 & 4.37 & \\
\hline & 11 & 44 & 1 & 26,004 & 0.385 & 87 & 21 & 120,303 & 1.746 & 0.220 & 0.04 & 1.37 & \\
\hline
\end{tabular}

Rates are expressed as crashes per 10,000 license days.

* The confidence interval does not include 1.0. Therefore, the higher rate of the medical conditions group is statistically significant. 
Table 7. Relative Risk for At-Fault Crashes, Single Functional Ability Category and Corresponding Comparison Groups, by Functional Ability Level

\begin{tabular}{|c|c|c|c|c|c|c|c|c|c|c|c|c|c|}
\hline \multirow[t]{2}{*}{ Condition } & \multirow[t]{2}{*}{ Level } & \multicolumn{4}{|c|}{ Medical Conditions } & \multicolumn{4}{|c|}{ Control Group } & \multicolumn{4}{|c|}{ Rate Ratio } \\
\hline & & Drivers & Crashes & \# Days & Rate & Drivers & Crashes & \# Days & Rate & Ratio & L95\% & U95\% & Significance \\
\hline \multirow[t]{9}{*}{ Diabetes } & 3 & 5,121 & 229 & $3,246,531$ & 0.705 & 9,956 & 894 & $16,002,739$ & 0.559 & 1.263 & 1.09 & 1.46 & 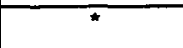 \\
\hline & 4 & 6,924 & 746 & $6,388,418$ & 1.168 & 13,576 & 1,538 & $20,812,910$ & 0.739 & 1.580 & 1.45 & 1.72 & * \\
\hline & 5 & 801 & 38 & 316,278 & 1.202 & 1,588 & 185 & $2,400,555$ & 0.771 & 1.559 & 1.10 & 2.20 & * \\
\hline & 6 & 192 & 4 & 25,235 & 1.585 & 379 & 42 & 549,517 & 0.764 & 2.074 & 0.76 & 5.66 & \\
\hline & 7 & 144 & 3 & 11,916 & 2.518 & 287 & 37 & 434,634 & 0.851 & 2.957 & 0.96 & 9.07 & \\
\hline & 8 & $\overline{11}$ & 0 & 847 & 0.000 & 22 & 2 & 36,551 & 0.547 & Zero Rate & & & \\
\hline & 9 & 6 & 0 & 455 & 0.000 & 12 & 0 & 15,397 & 0.000 & Zero Rate & & & \\
\hline & 10 & 18 & 0 & 6,627 & 0.000 & 36 & 5 & 50,640 & 0.987 & Zero Rate & & & \\
\hline & 11 & 33 & 1 & 9,119 & 1.097 & 66 & 10 & 93,870 & 1.065 & 1.029 & 0.13 & 8.04 & \\
\hline \multirow[t]{9}{*}{ Cardiovascular } & 3 & 16,192 & 517 & $9,342,197$ & 0.553 & 29,918 & 2,640 & $50,582,274$ & 0.522 & 1.060 & 0.96 & 1.17 & \\
\hline & 4 & 4,271 & 101 & $2,021,556$ & 0.500 & 8,201 & 727 & $13,126,357$ & 0.554 & 0.902 & 0.73 & 1.11 & \\
\hline & 5 & 982 & 19 & 255,469 & 0.744 & 1,926 & 172 & $2,991,355$ & 0.575 & 1.293 & 0.81 & 2.07 & \\
\hline & 6 & 138 & 0 & 14,079 & 0.000 & 270 & 22 & 414,798 & 0.530 & Zero Rate & & & \\
\hline & 7 & 10 & 0 & 878 & 0.000 & 20 & 3 & 29,323 & 1.023 & Zero Rate & & & \\
\hline & 8 & 6 & 0 & 1,253 & 0.000 & 12 & 2 & 18,385 & 1.088 & Zero Rate & & & \\
\hline & 9 & 1 & 0 & 128 & 0.000 & 2 & 0 & 2,997 & 0.000 & Zero Rate & & & \\
\hline & 10 & 3 & 0 & 1,222 & 0.000 & 6 & 1 & 8,418 & 1.188 & Zero Rate & & & \\
\hline & 11 & 11 & 2 & 5,369 & 3.725 & 22 & 1 & 35,036 & 0.285 & 13.051 & 2.06 & 82.89 & \# \\
\hline \multirow[t]{7}{*}{ Pulmonary } & 3 & 2,055 & 113 & $1,283,858$ & 0.880 & 4,058 & 421 & $6,083,179$ & 0.692 & 1.272 & 1.03 & 1.56 & " \\
\hline & 4 & 760 & 28 & 363,022 & 0.771 & 1,498 & 145 & $2,336,598$ & 0.621 & 1.243 & 0.83 & 1.86 & \\
\hline & 5 & 612 & 26 & 306,710 & 0.848 & 1,212 & 110 & $1,883,754$ & 0.584 & 1.452 & 0.95 & 2.22 & \\
\hline & 7 & 217 & 5 & 50,490 & 0.990 & 428 & 41 & 664,096 & 0.617 & 1.604 & 0.64 & 4.02 & \\
\hline & 9 & 20 & 0 & 3,850 & 0.000 & 40 & 3 & 67,371 & 0.445 & Zero Rate & & & \\
\hline & 10 & 14 & 0 & 2,691 & 0.000 & 28 & 3 & 47,373 & 0.633 & Zero Rate & & & \\
\hline & 11 & 8 & 1 & 733 & 13.643 & 16 & 4 & 25,487 & 1.569 & 8.693 & 1.41 & 53.45 & 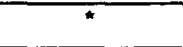 \\
\hline \multirow[t]{8}{*}{ Neuralgic } & 3 & 510 & 36 & 281,984 & 1.277 & 1,010 & 96 & $1,556,600$ & 0.617 & 2.070 & 1.42 & 3.01 & * \\
\hline & 4 & 402 & 28 & 206,311 & 1.357 & 797 & 64 & $1,241,932$ & 0.515 & 2.634 & 1.72 & 4.04 & 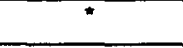 \\
\hline & 5 & 318 & 22 & 165,579 & 1.329 & 627 & 54 & 963,848 & 0.560 & 2.372 & 1.47 & 3.84 & * \\
\hline & 6 & 136 & 5 & 58,892 & 0.849 & 270 & 33 & 415,232 & 0.795 & 1.068 & 0.42 & 2.74 & \\
\hline & 7 & 60 & 2 & 21,018 & 0.952 & 119 & 14 & 190,673 & 0.734 & 1.296 & 0.30 & 5.68 & \\
\hline & 9 & 3 & 0 & 374 & 0.000 & 6 & 0 & 8,375 & 0.000 & Zero Rate & & & \\
\hline & 10 & 11 & 2 & 5,803 & 3.447 & 22 & 4 & 33,885 & 1.180 & 2.920 & 0.58 & 14.74 & \\
\hline & 11 & 9 & 1 & 5,595 & 1.787 & 18 & 1 & 24,214 & 0.413 & 4.328 & 0.34 & 54.80 & \\
\hline
\end{tabular}




\begin{tabular}{|c|c|c|c|c|c|c|c|c|c|c|c|c|c|}
\hline \multirow[t]{2}{*}{ Condition } & \multirow[t]{2}{*}{ Level } & \multicolumn{4}{|c|}{ Medical Conditions } & \multicolumn{4}{|c|}{ Control Group } & \multicolumn{4}{|c|}{ Rate Ratio } \\
\hline & & Drivers & Crashes & \# Days & Rate & Drivers & Crashes & \# Days & Rate & Ratio & L $95 \%$ & U 95\% & Significance \\
\hline \multirow[t]{8}{*}{ Epilepsy } & 3 & 564 & 53 & 322,206 & 1.645 & 1,111 & 155 & $1,677,433$ & 0.924 & 1.780 & 1.31 & 2.42 & " \\
\hline & 4 & 2,307 & 372 & $2,103,023$ & 1.769 & 4,562 & 588 & $6,763,679$ & 0.869 & 2.035 & 1.79 & 2.31 & " \\
\hline & 5 & 917 & 38 & 202,135 & 1.880 & 1,815 & 258 & $2,606,464$ & 0.990 & 1.899 & 1.36 & 2.65 & * \\
\hline & 6 & 281 & 8 & 21,759 & 3.677 & 557 & 73 & 794,758 & 0.919 & 4.003 & 2.04 & 7.86 & " \\
\hline & 7 & 317 & 4 & 26,087 & 1.533 & 626 & 95 & 899,850 & 1.056 & 1.452 & 0.54 & 3.93 & \\
\hline & 8 & 465 & 13 & 51,332 & 2.533 & 919 & 136 & $1,320,262$ & 1.030 & 2.458 & 1.42 & 4.26 & 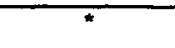 \\
\hline & 10 & 91 & 8 & 23,457 & 3.411 & 178 & 23 & 255,716 & 0.899 & 3.792 & 1.79 & 8.01 & " \\
\hline & 11 & 98 & 3 & 27,345 & 1.097 & 193 & 28 & 295,129 & 0.949 & 1.156 & 0.35 & 3.80 & \\
\hline \multirow[t]{7}{*}{ Psychiatric } & 3 & 6,219 & 586 & $4,528,381$ & 1.294 & 12,205 & 1,360 & $18,678,295$ & 0.728 & 1.777 & 1.62 & 1.96 & " \\
\hline & 4 & 1,730 & 117 & 668,171 & 1.751 & 3,424 & 400 & $5,080,122$ & 0.787 & 2.224 & 1.82 & 2.72 & * \\
\hline & 5 & 508 & 24 & 90,773 & 2.644 & 1,004 & 125 & $1,511,605$ & 0.827 & 3.197 & 2.12 & 4.83 & " \\
\hline & 6 & 207 & 11 & 31,172 & 3.529 & 409 & 54 & 623,137 & 0.867 & 4.072 & 2.24 & 7.41 & 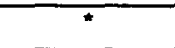 \\
\hline & 9 & 91 & 2 & 14,817 & 1.350 & 182 & 15 & 277,611 & 0.540 & 2.498 & 0.60 & 10.39 & \\
\hline & 10 & 17 & 0 & 4,507 & 0.000 & 34 & 6 & 52,107 & 1.151 & Zero Rate & & & \\
\hline & 11 & 20 & 0 & 7,951 & 0.000 & 40 & 5 & 63,855 & 0.783 & Zero Rate & & & \\
\hline \multirow[t]{9}{*}{ Vision } & 3 & 6,657 & 272 & $2,264,533$ & 1.201 & 12,814 & 1,473 & $19,078,918$ & 0.772 & 1.556 & 1.37 & 1.77 & * \\
\hline & 4 & 2,120 & 90 & 742,145 & 1.213 & 4,145 & 416 & $6,215,686$ & 0.669 & 1.812 & 1.45 & 2.27 & " \\
\hline & 5 & 1,854 & 131 & $1,286,255$ & 1.019 & 3,622 & 372 & $5,495,635$ & 0.677 & 1.505 & 1.23 & 1.83 & * \\
\hline & 6 & 1,240 & 75 & 700,795 & 1.070 & 2,372 & 242 & $3,504,635$ & 0.691 & 1.550 & 1.20 & 2.00 & 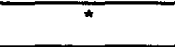 \\
\hline & 7 & 146 & 5 & 46,826 & 1.068 & 289 & 31 & 438,558 & 0.707 & 1.511 & 0.59 & 3.86 & \\
\hline & 8 & 141 & 15 & 53,346 & 2.812 & 278 & 29 & 395,674 & 0.733 & 3.836 & 2.15 & 6.84 & * \\
\hline & 9 & 32 & 0 & 5,704 & 0.000 & 63 & 13 & 91,639 & 1.419 & Zero Rate & & & \\
\hline & 10 & 59 & 6 & 39,825 & 1.507 & 118 & 10 & 170,892 & 0.585 & 2.575 & 0.97 & 6.83 & \\
\hline & 11 & 44 & 1 & 26,004 & 0.385 & 87 & 15 & 120,303 & 1.247 & 0.308 & 0.05 & 2.09 & \\
\hline
\end{tabular}

Rates are expressed as at-fault crashes per 10,000 license days.

* The confidence interval does not include 1.0. Therefore, the higher rate of the medical conditions group is statistically significant. 


\section{Diabetes mellitus and other metabolic conditions}

This was the second largest category, and included 10,069 licensed drivers with diabetes mellitus and thyroid, parathyroid, pituitary or other metabolic conditions. These results exclude the 7,245 drivers licensed in this category along with other medical conditions. The rate of citations was significantly lower than the comparison group for functional ability level 3 [odds ratio (OR) 0.82 ], and higher than the comparison group for levels 5 and 9 (OR 1.48 and 8.46 respectively). The absolute number of events was small in the latter category, only 1 for level 9 . The rate of crashes was significantly higher than the comparison group for levels 3 and 4 (OR 1.18 and 1.45 respectively). The rate of at-fault crashes was significantly higher than the comparison group for levels 3 (OR 1.24), 4 (OR 1.58) and 5 (OR 1.56).

To summarize, drivers with diabetes mellitus and other metabolic conditions at the numerically lowest functional ability levels (least restricted drivers) had higher rates of crashes and at-fault crashes than comparison drivers, and the effect was of fairly modest magnitude (OR 1.2-1.6). This effect disappeared at numerically higher levels (more restricted drivers) and was not seen at all for citations.

\section{Cardiovascular conditions}

This was the largest category, and included 18,990 licensed drivers with cardiovascular conditions including heart disease, rhythm disturbances, or history of myocardial infarctions, heart surgery or hypertension. This excludes the 9,504 drivers who were licensed in the cardiovascular conditions category along with other functional ability categories. The rate of citations was significantly lower than the comparison group for functional ability levels 3 and 4 (OR 0.78 and 0.72 respectively) and higher than the comparison group for level 11 (OR 4.75). The absolute number of events was small, only 8 , in category 11 . The rate of crashes was significantly higher than the comparison group for level 5 (OR 1.64). The rate of at-fault crashes was significantly higher than the comparison group for level 11 (OR 13.05), where the absolute number of events was small at 2.

To summarize, drivers with cardiovascular conditions at a single functional ability level, level 5 (unrestricted drivers), had higher rates of crashes, but not at-fault crashes, than comparison drivers, and the effect was of fairly modest magnitude (OR 1.64). This effect was not seen at other levels or for at-fault crashes, or for citations, where the rate was actually lower than comparison drivers for the numerically lowest functional ability levels. 


\section{Pulmonary conditions}

This category includes 2,615 drivers licensed with pulmonary conditions including pulmonary disease or symptoms, impaired function or severe respiratory difficulties. This excludes the 2,552 drivers who were licensed in the pulmonary conditions category along with other functional ability categories. The rate of citations was not significantly different than the comparison group for any functional ability level. The rate of crashes was significantly higher than the comparison group for levels 3 (OR 1.27) and 11 (OR 8.70): the absolute number of crashes for the latter level was small at 1 . The rate of at-fault crashes was significantly higher than the comparison group for levels 3 (OR 1.27) and 11 (OR 8.70): the absolute number of atfault crashes for the latter level was small at 1 .

To summarize, drivers with pulmonary conditions at functional ability level 3 , (the least restricted drivers) had higher rates of crashes and at-fault crashes than comparison drivers, and the effect was of fairly modest magnitude, OR roughly 1.3 ). This effect was not seen at other levels or for citations.

\section{Neurological conditions}

This category includes 887 drivers with neurological conditions including strokes, head injuries, cerebral palsy, multiple sclerosis, Parkinson disease, progressive conditions such as muscular atrophies and dystrophy, myasthenia gravis and other spinal cord and brain diseases. Note that epilepsy is considered a separate functional ability category. Alzheimer disease is not included in this category. (Alzheimer disease is included in the "learning, memory and communication" category, which contains a total of 107 individuals and therefore did no undergo analysis by functional ability level in this report). This excludes the 2,352 drivers who were licensed with neurological conditions along with other functional ability categories. Approximately $12.3 \%$ (119) of the drivers in this category fluctuated amongst the various functional ability levels over time. The rate of citations was not significantly different than the comparison group for any functional ability level. The rate of crashes was significantly higher than the comparison group for levels 3 (OR 1.63), 4 (OR 1.90) and 5 (OR 1.69). The rate of at-fault crashes was significantly higher than the comparison group for levels 3 (OR 2.07), 4 (OR 2.63) and 5 (OR 2.37).

To summarize, drivers with neurological conditions at functional ability level 3,4 and 5, (the least restricted drivers) had higher rates of crashes and at-fault crashes than comparison drivers, at an OR of roughly 2 . This effect was not seen at other levels or for citations.

\section{Epilepsy and other episodic conditions}

This category includes 2,620 drivers with epilepsy or related episodic conditions including syncope, cataplexy, narcolepsy, hypoglycemia, and episodic vertigo. This excludes the 934 drivers who were licensed with epilepsy along with other functional ability categories. Approximately $27.5 \%$ (745) of the drivers in this category fluctuated amongst the various functional ability levels over time. The rate of citations was not significantly different than the 
comparison group for any functional ability level. The rate of crashes was significantly higher than the comparison group for levels 3 (OR 1.71), 4 (OR 1.73) 5 (OR 1.69), and 6 (OR 2.07). The rate of at-fault crashes was significantly higher than the comparison group for levels 3 (OR 1.78), 4 (OR 2.04), 5 (OR 1.90), 6 (OR 4.0), 8 (OR 2.49), and 10 (OR 1.78).

To summarize, drivers with epilepsy and other episodic conditions at functional ability level 3-6 (the least restricted drivers) had higher rates of crashes than comparison drivers, while rates of at-fault crashes were higher for most levels; the OR was roughly 2 . No effect was seen for citations.

\section{Psychiatric or emotional conditions}

This category includes 6,703 drivers with history of psychiatric or emotional conditions, psychotic illness, including suicidal tendencies, perceptual distortions, psychomotor retardation, schizophrenia, major depressive disorders, bipolar disorders and/or organic brain syndromes. This does not include the 2,065 drivers who were licensed in this category along with other functional ability categories. The rate of citations was significantly higher than the comparison group for levels 3 (OR 1.16), 4 (OR 1.67) and 5 (OR 1.98). The rate of crashes was significantly higher than the comparison group for levels 3 (OR 1.54), 4 (OR 1.73) 5 (OR 2.27), and 6 (OR 2.58). The rate of at-fault crashes was significantly higher than the comparison group for levels 3 (OR 1.78), 4 (OR 2.22) 5 (OR 3.20), and 6 (OR 4.0).

To summarize, drivers with psychiatric or emotional conditions at functional ability level 3-6 had higher rates of citations, crashes and at-fault crashes than comparison drivers. The increase in rate was modest for citations (OR about 1.5) but was moderately high for crashes (OR 1.5-2.5) and particularly for at-fault crashes in numerically higher functional ability levels (OR up to 34).

\section{Visual acuity}

This category includes 11,363 drivers with history of eye conditions that may affect vision. The rate of citations was significantly higher than the comparison group for levels 3 (OR 1.36), 4 (OR 1.41), 5 (OR 1.44), 6 (OR 1.27), and 8 (OR 2.51). The rate of crashes was significantly higher than the comparison group for levels 3 (OR 1.41), 4 (OR 1.51), 5 (OR 1.44), 6 (OR 1.29), and 8 (OR 2.87). The rate of at-fault crashes was significantly higher than the comparison group for levels 3 (OR 1.56), 4 (OR 1.81), 5 (OR 1.51), 6 (OR 1.55), and 8 (OR 3.84). The number of drivers and events in level 8 was small.

To summarize, drivers with visual conditions at functional ability level 3-6 and 8 had higher rates of citations, crashes and at-fault crashes than comparison drivers. The increase in rate was generally modest (OR about 1.5). 


\section{MULTIPLE MEDICAL CONDITIONS}

Analyses performed for drivers who reported multiple medical conditions are presented in Tables 8-14. Individuals with three- and four-way combinations of medical conditions existed, but in small numbers for each, therefore only two-way combinations that included adequate numbers for analysis were considered (see Tables 3 and 4). Similarly, small numbers at each functional ability level for each medical condition precluded meaningful analysis by individual functional ability level. Therefore, functional ability levels were collapsed into unrestricted (levels 3-5) and unrestricted (levels 6-11) groups for analysis. Table 8 presents the relative risk for all adverse driving events (citations, crashes, and at-fault crashes) combined, by restriction status. Tables 914 present the relative risk for citations, crashes, and at-fault crashes for specific combinations of medical conditions. 
Table 8. Relative Risk for All Adverse Driving Events $\nmid$, Drivers with Multiple Medical Conditions and Corresponding Comparison Groups by Combined Restriction Status, Utah 1992 - 1996

\begin{tabular}{|c|c|c|c|c|c|c|c|c|c|c|c|c|c|}
\hline & \multirow{2}{*}{$\begin{array}{c}\text { Restriction } \\
\text { Statusף }\end{array}$} & \multicolumn{4}{|c|}{ Medical Conditions } & \multicolumn{4}{|c|}{ Comparison Group } & \multicolumn{4}{|c|}{ Rate Ratio } \\
\hline & & Drivers & \# Events & \# Days & Rate & Comparison & \# Events & \# Days & Rate & Ratio & L95\% & U95\% & Significance \\
\hline \multirow[t]{2}{*}{ Citation } & Not Restricted & 13,408 & 2,122 & $12,430,892$ & 1.71 & 25,496 & 7,2247 & $41,429,463$ & 1.74 & 0.98 & 0.93 & 1.03 & \\
\hline & Restricted & 2,414 & 100 & 662,027 & 1.51 & 4,774 & 1,380 & $7,322,259$ & 1.88 & 0.80 & 0.65 & 0.98 & $\hbar$ \\
\hline \multirow[t]{2}{*}{ Crash } & Not Restricted & 13,408 & 1,965 & $12,430,892$ & 1.58 & 25,496 & 4,659 & $41,429,463$ & 1.12 & 1.41 & 1.33 & 1.45 & * \\
\hline & Restricted & 2,414 & 97 & 662,027 & 1.47 & 4,774 & 840 & $7,322,259$ & 1.15 & 1.28 & 1.04 & 1.58 & * \\
\hline \multirow[t]{2}{*}{ At Fault Crash } & Not Restricted & 13,408 & 1,229 & $12,430,892$ & 0.99 & 25,496 & 2,567 & $41,429,463$ & .62 & 1.60 & 1.49 & 1.71 & * \\
\hline & Restricted & 2,414 & 73 & 662,027 & 1.10 & 4,774 & 483 & $7,322,259$ & .66 & 1.67 & 1.31 & 2.13 & * \\
\hline
\end{tabular}

*The confidence interval does not include 1.0. Therefore, the higher rate of the medical conditions group is statistically significant.

** indicates that the medical conditions group has a statistically significant lower rate.

I Not restricted: Functional ability levels 3-5. Restricted: Functional ability levels 6-11.

$\dagger$ Adverse driving events: Citations, crashes, and at-fault crashes. 
Table 9. Relative Risk for Citations, Unrestricted Drivers in Two Functional Ability Categories and Corresponding Comparison Groups

\begin{tabular}{|c|c|c|c|c|c|c|c|c|c|c|c|c|c|}
\hline \multirow[b]{2}{*}{ Condition } & \multirow{2}{*}{$\begin{array}{l}\text { Restriction } \\
\text { Status }\end{array}$} & \multicolumn{4}{|c|}{ Medical Conditions } & \multicolumn{4}{|c|}{ Control Group } & \multicolumn{4}{|c|}{ Rate Ratio } \\
\hline & & Drivers & Citations & \# Days & Rate & Drivers & Citations & \# Days & Rate & Ratio & L95\% & U 95\% & Significance \\
\hline $\begin{array}{l}\text { Diabetes and } \\
\text { Cardiovascular }\end{array}$ & Not Restricted & 5,149 & 421 & $3,715,559$ & 1.133 & 9,878 & 2,256 & $16,149,087$ & 1.397 & 0.811 & 0.731 & 0.900 & k* \\
\hline $\begin{array}{l}\text { Diabetes and } \\
\text { Pulmonary }\end{array}$ & Not Restricted & 653 & 48 & 409,290 & 1.173 & 1,289 & 290 & $2,031,244$ & 1.428 & 0.821 & 0.606 & 1.114 & \\
\hline $\begin{array}{l}\text { Diabetes and } \\
\text { Neurological }\end{array}$ & Not Restricted & 521 & 49 & 313,089 & 1.565 & 1,029 & 259 & $1,630,494$ & 1.588 & 0.985 & 0.726 & 1.337 & \\
\hline $\begin{array}{l}\text { Diabetes and } \\
\text { Psychiatric }\end{array}$ & Not Restricted & 434 & 61 & 287,196 & 2.124 & 861 & 288 & $1,363,088$ & 2.113 & 1.005 & 0.763 & 1.325 & \\
\hline $\begin{array}{l}\text { Diabetes and } \\
\text { Visual Acuity }\end{array}$ & Not Restricted & 456 & 19 & 151,781 & 1.252 & 898 & 214 & $1,370,701$ & 1.561 & 0.802 & 0.502 & 1.281 & \\
\hline $\begin{array}{l}\text { Cardiovascular and } \\
\text { Pulmonary }\end{array}$ & Not Restricted & 1,611 & 110 & 974,995 & 1.128 & 3,151 & 703 & $5,040,618$ & 1.395 & 0.809 & 0.662 & 0.989 & ** \\
\hline $\begin{array}{l}\text { Cardiovascular and } \\
\text { Neurological }\end{array}$ & Not Restricted & 759 & 51 & 437,952 & 1.165 & 1,490 & 342 & $2,348,393$ & 1.456 & 0.800 & 0.596 & 1.072 & \\
\hline $\begin{array}{l}\text { Cardiovascular and } \\
\text { Psychiatric }\end{array}$ & Not Restricted & 758 & 64 & 438,084 & 1.461 & 1,500 & 425 & $2,391,625$ & 1.777 & 0.822 & 0.632 & 1.069 & \\
\hline $\begin{array}{l}\text { Cardiovascular and } \\
\text { Visual Acuity }\end{array}$ & Not Restricted & 437 & 13 & 139,103 & 0.935 & 858 & 148 & $1,288,721$ & 1.148 & 0.814 & 0.462 & 1.433 & \\
\hline $\begin{array}{l}\text { Cardiovascular and } \\
\text { Musculoskeletal }\end{array}$ & Not Restricted & 478 & 20 & 226,092 & 0.885 & 946 & 180 & $1,464,925$ & 1.229 & 0.720 & 0.455 & 1.140 & \\
\hline $\begin{array}{l}\text { Neurological and } \\
\text { Musculoskeletal }\end{array}$ & Not Restricted & 419 & 61 & 220,366 & 2.768 & 830 & 353 & $1,313,067$ & 2.688 & 1.030 & 0.785 & 1.351 & \\
\hline $\begin{array}{l}\text { Neurological and } \\
\text { Functional Motor }\end{array}$ & Not Restricted & 499 & 90 & 284,244 & 3.166 & 986 & 406 & $1,556,055$ & 2.609 & 1.214 & 0.966 & 1.524 & \\
\hline $\begin{array}{l}\text { Musculoskeletal and } \\
\text { Functional Motor }\end{array}$ & Not Restricted & 639 & 87 & 365,992 & 2.377 & 1,264 & 482 & $1,983,002$ & 2.431 & 0.978 & 0.778 & 1.229 & \\
\hline
\end{tabular}

TNot restricted: Functional ability levels 3-5. Restricted: Functional ability levels 6-11.

Rates are expressed as citations per 10,000 license days.

Medical conditions groups did not have a statistically significant higher rate in any of the combination categories.

** indicates that the medical conditions group has a statistically significant lower rate. 
Table 10. Relative Risk for Crashes, Unrestricted Drivers in Two Functional Ability Categories and Corresponding Comparison Groups

\begin{tabular}{|c|c|c|c|c|c|c|c|c|c|c|c|c|c|}
\hline \multirow[b]{2}{*}{ Condition } & \multirow{2}{*}{$\begin{array}{l}\text { RestrictionT } \\
\text { Status }\end{array}$} & \multicolumn{4}{|c|}{ Medical Conditions } & \multicolumn{4}{|c|}{ Control Group } & \multicolumn{4}{|c|}{ Rate Ratio } \\
\hline & & Drivers & Crashes & \# Days & Rate & Drivers & Crashes & \# Days & Rate & Ratio & L 95\% & U 95\% & Significance \\
\hline $\begin{array}{l}\text { Diabetes and } \\
\text { Cardiovascular }\end{array}$ & Not Restricted & 5,149 & 447 & $3,715,559$ & 1.203 & 9,878 & 1,660 & $16,149,087$ & 1.028 & 1.170 & 1.054 & 1.299 & $*$ \\
\hline $\begin{array}{l}\text { Diabetes and } \\
\text { Pulmonary }\end{array}$ & Not Restricted & 653 & 51 & 409,290 & 1.246 & 1,289 & 218 & $2,031,244$ & 1.073 & 1.161 & 0.856 & 1.574 & \\
\hline $\begin{array}{l}\text { Diabetes and } \\
\text { Neurological } \\
\end{array}$ & Not Restricted & 521 & 54 & 313,089 & 1.725 & 1.029 & 189 & $1,630,494$ & 1.159 & 1.488 & 1.102 & 2.009 & * \\
\hline $\begin{array}{l}\text { Diabetes and } \\
\text { Psychiatric }\end{array}$ & Not Restricted & 434 & 52 & 287,196 & 1.811 & 861 & 163 & $1,363,088$ & 1.196 & 1.514 & 1.111 & 2.064 & * \\
\hline $\begin{array}{l}\text { Diabetes and } \\
\text { Visual Acuity }\end{array}$ & Not Restricted & 456 & 36 & 151,781 & 2.372 & 898 & 143 & $1,370,701$ & 1.043 & 2.273 & 1.593 & 3.244 & * \\
\hline $\begin{array}{l}\text { Cardiovascular and } \\
\text { Pulmonary }\end{array}$ & Not Restricted & 1,611 & 106 & 974,995 & 1.087 & 3,151 & 519 & $5,040,618$ & 1.030 & 1.056 & 0.857 & 1.301 & \\
\hline $\begin{array}{l}\text { Cardiovascular and } \\
\text { Neurological }\end{array}$ & Not Restricted & 759 & 45 & 437,952 & 1.028 & 1,490 & 275 & $2,348,393$ & 1.171 & 0.877 & 0.640 & 1.202 & \\
\hline $\begin{array}{l}\text { Cardiovascular and } \\
\text { Psychiatric }\end{array}$ & Not Restricted & 758 & 58 & 438,084 & 1.324 & 1,500 & 249 & $2,391,625$ & 1.041 & 1.272 & 0.956 & 1.691 & \\
\hline $\begin{array}{l}\text { Cardiovascular and } \\
\text { Visual Acuity } \\
\end{array}$ & Not Restricted & 437 & 18 & 139,103 & 1.294 & 858 & 131 & $1,288,721$ & 1.017 & 1.273 & 0.779 & 2.081 & \\
\hline $\begin{array}{l}\text { Cardiovascular and } \\
\text { Musculoskeletal }\end{array}$ & Not Restricted & 478 & 17 & 226,092 & 0.752 & 946 & 129 & $1,464,925$ & 0.881 & 0.854 & 0.515 & 1.415 & \\
\hline $\begin{array}{l}\text { Neurological and } \\
\text { Musculoskeletal }\end{array}$ & Not Restricted & 419 & 45 & 220,366 & 2.042 & 830 & 164 & $1,313,067$ & 1.249 & 1.635 & 1.179 & 2.266 & * \\
\hline $\begin{array}{l}\text { Neurological and } \\
\text { Functional Motor }\end{array}$ & Not Restricted & 499 & 73 & 284,244 & 2.568 & 986 & 174 & $1,556,055$ & 1.118 & 2.297 & 1.761 & 2.995 & 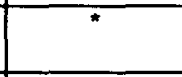 \\
\hline $\begin{array}{l}\text { Musculoskeletal and } \\
\text { Functional Motor }\end{array}$ & Not Restricted & 639 & 67 & 365,992 & 1.831 & 1,264 & 230 & $1,983,002$ & 1.160 & 1.578 & 1.205 & 2.067 & * \\
\hline
\end{tabular}

I Not restricted: Functional ability levels 3-5. Restricted: Functional ability levels 6-11.

Rates are expressed as crashes per 10,000 license days.

* The confidence interval does not include 1.0. Therefore, the higher rate of the medical conditions group is statistically significant. 
Table 11. Relative Risk for At-Fault Crashes, Unrestricted Drivers in Two Functional Ability Categories and Corresponding Comparison Groups

\begin{tabular}{|c|c|c|c|c|c|c|c|c|c|c|c|c|c|}
\hline \multirow[b]{2}{*}{ Condition } & \multirow{2}{*}{$\begin{array}{l}\text { RestrictionI } \\
\text { Status }\end{array}$} & \multicolumn{4}{|c|}{ Medical Conditions } & \multicolumn{4}{|c|}{ Control Group } & \multicolumn{4}{|c|}{ Rate Ratio } \\
\hline & & Drivers & Crashes & \# Days & Rate & Drivers & Crashes & \# Days & Rate & Ratio & L 95\% & U 95\% & Significance \\
\hline $\begin{array}{l}\text { Diabetes and } \\
\text { Cardiovascular }\end{array}$ & Not Restricted & 5,149 & 283 & $3,715,559$ & 0.762 & 9,878 & 872 & $16,149,087$ & 0.540 & 1.411 & 1.234 & 1.612 & 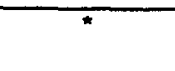 \\
\hline $\begin{array}{l}\text { Diabetes and } \\
\text { Pulmonary }\end{array}$ & Not Restricted & 653 & 30 & 409,290 & 0.733 & 1,289 & 115 & $2,031,244$ & 0.566 & 1.295 & 0.867 & 1.933 & \\
\hline $\begin{array}{l}\text { Diabetes and } \\
\text { Neurological }\end{array}$ & Not Restricted & 521 & 33 & 313,089 & 1.054 & 1,029 & 104 & $1,630,494$ & 0.638 & 1.652 & 1.122 & 2.435 & 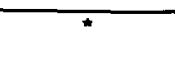 \\
\hline $\begin{array}{l}\text { Diabetes and } \\
\text { Psychiatric }\end{array}$ & Not Restricted & 434 & 32 & 287,196 & 1.114 & 861 & 79 & $1,363,088$ & 0.580 & 1.922 & 1.284 & 2.878 & * \\
\hline $\begin{array}{l}\text { Diabetes and } \\
\text { Visual Acuity }\end{array}$ & Not Restricted & 456 & 22 & 151,781 & 1.449 & 898 & 85 & $1,370,701$ & 0.620 & 2.337 & 1.483 & 3.684 & * \\
\hline $\begin{array}{l}\text { Cardiovascular and } \\
\text { Pulmonary }\end{array}$ & Not Restricted & 1,611 & 56 & 974,995 & 0.574 & 3,151 & 278 & $5,040,618$ & 0.552 & 1.041 & 0.782 & 1.388 & \\
\hline $\begin{array}{l}\text { Cardiovascular and } \\
\text { Neurological }\end{array}$ & Not Restricted & 759 & 33 & 437,952 & 0.754 & 1,490 & 152 & $2,348,393$ & 0.647 & 1.164 & 0.799 & 1.696 & \\
\hline $\begin{array}{l}\text { Cardiovascular and } \\
\text { Psychiatric }\end{array}$ & Not Restricted & 758 & 31 & 438,084 & 0.708 & 861 & 79 & $1,363,088$ & 0.580 & 1.221 & 0.806 & 1.848 & \\
\hline $\begin{array}{l}\text { Cardiovascular and } \\
\text { Visual Acuity }\end{array}$ & Not Restricted & 437 & 11 & 139,103 & 0.791 & 858 & 80 & $1,288,721$ & 0.621 & 1.274 & 0.679 & 2.389 & \\
\hline $\begin{array}{l}\text { Cardiovascular and } \\
\text { Musculoskeletal }\end{array}$ & Not Restricted & 478 & 13 & 226,092 & 0.575 & 946 & 77 & $1,464,925$ & 0.526 & 1.094 & 0.608 & 1.969 & \\
\hline $\begin{array}{l}\text { Neurological and } \\
\text { Musculoskeletal }\end{array}$ & Not Restricted & 419 & 31 & 220,366 & 1.407 & 830 & 84 & $1,313,067$ & 0.640 & 2.199 & 1.472 & 3.285 & * \\
\hline $\begin{array}{l}\text { Neurological and } \\
\text { Functional Motor }\end{array}$ & Not Restricted & 499 & 49 & 284,244 & 1.724 & 986 & 90 & $1,556,055$ & 0.578 & 2.980 & 2.140 & 4.151 & * \\
\hline $\begin{array}{l}\text { Musculoskeletal and } \\
\text { Functional Motor }\end{array}$ & Not Restricted & $\overline{639}$ & 46 & 365,992 & 1.257 & 1,264 & 127 & $1,983,002$ & 0.640 & 1.962 & 1.409 & 2.732 & 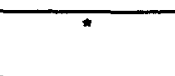 \\
\hline
\end{tabular}

T Not restricted: Functional ability levels 3-5. Restricted: Functional ability levels 6-11.

Rates are expressed as at-fault crashes per 10,000 license days.

* The confidence interval does not include 1.0. Therefore, the higher rate of the medical conditions group is statistically significant. 
Table 12. Relative Risk for Citations, Restricted Drivers in Two Functional Ability Categories, and Corresponding Comparison Groups

\begin{tabular}{|c|c|c|c|c|c|c|c|c|c|c|c|c|c|}
\hline \multirow[b]{2}{*}{ Condition } & \multirow{2}{*}{$\begin{array}{l}\text { Restriction } \uparrow \\
\text { Status }\end{array}$} & \multicolumn{4}{|c|}{ Medical Conditions } & \multicolumn{4}{|c|}{ Control Group } & \multicolumn{4}{|c|}{ Rate Ratio } \\
\hline & & Drivers & Citations & \# Days & Rate & Drivers & Citations & \#Days & Rate & Ratio & L 95\% & U 95\% & Significance \\
\hline $\begin{array}{l}\text { Diabetes and } \\
\text { Cardiovascular }\end{array}$ & Restricted & 369 & 5 & 63,087 & 0.793 & 732 & 145 & $1,169,976$ & 1.239 & 0.640 & 0.264 & 1.548 & \\
\hline $\begin{array}{l}\text { Diabetes and } \\
\text { Visual Acuity }\end{array}$ & Restricted & 136 & 5 & 37,775 & 1.324 & 268 & 41 & 411,682 & 0.996 & 1.329 & 0.527 & 3.353 & \\
\hline $\begin{array}{l}\text { Cardiovascular and } \\
\text { Pulmonary }\end{array}$ & Restricted & 257 & 4 & 59,324 & 0.674 & 504 & 104 & 795,688 & 1.307 & 0.516 & 0.193 & 1.375 & \\
\hline $\begin{array}{l}\text { Cardiovascular and } \\
\text { Neurological }\end{array}$ & Restricted & 186 & 1 & 49,253 & 0.203 & 369 & 75 & 567,701 & 1.321 & 0.154 & 0.028 & 0.851 & $\star \star$ \\
\hline $\begin{array}{l}\text { Cardiovascular and } \\
\text { Visual Acuity }\end{array}$ & Restricted & 145 & 7 & 41,661 & 1.680 & 287 & 38 & 444,009 & 0.856 & 1.963 & 0.890 & 4.330 & \\
\hline $\begin{array}{l}\text { Neurological and } \\
\text { Musculoskeletal }\end{array}$ & Restricted & 176 & 14 & 68,648 & 2.039 & 349 & 141 & 538,049 & 2.621 & 0.778 & 0.450 & 1.346 & \\
\hline $\begin{array}{l}\text { Neurological and } \\
\text { Functional Motor }\end{array}$ & Restricted & 176 & 12 & 62,282 & 1.927 & 350 & 162 & 528,730 & 3.064 & 0.629 & 0.352 & 1.124 & \\
\hline $\begin{array}{l}\text { Musculoskeletal and } \\
\text { Functional Motor }\end{array}$ & Restricted & 149 & 9 & 53,274 & 1.689 & 297 & 131 & 457,298 & 2.865 & 0.590 & 0.302 & 1.150 & \\
\hline
\end{tabular}

If Not restricted: Functional ability levels 3-5. Restricted: Functional ability levels 6-11.

Rates are expressed as citations per 10,000 license days.

Medical conditions groups did not have a statistically significant higher rate in any of the combination categories.

** indicates that the medical conditions group has a statistically significant lower rate. 
Table 13. Relative Risk for All Crashes, Restricted Drivers in Two Functional Ability Categories, and Corresponding Comparison Groups

\begin{tabular}{|c|c|c|c|c|c|c|c|c|c|c|c|c|c|}
\hline \multirow[b]{2}{*}{ Condition } & \multirow[t]{2}{*}{ Restriction } & \multicolumn{4}{|c|}{ Medical Conditions } & \multicolumn{4}{|c|}{ Control Group } & \multicolumn{4}{|c|}{ Rate Ratio } \\
\hline & & Drivers & Crashes & \# Days & Rate & Drivers & Crashes & \# Days & Rate & Ratio & L95\% & U 95\% & Significance \\
\hline $\begin{array}{l}\text { Diabetes and } \\
\text { Cardiovascular }\end{array}$ & Restricted & 369 & 11 & 63,087 & 1.744 & 732 & 110 & $1,169,976$ & 0.940 & 1.855 & 1.008 & 3.413 & * \\
\hline $\begin{array}{l}\text { Diabetes and } \\
\text { Visual Acuity }\end{array}$ & Restricted & 136 & 7 & 37,775 & 1.853 & 268 & 43 & 411,682 & 1.045 & 1.774 & 0.807 & 3.901 & \\
\hline $\begin{array}{l}\text { Cardiovascular and } \\
\text { Pulmonary }\end{array}$ & Restricted & 257 & 2 & 59,324 & 0.337 & 504 & 79 & 795,688 & 0.993 & 0.340 & 0.089 & 1.293 & \\
\hline $\begin{array}{l}\text { Cardiovascular and } \\
\text { Neurological }\end{array}$ & Restricted & 186 & 2 & 49,253 & 0.406 & 369 & 73 & 567,701 & 1.286 & 0.316 & 0.084 & 1.194 & \\
\hline $\begin{array}{l}\text { Cardiovascular and } \\
\text { Visual Acuity }\end{array}$ & Restricted & 145 & 7 & 41,661 & 1.680 & 287 & 44 & 444,009 & 0.991 & 1.696 & 0.771 & 3.730 & \\
\hline $\begin{array}{l}\text { Neurological and } \\
\text { Musculoskeletal }\end{array}$ & Restricted & 176 & 17 & 68,648 & 2.476 & 349 & 55 & 538,049 & 1.022 & 2.423 & 1.431 & 4.102 & 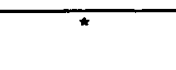 \\
\hline $\begin{array}{l}\text { Neurological and } \\
\text { Functional Motor }\end{array}$ & Restricted & 176 & 15 & 62,282 & 2.408 & 350 & 57 & 528,730 & 1.078 & 2.234 & 1.284 & 3.887 & 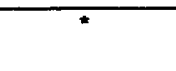 \\
\hline $\begin{array}{l}\text { Musculoskeletal and } \\
\text { Functional Motor }\end{array}$ & Restricted & 149 & 11 & 53,274 & 2.065 & 297 & 48 & 457,298 & 1.050 & 1.967 & 1.034 & 3.741 & 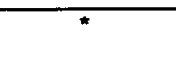 \\
\hline
\end{tabular}

T Not restricted: Functional ability levels 3-5. Restricted: Functional ability levels 6-11.

Rates are expressed as crashes per 10,000 license days.

* The confidence interval does not include 1.0. Therefore, the higher rate of the medical conditions group is statistically significant. 
Table 14. Relative Risk for At-Fault Crashes, Restricted Drivers in Two Functional Ability Categories, and Corresponding Comparison Groups

\begin{tabular}{|c|c|c|c|c|c|c|c|c|c|c|c|c|c|}
\hline \multirow[b]{2}{*}{ Condition } & \multirow{2}{*}{ Restriction } & \multicolumn{4}{|c|}{ Medical Conditions } & \multicolumn{4}{|c|}{ Control Group } & \multicolumn{4}{|c|}{ Rate Ratio } \\
\hline & & Drivers & Crashes & \# Days & Rate & Drivers & Crashes & \# Days & Rate & Ratio & L 95\% & U 95\% & Significance \\
\hline $\begin{array}{l}\text { Diabetes and } \\
\text { Cardiovascular }\end{array}$ & Restricted & 369 & 10 & 63,087 & 1.585 & 732 & 60 & $1,169,976$ & 0.513 & 3.091 & 1.638 & 5.834 & 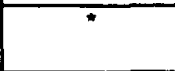 \\
\hline $\begin{array}{l}\text { Diabetes and } \\
\text { Visual Acuity }\end{array}$ & Restricted & 136 & 7 & 37,775 & 1.853 & 268 & 30 & 411,682 & 0.729 & 2.543 & 1.150 & 5.623 & 7 \\
\hline $\begin{array}{l}\text { Cardiovascular and } \\
\text { Pulmonary }\end{array}$ & Restricted & 257 & 2 & 59,324 & 0.337 & 504 & 44 & 795,688 & 0.553 & 0.610 & 0.150 & 2.479 & \\
\hline $\begin{array}{l}\text { Cardiovascular and } \\
\text { Neurological }\end{array}$ & Restricted & 186 & 2 & 49,253 & 0.406 & 369 & 40 & 567,701 & 0.705 & 0.576 & 0.142 & 2.343 & \\
\hline $\begin{array}{l}\text { Cardiovascular and } \\
\text { Visual Acuity }\end{array}$ & Restricted & 145 & 7 & 41,661 & 1.680 & 287 & 29 & 444,009 & 0.653 & 2.573 & 1.161 & 5.699 & * \\
\hline $\begin{array}{l}\text { Neurological and } \\
\text { Musculoskeletal }\end{array}$ & Restricted & 176 & 10 & 68,648 & 1.457 & 349 & 24 & 538,049 & 0.446 & 3.266 & 1.628 & 6.552 & * \\
\hline $\begin{array}{l}\text { Neurological and } \\
\text { Functional Motor }\end{array}$ & Restricted & 176 & 12 & 62,282 & 1.927 & 350 & 31 & 528,730 & 0.586 & 3.286 & 1.753 & 6.162 & * \\
\hline $\begin{array}{l}\text { Musculoskeletal and } \\
\text { Functional Motor }\end{array}$ & Restricted & 149 & 8 & 53,274 & 1.502 & 297 & 22 & 457,298 & $0 . \overline{481}$ & 3.121 & 1.449 & 6.722 & * \\
\hline
\end{tabular}

T Not restricted: Functional ability levels 3-5. Restricted: Functional ability levels 6-11.

Rates are expressed as at-fault crashes per 10,000 license days.

* The confidence interval does not include 1.0. Therefore, the higher rate of the medical conditions group is statistically significant. 


\section{All Drivers licensed in multiple functional ability categories}

This category includes 13,408 drivers licensed during the study period. Rates for unrestricted drivers (functional ability levels 3-5) in this category were $1.71,1.58$ and 0.99 per 10,000 license days for citation, all crash and at fault crashes respectively compared to $1.74,1.12$ and 0.62 respectively for their corresponding comparison group. The rates for the restricted drivers (functional ability levels 6-11) in this category were all 1.51, 1.47 and 1.10 per 10,000 licensed days for citation, crash and at fault crash compared to $1.88,1.15$ and 0.66 for their corresponding comparison group.

The relative risks (odds ratios) for citation, crash and at-fault crashes were $0.98,1.41$ and 1.60 for unrestricted drivers, and $0.80,1.28$ and 1.67 for restricted drivers for citation, crash and atfault crash during the study period. The confidence levels for all crash and at-fault crash in both groups were higher than those of their respective comparison groups at a statistical significance level of $5 \%$. However, the rate of citation for restricted drivers was significantly lower than that of their corresponding comparison group, while the rate of citation for unrestricted drivers was similar to the rate of the comparison drivers.

\section{Diabetes Mellitus and other Metabolic Conditions plus Cardiovascular Conditions}

This was the largest group of individuals with multiple medical conditions, and included 5149 unrestricted and 369 restricted drivers licensed during the study period. Rates for unrestricted drivers were $1.133,1.203$, and 0.762 per 10,000 license days for citations, crashes, and at-fault crashes respectively, compared with $1.397,1.028$, and 0.540 for the corresponding comparison groups. Rates were significantly lower than comparison drivers for citations (OR 0.81 ). Rates were significantly higher than comparison drivers for crashes and at-fault crashes (OR 1.03 and 1.41 respectively).

Rates for restricted drivers were $0.793,1.744$ and 1.585 per 10,000 license days for citations, crashes, and at-fault crashes respectively, compared with $1.239,0.940$, and 0.513 for the corresponding control groups. Rates were significantly higher than comparison drivers for crashes and at-fault crashes (OR 1.86 and 3.09 respectively). Absolute numbers of these latter two events were small.

\section{Diabetes Mellitus and other Metabolic Conditions plus Pulmonary Conditions}

This group included 653 unrestricted drivers licensed during the study period; the number of restricted drivers with this combination of conditions was too small for meaningful analysis. Rates for unrestricted drivers were $1.173,1.246$ and 0.733 per 10,000 license days for citations, crashes, and at-fault crashes respectively, compared with $1.428,1.073$ and 0.566 for the corresponding comparison groups. These rates did not differ significantly. 


\section{Diabetes Mellitus and other Metabolic Conditions plus Neurological Conditions}

This group included 521 unrestricted drivers licensed during the study period; the number of restricted drivers with this combination of conditions was too small for meaningful analysis. Rates for unrestricted drivers were $1.565,1.725$, and 1.054 per 10,000 license days for citations, crashes, and at-fault crashes respectively, compared with $1.588,1.159$, and 0.638 for the corresponding comparison groups. Rates were significantly higher than the comparison groups for crashes and at-fault crashes (OR 1.49 and 1.65 respectively).

\section{Diabetes Mellitus and other Metabolic Conditions plus Psychiatric Conditions}

This group included 434 unrestricted drivers licensed during the study period; the number of restricted drivers with this combination of conditions was too small for meaningful analysis. Rates for unrestricted drivers were $2.124,1.811$, and 1.114 per 10,000 license days for citations, crashes, and at-fault crashes respectively, compared with $2.113,1.196$, and 0.580 for the corresponding comparison groups. Rates were significantly higher than the comparison groups for crashes and at-fault crashes (OR 1.514 and 1.1.922 respectively).

\section{Diabetes Mellitus and other Metabolic Conditions plus Visual Acuity}

This group included 456 unrestricted and 136 restricted drivers licensed during the study period. Rates for unrestricted drivers were $1.252,2.372$ and 1.449 per 10,000 license days for citations, crashes, and at-fault crashes respectively, compared with $1.561,1.043$ and 0.620 for the corresponding comparison groups. Rates were significantly higher than the comparison groups for crashes and at-fault crashes (OR 2.27 and 2.34 respectively).

Rates for restricted drivers were $1.324,1.853$ and 1.853 per 10,000 license days for citations, crashes, and at-fault crashes respectively, compared with $0.996,1.045$, and 0.729 for the corresponding control groups. Rates were significantly higher than comparison drivers for atfault crashes (OR 2.54). Absolute numbers of at-fault crashes were small.

\section{Cardiovascular plus Pulmonary}

This group included 1611 unrestricted and 257 restricted drivers licensed during the study period. Rates for unrestricted drivers were $1.128,1.087$ and 0.574 per 10,000 license days for citations, crashes, and at-fault crashes respectively, compared with $1.395,1.030$ and 0.552 for the corresponding comparison groups. The rate for citations was significantly lower than the comparison groups (OR 0.81 ), while rates for crashes and at-fault crashes did not differ significantly from the comparison groups.

Rates for restricted drivers were $0.674,0.337$ and 0.337 per 10,000 license days for citations, crashes, and at-fault crashes respectively, compared with $1.307,0.993$ and 0.553 for the 
corresponding comparison groups. These rates did not differ significantly from the comparison groups.

\section{Cardiovascular plus Neurological}

This group included 759 unrestricted and 186 restricted drivers licensed during the study period. Rates for unrestricted drivers were 1.165, 1.028 and 0.754 per 10,000 license days for citations, crashes, and at-fault crashes respectively, compared with $1.456,1.171$ and 0.647 for the corresponding comparison groups. These rates did not differ significantly from the comparison groups.

Rates for restricted drivers were $0.203,0.406$ and 0.406 per 10,000 license days for citations, crashes, and at-fault crashes respectively, compared with $1.321,1.286$ and 0.705 for the corresponding comparison groups. The rate for citations was significantly lower than the comparison groups (OR 0.15), while rates for crashes and at-fault crashes did not differ significantly from the comparison groups.

\section{Cardiovascular plus Psychiatric Conditions}

This group included 758 unrestricted drivers licensed during the study period; the number of restricted drivers with this combination of conditions was too small for meaningful analysis. Rates for unrestricted drivers were $1.461,1.32$ and 0.708 per 10,000 license days for citations, crashes, and at-fault crashes respectively, compared with $1.777,1.041$ and 0.580 for the corresponding comparison groups. These rates did not differ significantly from the comparison groups.

\section{Cardiovascular plus Visual Acuity}

This group included 437 unrestricted and 145 restricted drivers licensed during the study period. Rates for unrestricted drivers were $0.935,1.294$ and 0.791 per 10,000 license days for citations, crashes, and at-fault crashes respectively, compared with $1.148,1.017$ and 0.621 for the corresponding comparison groups. These rates did not differ significantly from the comparison groups.

Rates for restricted drivers were $1.680,1.680$ and 1.680 per 10,000 license days for citations, crashes, and at-fault crashes respectively, compared with $0.856,0.991$ and 0.653 for the corresponding comparison groups. The rates for citations and crashes did not differ significantly from the comparison groups, while the rate for at-fault crashes was significantly higher (OR 2.57). 


\section{Cardiovascular plus Musculoskeletal}

This group included 478 unrestricted drivers licensed during the study period; the number of restricted drivers with this combination of conditions was too small for meaningful analysis. Rates for unrestricted drivers were $0.885,0.752$, and 0.575 per 10,000 license days for citations, crashes, and at-fault crashes respectively, compared with $1.229,0.881$ and 0.526 for the corresponding comparison groups. These rates did not differ significantly from the comparison groups.

\section{Neurological plus Musculoskeletal}

This group included 419 unrestricted and 176 restricted drivers licensed during the study period. Rates for unrestricted drivers were $2.768,2.042$, and 1.407 per 10,000 license days for citations, crashes, and at-fault crashes respectively, compared with $2.688,1.249$ and 0.640 for the corresponding comparison groups. The rates for citations did not differ significantly from the comparison group, while the rate for crashes and at-fault crashes were significantly higher (OR 1.64 and 2.20 respectively).

Rates for restricted drivers were $2.039,2.476$ and 1.457 per 10,000 license days for citations, crashes, and at-fault crashes respectively, compared with $2.621,1.022$ and 0.446 for the corresponding comparison groups. The rates for citations did not differ significantly from the comparison group, while the rate for crashes and at-fault crashes were significantly higher (OR 2.42 and 3.27 respectively).

\section{Neurological plus Functional Motor}

This group included 499 unrestricted and 176 restricted drivers licensed during the study period. Rates for unrestricted drivers were 3.166, 2.568 and 1.724 per 10,000 license days for citations, crashes, and at-fault crashes respectively, compared with $2.609,1.118$ and 0.578 for the corresponding comparison groups. The rates for citations did not differ significantly from the comparison group, while the rates for crashes and at-fault crashes were significantly higher (OR 2.30 and 2.98 respectively).

Rates for restricted drivers were $1.927,2.408$ and 1.927 per 10,000 license days for citations, crashes, and at-fault crashes respectively, compared with $3.064,1.078$ and 0.586 for the corresponding comparison groups. The rates for citations did not differ significantly from the comparison group, while the rate for crashes and at-fault crashes were significantly higher (OR 2.23 and 3.29 respectively). 


\section{Musculoskeletal plus Functional Motor}

This group included 639 unrestricted and 149 restricted drivers licensed during the study period. Rates for unrestricted drivers were 2.377, 1.831 and 1.257 per 10,000 license days for citations, crashes, and at-fault crashes respectively, compared with $2.431,1.160$ and 0.640 for the corresponding comparison groups. The rates for citations did not differ significantly from the comparison group, while the rates for crashes and at-fault crashes were significantly higher (OR 1.58 and 1.96 respectively).

Rates for restricted drivers were $1.689,2.065$ and 1.502 per 10,000 license days for citations, crashes, and at-fault crashes respectively, compared with $2.865,1.050$ and 0.481 for the corresponding comparison groups. The rates for citations did not differ significantly from the comparison group, while the rate for crashes and at-fault crashes were significantly higher (OR 1.967 and 3.121 respectively). 


\section{DISCUSSION}

In this study, we have determined the rates of citations, crashes and at-fault crashes of drivers licensed in the medical conditions program and compared them to the rates of demographically similar drivers. Our study describes the driving performance of drivers who voluntarily report their medical conditions to the licensing agency. It does not describe the direct influence of medical conditions on driving performance.

This study is a continuation and expansion of our previous work in this area: Evaluating Drivers Licensed with Medical Conditions in Utah, 1992-1996, which was completed in June 1999 (DOT HS 809 023, available from the National Technical Information Service, Springfield, Virginia 22161). The Executive Summary for that first report is included as Appendix D. As in that first study, we evaluated the rates of various adverse driving events experienced by all 68,770 drivers licensed in the state with medical conditions. In that study, we reported analysis of each functional ability category (medical condition) by restriction status; that is, the various functional ability levels were collapsed into unrestricted (levels 3-5) and restricted (levels 6-11) groups for analysis. (Recall that levels 1-2 are irrelevant for the general population of drivers, and that level 12 signifies no driving permitted.) Also in the first study, those individuals who were in more than one functional ability category (reported more than one medical condition) did not undergo subgroup analysis for specific combinations of conditions. Rather, they were analyzed together as a single group of "drivers with multiple medical conditions".

In the present study, we performed more detailed analyses, in order to expand on existing knowledge of the effects of specialized licensing programs that regulate such drivers (11-13). Rather than being collapsed into unrestricted and restricted groups, each functional ability category (medical condition) was analyzed for each functional ability level. Further, drivers in more than one functional ability category were analyzed by specific combinations of medical conditions.

Approximately $80 \%(54,825)$ of the study population reported a single medical condition for the study period. When these drivers were analyzed for adverse driving events by specific medical condition and functional ability level, some patterns could be discerned. The rate of citations for medical conditions drivers did not differ in any consistent way from that of comparison drivers. The rates of crashes and at-fault crashes, however, were significantly higher than the comparison group for some functional ability levels for most functional ability categories (medical conditions). Further, this effect was generally seen at the numerically lowest functional ability levels, where driving privileges were not restricted (recall that the numerically lowest functional ability levels are the least restrictive). Specifically, categories showing significantly higher rates of citations included psychiatric conditions and visual acuity, levels 3-5. Categories showing significantly higher rates for crashes and at-fault crashes included all medical conditions except cardiovascular, for levels 3-5 depending on the specific condition (but always including level 3). Note that "significantly" is used here in its statistical sense. It does not necessarily follow that these differences have major import for public safety or for the medical conditions program.

Approximately $20 \%(13,408)$ of the study population were in more than one functional ability category (reported more than one medical condition) for the study period. Most $(10,595)$ of 
these individuals reported two such conditions, although combinations of as many as 7 did occur. Although an extremely large number of different combinations were mathematically possible, only a limited number of two-way combinations (and no combinations of three or more functional ability categories) contained sufficient numbers of individuals for analysis. The rates of citations for these drivers with combinations of medical conditions did not generally differ from the comparison groups. Rates of crashes and at-fault crashes were higher than the comparison groups for approximately half of the combinations analyzed. In these cases, unrestricted (functional ability levels 3-5) and restricted (levels 6-11) did not appear to differ markedly. Specifically, higher rates of crashes and at-fault crashes, compared to comparison drivers, were found for drivers with the following combinations of medical conditions:

\section{Unrestricted Drivers Restricted Drivers}

diabetes and cardiovascular diabetes and cardiovascular

diabetes and neurological neurological and musculoskeletal

diabetes and psychiatric neurological and functional motor

diabetes and visual acuity musculoskeletal and functional motor

neurological and musculoskeletal cardiovascular and visual acuity (at-fault crashes only)

neurological and functional motor

musculoskeletal and functional motor

We have presented a degree of risk for each category as a relative risk (odds ratio). This is a ratio of the rates of events that compare medical condition drivers to the rates of comparison drivers. While this ratio compares rates of adverse driving events for medical condition populations to those of demographically similar drivers, the numbers of events themselves are also of interest. The absolute numbers of adverse driving events for many subgroups described in this study are very small, often less than 100 and sometimes less than 10. Medical condition and functional ability level subgroups with high relative risks, but low numbers of occurrences, probably do not have a major adverse impact on public safety. Thus, the risk caused by these groups may not warrant changes to this safety program.

As noted elsewhere, small numbers in subgroups was a major obstacle to data analysis in this study. In order to compensate for this, it might seem logical to analyze all the functional ability levels in aggregate, by combining all the various medical conditions. That is, drivers from functional ability level 3 for each functional ability category (medical condition) could be combined into one group containing all drivers at functional ability level 3 , and similarly for every other level. We considered conducting such an analysis, but have elected not to do so. Primarily, this is because there is no particular commonality between functional ability levels for different medical conditions. For instance, functional level 3 is defined differently for diabetes than it is for visual acuity. There is no basis for concluding that functional ability level 6 assigned for diabetes, for instance, implies the same degree of impairment as the same level assigned for psychiatric conditions. A global analysis by functional ability level might lead to a conclusion that the levels should be modified globally, but such a conclusion probably would not be warranted since there is no fundamental similarity amongst functional ability levels across medical conditions categories. 
As with our first study of this program, there are two major limitations that must be considered when evaluating these results. First, accurate measurements of exposure (miles driven) and other factors that affect the risk of citation or crash are not available. In the absence of exposure data, we reasoned that the amount and conditions of driving for persons with medical conditions could be estimated by selecting comparison drivers using age group, county of residence, and sex. This may in fact be incorrect, as other factors influence the number of miles that people drive. They include marital and economic status, employment, higher education, being a member of a social or religious organization, residential demographics, and the condition itself $(1,14,15)$.

The second major limitation of our study is that the medical conditions program relies on selfreporting through a general questionnaire administered by the Utah Driver License Division. This is also a major limitation of the medical conditions program itself. There is actually a disincentive for applicants to report a medical condition, since doing so may require a longer wait for a driver license or a visit to a health care professional or both. Medgyesi and Koch showed that for every driver with a cardiovascular disease known to the licensing division in Saskatchewan, Canada through its medical review program, there were 94 such drivers who were unknown (16). The proportion of drivers who have medical conditions and actually report their conditions is unknown in Utah. The Utah Department of Health estimates that the prevalence of diabetes was $2.9 \%(57,900)$ of the general population in $1996(17)$; however less than half $(26,458,46 \%)$ of these persons, although not all would be licensed drivers, reported their condition to the driver license division.

In addition to these two major limitations, other potential problems with the system may exist. For instance, drivers who were required to have an evaluation by a physician might have "doctor-shopped" to acquire a more favorable rating and thus avoid restrictions on their driving privileges. Further, it is unknown how consistently health care professionals assign functional ability levels according to the guidelines. Compliance with the program for restricted drivers (e.g., time, area or speed) was also assumed. For example, while some restricted drivers are not supposed to drive after dark because of the restrictions placed upon their driver licenses, we did not verify that these drivers were following their restrictions at the time of the crash or citation. 


\section{CONCLUSIONS AND RECOMMENDATIONS}

The determination of citation, crash and at fault crash rates by medical conditions, functional ability level and the corresponding estimates of relative risk provide useful information for the evaluation of the existing medical conditions program in Utah. The results of this study indicate where the citation and crash risk for the medical condition population exceeds the risk for the general population.

The results of this study suggest that participation in the program does not completely negate the adverse effects of medical conditions on driving. This does not mean that the existing program is not beneficial to public safety. It is important that this study be considered in context, considering both the limitations of the study and of the medical conditions program itself. Conceivably, the existing program could be changed in order to reduce the excess risk of drivers with medical conditions to approximate the risks of the general driving population. Further analyses may be necessary to make specific recommendations for reducing risks by specific functional ability categories. However, general recommendations and observations can be made in order to provide a framework for improving the current system. They include:

Simplification of the existing program, where possible, should be considered to improve evaluation. The need for simplification became clearer when the analysis by specific functional ability level was done. With twelve functional ability levels available for each functional ability category (medical condition), a total of 144 distinct subgroups are created. Although some of these cells were large, others were very small. Many contained less than 25 drivers, and some cells were empty entirely. In these cells, the absolute number of adverse driving events was very few, making useful data analysis impossible. Such a structure only increases the administrative burden without measurable benefit to the program. The problem of small cell size was also encountered in the groups of drivers with multiple medical conditions, which comprises a sizable minority, $20 \%$, of all program drivers. The current program would appear to require a separate functional ability level for each medical condition or functional ability category. This might potentially result in several different restriction levels or licensing periods or both, for the same individual. Restructuring of the program to account for this seamlessly would be worthwhile.

Moving the "restriction line" does not appear to be warranted for most categories. We previously suggested that priority for modification of the system be for those categories where the rate of adverse events seems inordinately high. We further suggested that this might be reasonably defined as a rate that exceeds that of the comparison populations by a factor of 2 or more. Many of the subgroups for which this is true contain small numbers of individuals, such that modification of the program is probably not worthwhile. There are a few subgroups where modification might be considered based on that criterion, however. These are categories containing reasonable numbers of individuals where the relative risk of crashes and/or at-fault crashes exceeds, or at least approaches, 2. Specifically, these are epilepsy, psychiatric, and neurological categories, at functional ability levels 3-6. These are mostly unrestricted drivers, since levels 3-5 do not signify restriction of driving privileges. Since the medical conditions program intervenes on behalf of public safety primarily by restriction of driving activities, the logical action might be increasing restrictions for these drivers. That would have to be done by altering the definitions of the functional ability levels in such a way that some currently 
unrestricted drivers would have restrictions placed on them. Whether increasing restrictions in this fashion would be acceptable to the public or politically feasible is debatable.

Modification of the restriction pattern may be considered for drivers with more than one medical condition. The relative risk for crashes and at-fault crashes for drivers with more than one medical condition exceeded that of comparison drivers in roughly half of the combinations examined. The ratio exceeded 2 in a fair number of those. This was true for both unrestricted and restricted drivers. This may be interpreted to mean that the present system, wherein the functional ability level is assigned somewhat independently for each medical condition, may underestimate the amount of driving impairment experienced by these drivers with medical conditions. Taking multiple conditions into consideration when assigning functional ability level seems warranted, considering that 1 in $5(20 \%)$ of medical conditions program drivers report multiple conditions.

Any further research into the medical condition program should evaluate these data in the light of exposure data. The main activity of this program is to impose restrictions (by assigning them a functional ability level) on the driving activities of individuals deemed to have diminished driving skills as a result of medical problems. The underlying assumption here is that placing restrictions on drivers compensates for diminished driving competence. It is not certain that this is true, however. Demonstration of this would require that one show that rate of adverse driving events per mile driven be reduced by placement of restrictions. Although we have used age- and location-matching as a proxy for exposure, we cannot be very confident that the exposure rates are, in fact, comparable. It is possible that the existing program could be used to gather exposure data at reasonable expense. Applicants for driver's licenses could be required, as a condition of licensure, to estimate their annual mileage and describe the type of driving they do at the time of license application and renewal.

There is immediate need for research into the medical conditions program to test whether restrictions on driving improve public safety. The main product of the medical conditions driver program is the imposition of restrictions on the driving privileges of certain drivers. The unspoken underlying assumption in the program is that such restrictions improve safety. That is, given that medical conditions impair driving ability and thus adversely affect safety, it is assumed that restriction of driving activities by the program compensates for this impairment so as to make the driver acceptably safe. Whether this is in fact true is unknown; indeed, it appears to be a rather major leap of faith. We believe this is the biggest current need for research in the area of medical condition. Data analysis in this report could not be said to prove that the medical conditions program accomplishes its major goal, that of ensuring safe driving by people with medical programs, at all. Indeed, it could be interpreted as suggesting the opposite.

Efforts to modify the existing program should be prioritized by the Utah Driver License Division and the Utah Medical Advisory Board. Additionally, these agencies should work together to determine the range, scope and order of future research that is necessary to develop the appropriate modifications specific to each functional ability category. Consideration should also be given to this study's existing limitations described in the previous section. 
Priorities should be placed on functional ability categories that had smaller estimates of statistically significant risks but larger populations (i.e., vision). As described above, we suggested that a relative risk ratio of 2 or greater would identify a subgroup with sufficiently greater risk such that modification of the program might be useful in that area. However, it may also be useful to direct some attention toward the largest subgroups even if their risk ratios are somewhat smaller. By slightly reducing the risk for a larger number of drivers, the benefit to public safety may be even greater than reducing a large risk for a small number of persons. Functional ability categories that potentially meet this description include diabetes and other metabolic conditions, visual acuity and psychiatric and emotional conditions.

Any modifications to the existing program should be carefully documented. Because of the nature of the medical condition program, changes would be implemented over time. Thus, careful documentation of the date of implementation on an individual level (i.e., the renewal date for the license holder when he/she is affected by the changes) is required in order to evaluate the effects of such changes. Accordingly, the effects of changes implemented on rates of events and estimates of risk should be measured to assure that they are of benefit to public safety.

Any changes to the medical conditions programs should be made cautiously and with consideration of acceptable levels of risk in the real world. Clearly, society at large is willing to accept some risk while using the public roads. Obviously, part of this risk is tolerating some drivers who are less safe than the norm. Teenage males are an obvious example; the general awareness that this age group is more likely to have adverse driving events does not prevent them from being issued driver's licenses. Although medical conditions drivers may have higher rates of some such adverse events, the increased risk posed thereby may be acceptable to society. Some consideration of acceptable levels of risk may be advisable.

Finally, this analysis should not be construed to mean that the medical conditions program is faulty or seriously flawed. Indeed, the results shown here could be as easily interpreted to mean that the program is working well. Adverse driving events in most subgroups of program drivers would seem to be under reasonable control. Wholesale changes to the program cannot be recommended based on data analyzed here. 


\section{References}

1. Retchin SM, Anapolle J. An overview of the older driver. Clin Geriatr Med 1993;9:27996.

2. Waller JA. Chronic medical conditions and traffic safety: review of the California experience. $N$ Engl J Med 1965;273:1413-20.

3. Traffic safety plan for older persons. Washington, D.C.: Office of Budget and Policy Development, National Highway Traffic Safety Administration, U.S. Department of Transportation; 1993.

4. Johnson S, Walker J. Benefits of Safety Belts and Motorcycle Helmets. Washington, DC: U.S. Department of Transportation National Highway Traffic Safety Administration; 1996.

5. Eberhard J. personal communication. In:; 1999.

6. Jaro MA. Probabilistic linkage of large public health data files . Stat Med 1995;14:491-8.

7. Johnson S, Utter D. So you want to link your state data. Washington, D.C.: National Association of Governors Highway Safety Representatives; 1996.

8. Eberhard J. Safe mobility for senior citizens. IATSS Research 1996;20:29-37.

9. Hans M. When should older drivers give up the keys? Trajfic Safety 1996:12-5.

10. Kahn H, Sempos C. Statistical methods in epidemiology. In: MacMahon B, editor. Monographs in Epidemiology and Biostatistics. New York: Oxford University Press; 1989.

11. Janke M. Reportable medical conditions and driver risk. Alchohol, Drugs and Driving 1993;9:167-83.

12. Davis TG, Wehling EH, Carpenter RL. Oklahoma's medically restricted drivers. A study of selected medical conditions. J Okla State Med Assoc 1973;66:322-7.

13. Salzberg P, Moffat J. Special exam program: an evaluation. Olympia, WA: Washington State Department of Licensing; 1998.

14. Hu P, Trumble D, Lu A. Driving decisions and vehicle crashes among older drivers. Oak Ridge, TN: Oak Ridge National Laboratory; 1995.

15. Rehm CG, Ross SE. Elderly drivers involved in road crashes: a profile. Am Surg $1995 ; 61: 435-7$.

16. Medgyesi M, Koch D. Medical impairments to driving: cardiovascular disease. In: 39th Annual Association for the Advancement of Automotive Medicine; 1995; Chicago, IL; 1995.

17. Zhu B-P, Bangeter K. 1996 Utah Health Status Survey. Chronic medical conditions. Salt Lake City, UT: Utah Department of Health; 1996. 
Appendix A. State of Utah Functional Ability in Driving: Guidelines and Standards for Health Care Professionals 


\title{
State of Utah Department of Public Safety Driver License Division
}

\author{
FUNCTIONAL ABILITY \\ IN DRIVING: \\ GUIDELINES AND \\ STANDARDS FOR \\ HEALTH CARE PROFESSIONALS
}

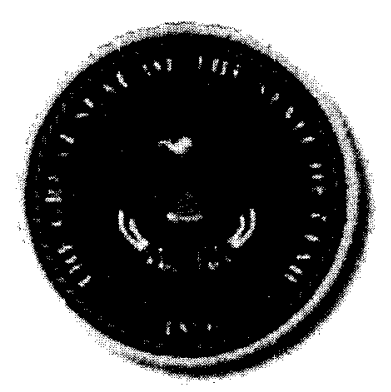

Utah State Driver License

Medical Advisory Board

1992 Edition 


\section{TABLE OF CONTENTS}

Introduction

Index

Application of DOT Medical Standards

General Profile Levels \& Restrictions

Medical Categories

A - DIABETES MELLITUS AND OTHER METABOLIC CONDITIONS PROFILE LEVEL CHART

B - CARDIOVASCULAR

PROFILE LEVEL CHART

C - PULMONARY

PROFILE LEVEL CHART

D - NEUROLOGIC

PROFILE LEVEL CHART

E - EPILEPSY AND OTHER EPISODIC CONDITIONS

PROFILE LEVEL CHART

F - LEARNING, MEMORY AND COMMUNICATIONS

PROFILE LEVEL CHART

G -PSYCHIATRIC OR EMOTIONAL CONDITIONS

PROFILE LEVEL CHART

H - ALCOHOL AND OTHER DRUGS

PROVILE LEVEL CHART

I - VISUAL ACUITY

PROFILE LEVEL CHART

$J$-MUSCULOSKELETAL ABNORMALITYICHRONIC MEDICAL DEBILITY PROFILE LEVEL CHART

K - FUNCTIONAL MOTOR ABILITY

PROFILE LEVEL CHART

L - HEARING

PROFILE LEVEL CHART

\section{APPENDICES}

I - Principles Used in Guidelines and Standards

II - Utah Medical Code, Operators' License Act

III - Diabetes Mellitus - Commercial Drivers

IV - Side Affects - Common Blood Pressure Medications

$V$ - Suggested Reading

VI - Driver License Medical Advisory Board Members 


\title{
Forward from Director Dave Beach
}

\author{
STATE OF UTAH
}

FUNCTIONAL ABILITY IN DRIVING:

\section{GUIDELINES AND STANDARDS FOR HEALTH CARE PROFESSIONALS}

\author{
Last update 05/22/00
}

Utah residents are individually responsible for their health when driving. All applicants for licenses will complete a health questionnaire to show their functional ability to drive. If there is a significant health problem, they will take their questionnaire, medical and/or vision forms to a health care professional, who will confirm the category as accurate or change it to be consistent with the true medical situation. The health care professional will be expected to discuss the applicant's health as it relates to driving and to make special recommendations in unusual circumstances. Based upon a completed functional ability evaluation, the Director of the Driver License Division may issue a license with or without limitations as outlined in these Guidelines and Standards approved by the Utah Driver License Medical Advisory Board. Health care professionals can increase highway safety by carefully applying these guidelines and standards and counseling with their patients' about driving.

\section{Drivers' Responsibilities}

The 1988 Utah State Legislature reaffirmed these responsibilities* related to physical, mental or emotional impairments of drivers:

1. Utah drivers are responsible to refrain from driving if there is uncertainty because of "a physical, mental or emotional impairment which may affect driving safety."

2. Utah drivers in such a situation are expected to seek competent medical evaluation and advice about the significance of the impairment as it relates to driving safety.

3. Utah drivers are responsible for reporting "a physical, mental or emotional impairment which may affect driving safety" to the Department of Public Safety through its Driver License Division or its agents in its various offices.

\section{Health Care Professionals' Responsibilities}

The same legislation applies to Utah health care professionals in these ways:"

1. Health care professionals may be requested by their patients to make reports to the Driver License Division about impairments which may affect driving safety, but the final responsibility for issuing a driver license lies with the Director of the Driver License Division.

2. In addition to making accurate reports when authorized by their patients, health care professionals are expected to counsel their patients about how their condition affects safe driving. For example, if patients are put on medication which may cause changes in alertness or coordination, their health care professional should advise them not to drive at least until a dosage is established which will not affect safe driving. Or, if visual acuity drops they should similarly be advised, at least until corrective action has been taken to improve their vision. The following quotation from the 1988 law recognizes this important function:

"Physicians who care for patients with physical, mental or emotional impairments which may affect their driving safety, whether defined by published guidelines and standards or not, are responsible for making 
available to their patients, without reservation, their recommendations and appropriate information related to driving safety and responsibilities." The guidelines and standards which follow will be a useful reference in such counseling.

\section{Immunity in Reporting Potential Risks}

The Legislature eliminated a major obstacle for health care professionals with its provision that "A health care professional or other person who becomes aware of a physical, mental, or emotional impairment that appears to present an imminent threat to driving safety and reports this information to the division in good faith has immunity from any damages claimed as a result of making the report"*

*Utah Code Annotated 1953: 53-3-303 (12) and 53-3-303 (14)(c).

\section{Utah Driver License Medical Advisory Board}

A Driver License Medical Advisory Board was created to advise the Director of the Driver License Division and to recommend written guidelines and standards for determining the physical, mental and emotional capabilities appropriate to various types of driving. Members of the Board have been appointed by the State Health Director to represent a variety of special areas.

If patients are uncertain about interpretations of these guidelines and standards or have special circumstances they may request a review by a panel of Board members. All of the actions of the Director and Board are subject to judicial review. The Board operates under bylaws approved by the Commissioner of Public Safety.

The Advisory Board has developed the following functional ability profile guidelines and standards in an effort to minimize the conflict between the individual's desire to drive and the community's desire for safety. Through education, medical assistance and cooperative efforts, an ideal balance may be reached. Principles followed by the Advisory Board in developing the guidelines and standards are shown in Appendix I.

\section{Functional Ability Profile Categories}

Functional ability to operate a vehicle safely may be affected by a wide range of physical, mental or emotional impairments. To simplify reporting and to make possible a comparison of relative risks and limitations, the Medical Advisory Board has adopted physical, emotional and behavioral functional ability profiles including 12 categories, with multiple levels under each category listed below. Vehicle operation history should be included as a significant part of a complete medical history.

\section{CATEGORY A DIABETES AND OTHER METABOLIC CONDITIONS \\ CATEGORY B CARDIOVASCULAR \\ CATEGORY C PULMONARY \\ CATEGORY D NEUROLOGIC \\ CATEGORY E EPILEPSY AND OTHER EPISODIC CONDITIONS \\ CATEGORY F LEARNING, MEMORY AND COMMUNICATION \\ CATEGORY G PSYCHIATRIC OR EMOTIONAL CONDITIONS \\ CATEGORY H ALCOHOL AND OTHER DRUGS \\ CATEGORY I VISUAL ACUITY \\ CATEGORY J MUSCULOSKELETAL ABNORMALITY OR CHRONIC MEDICAL DEBILITY \\ CATEGORY K FUNCTIONAL MOTOR IMPAIRMENT \\ CATEGORY L HEARING}

\section{Use of the Functional Ability Profile:}

When requested by the staff of the Driver License Division, applicants must report information regarding their physical, mental and emotional health. This may be in the form of a short screening questionnaire or 
a more extensive profiling outline. On completion of this and other requirements, a license may be issued immediately or the applicant may be requested to take the profile record to his or her own health care professional for confirmation of the profile or change as the health care professional believes is indicated.

These guidelines and standards contain twelve sections, one for each functional ability category. Each begins with a short narrative summary of basic concepts, definitions and working ground rules. Each summary is followed by a chart showing: (1) twelve profile levels based upon history, laboratory findings or other information; (2) profile levels which must be confirmed (or modified) by a health care professional; (3) intervals between health care professional confirmation of the profile; (4) license class and restrictions will generally be used by personnel of the Driver License Division to issue licenses consistent with the functional ability profile.

In almost all cases, a health care professional caring for a patient will have adequate information to confirm or modify the profile. However, if there is a significant problem affecting driving which is outside their area of capability, ordinary medical practices should apply. For example, a condition requiring a specialized diagnosis or opinion would suggest a referral to an appropriate specialist before completing the profile. On the other hand, a specialist who has seen a patient only for a limited or technical service may: (1) decline to complete the full profile (especially if there are multiple problems); (2) suggest patients see their personal health care professional; and (3) provide pertinent information to help in completion of the profile. In some circumstances where the limited condition is the only one affecting driving, a health care professional may confirm the profile based upon history without extensive examinations or tests if they are satisfied with the patient's reliability.

Where non-commercial driver applicants' self-reported profiles contain no indication of a significant impairment other than in the Visual Category, they may be sent for an eye examination without confirmation of the rest of the profile.

Reports should be based upon reasonably current information. In case of doubt, medical common sense should prevail.

Since no special tests are required by the guidelines and standards beyond those needed by a health care professional for adequate diagnosis or treatment, no additional expense should result except in unusual circumstances or in cases where individuals may wish to submit additional information, such as a review by a recognized specialist in specific medical conditions, in preparation for review by a medical panel.

Reports of profiles must be signed by a health care professional licensed to practice, although they may rely upon portions of examinations done under their supervision. The Certificate of Visual Examination may be reported by licensed optometrists as well.

\section{Relation of Functional Ability Profiles to Driving Risk/Responsibilities}

The table on Page 6 shows, in general, the relationship between functional ability profile levels and the type of risk and responsibility involved in driving. The relationships to profile levels are based upon available data and input from public hearings as interpreted by the Medical Advisory Board.

Operators of commercial vehicles come under different licensing requirements. As far as possible, these have been incorporated into appropriate profiles. All Utah school bus operators and operators of most commercial motor vehicles must meet Federal Department of Transportation Medical Standards. In 1992, the division will be pilot testing the use of these guidelines and standards and report forms as a substitute for federal forms. The Federal Medical Standards have been interpolated without change into these revised guidelines and standards for this purpose.

Setting limitations on driving for persons with impairments of functional ability works to increase public safety and at the same time to permit individuals a maximum degree of freedom of movement in two ways. First, in cases of decreased vision or motor control, avoiding high speeds will reduce the number, 
as well as the seriousness, of accidents. Second, in situations of some increase in the chance of an accident occurring, cutting down on the extent of exposure on the highway by limiting driving areas or times of day will reduce the total number of accidents and yet allow a person perhaps enough mobility to maintain a job with a single round trip each working day. These factors are difficult to define and measure but an effort has been made to accumulate and develop accurate data in order to refine limitations in the interest of safety.

In some cases, functional ability profiles indicating driving impairment in more than one category may be the basis for a more limited license than if there is only one impairment, but generally any limitation will relate to the single profile showing most impairment. As these functional ability profiles are used in determining driver licenses, data will be gathered as to the driving safety record of various groups as a basis for revision of the levels. Data secured from other sources will also be used.

Denial of driving privileges based upon medical reasons does not constitute a "disability" as defined by the Americans With Disabilities Act.

\section{Changes in Functional Ability}

After a driver is licensed, they need not report short term illnesses or abnormalities lasting less than three months to the Driver License Division, provided they refrain from all driving until recovery to the previous level of function for which they were licensed. When a condition persists beyond three months or it becomes apparent that it will persist, it should be reported to the Driver License Division. The license may be revalidated as soon as the condition has become stable at a level appropriate for driving.

\section{Suggestions and Questions}

Health care professionals who use these guidelines and standards are invited to direct questions or suggestions to the Driver License Division or to any of the current members of the Medical Advisory Board.

\section{Aspects of Licensing and Medical Certification of Commercial Drivers}

For the foreseeable future, these guidelines and standards will apply to the licensing of drivers of commercial vehicles, both for interstate and intrastate driving.

The Utah State Driver License Medical Advisory Board has reviewed the Federal Department of Transportation requirements for commercial drivers and worked out an appropriate profile level for each category. The examining health care professional will need only mark the profile in the usual fashion. In general, a profile of 1, 2, 3 and 4 , depending on the category, will qualify the applicant for a commercial license.

Because of the greater responsibilities involved, this program will differ from the usual licensing procedures for private vehicle drivers in four ways:

(1).A copy of the Abbreviated Health Profile should be retained by the examining health care professional. The remaining two copies should be given to the driver. One of these must be submitted to the Driver License Division. Drivers may retain the final copy for their use.

(2) For a commercial license or medical certificate, a check on hearing is required (though not for a private vehicle). Thus, an additional profile Category $L$ has been added. For a commercial license, an ability to perceive a forced whisper at five feet in the better ear, with or without use of a hearing aid, is satisfactory. Loss of between $40-65$ decibels in the better ear may qualify for an intrastate commercial license. Loss of more than an average of 65 decibels in the better ear is disqualifying (ANS 224.5-1951).

(3) Recognition of red, green and amber used in traffic lights may be tested with simple color cards, rather than more complex test devices. 
(4) Rather than simply marking the profile for a single category in question, assuming the others to be satisfactory, for commercial licensing the health care professional will be expected to check off all categories after they have satisfied themselves by history or examination of the proper level. In appropriate cases, a report from an ophthalmologist, optometrist, other health care professional, or an audiogram may be attached.

Some experienced drivers have been "grandfathered" with slightly less rigid standards, but future drivers may not be.

Some profile levels recommend "intrastate" commercial driving restrictions. Whether such restricted driving privileges may actually be issued is subject to federal and state approval.

Health care professionals may use their own routine forms for recording their examination on which the profile is based. The Licensing Profile Worksheet may be used for their records or disregarded at the health care professional's discretion.

In these guidelines and standards, notes have been placed at the end of the narrative for each profile category to assist in understanding the basis for reporting for commercial drivers. As before, the administrative responsibility for granting licenses rests with the State Driver License Division based upon medical information provided. This relieves the health care professional from vulnerability in having to certify the driver as "qualified to drive" under a complex set of regulations.

It is believed that these relatively minor modifications of our previous Functional Ability In Driving: Guidelines For Physicians which have been in use for over eleven years will be simpler than establishing a whole new system to handle licensing of both intrastate and interstate commercial vehicle drivers.

\section{Application of DOT Medical Standards}

The 1992 Functional Ability in Driving: Guidelines and Standards for Health Care Professionals has incorporated the DOT Medical Standards as applying to ALL commercial driving, irrespective of the type of vehicle or cargo involved, i.e., Class A, B, C, and D of Utah's Classified License System.

(1) Federal Standards are applicable to all commercial drivers, both interstate and intrastate who are subject to standards contained in Part 391 of the Federal Motor Carrier Safety Regulations.

(2) Use of profiles will provide the only meaningful method of gathering data on health aspects of safety of commercial drivers.

(3) Hence, for the "Utah Medical Pilot Project", present DOT Standards have been integrated into the new Guidelines and Standards, similar to the first edition, when the state issued intrastate chauffeurs' (commercial) licenses. Commercial drivers must be profiled in all twelve categories in order to meet federal standards for examination.

(4) Since present DOT Medical Standards leave a great deal to the discretion of the individual examining health care professional, they have been interpreted by the Board to show the proper profiles appropriate for a commercial license.

(5) Since DOT Standards allow only "one medical standard" to drive all commercial vehicles, no differentiation has been attempted, although use of profile methodology will facilitate a more meaningful equating of profiles with the degree of risk or responsibility for various vehicles, passengers or cargoes. For example, at a future date, it may not be necessary to hold a taxi driver to the same standards as one who drives an interstate bus or multi-axle truck.

(6) Since DOT Standards allow for waivers for absence or impairment of extremities, this feature has been retained by using the members of the Driver License Medical Advisory Board as the approval 
mechanism, if it is recommended by the examining health care professional and the applicant passes driving skills tests administered by specially trained Driver License Examiners.

(7) There appears to be no medical reason to carry a separate medical examiner's certificate, if a license has been issued based on medical information.

(8) U.S. DOT Regulations permit drivers who were driving in Exempt Intracity Zones during the one year preceding November 18,1988 , to continue such driving as long as the drivers medical condition(s) has not "substantially worsened" since November 18,1988 . Such drivers, even though their medical condition may not have met DOT Standards, are required to have a Medical Certificate issued only for twelve months or less if the examining health care professional so determines. These drivers must furnish the health care professional, the medical data first used by a health care professional to determine the driver could operate in an Exempt Intracity Zone. The current examining health care professional should mark the box at the top right of the Functional Ability Evaluation/Medical Certificate Report indicating "Exempt Intracity Zone" when applicable. Under the Medical Pilot Program some of these drivers may now qualify for intrastate only restrictions for commercial driving, thus broadening their opportunities. This decision is dependent upon the profile level indicated by the examining health care professional. 
INDEX

\begin{tabular}{|c|c|c|c|}
\hline 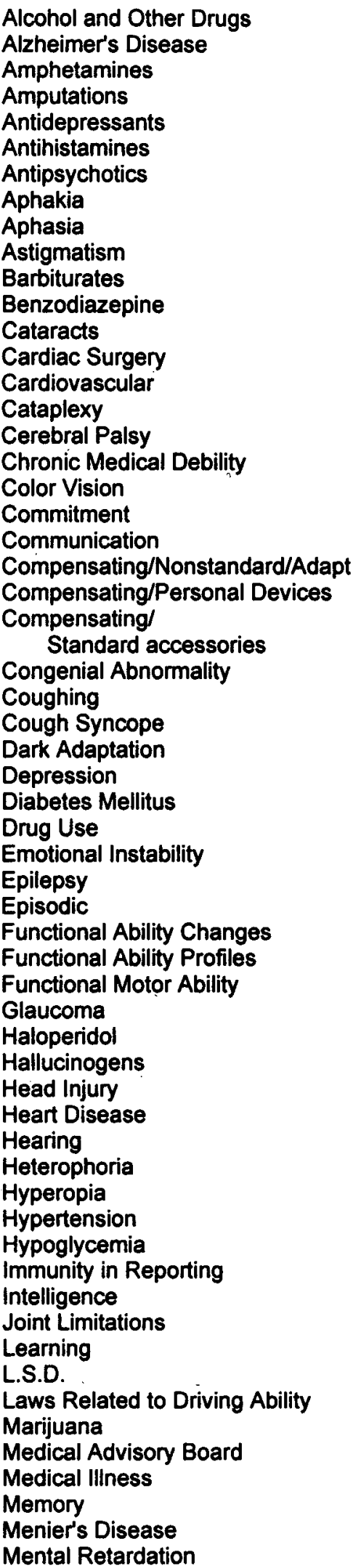 & 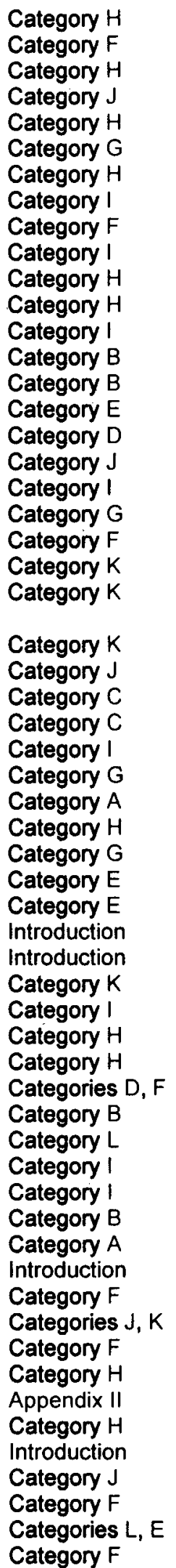 & $\begin{array}{l}\text { Monocular Vision } \\
\text { Mood Altering Drugs } \\
\text { Multiple Sclerosis } \\
\text { Musculoskeletal Abnormality } \\
\text { Myocardial Infarction } \\
\text { Myopia } \\
\text { Narcolepsy } \\
\text { Neurologic } \\
\text { Nystagmus } \\
\text { Osteoporosis } \\
\text { Pain } \\
\text { Panel, Medical Advisory Board } \\
\text { Parathyroid } \\
\text { Parkinson's Disease } \\
\text { Phenothiazines } \\
\text { Presbyopia } \\
\text { Psychiatric } \\
\text { Ptosis } \\
\text { Pulmonary } \\
\text { Responsibilities, Drivers' } \\
\text { Responsibilities, Health Care } \\
\text { Rhythm, Cardiac } \\
\text { Retardation } \\
\text { Schizophrenia } \\
\text { Seizures } \\
\text { Sleep Apnea } \\
\text { Sleeping Pills } \\
\text { Stereopsis } \\
\text { Strokes } \\
\text { Syncope } \\
\text { Telescopic Lenses } \\
\text { Thyroid } \\
\text { Vascular } \\
\text { Visual Acuity } \\
\text { Visual Fields }\end{array}$ & $\begin{array}{l}\text { Category A } \\
\text { Category H } \\
\text { Category I } \\
\text { Category H } \\
\text { Category D } \\
\text { Category J } \\
\text { Category B } \\
\text { Category I } \\
\text { Category E } \\
\text { Category D } \\
\text { Category I } \\
\text { Category J } \\
\text { Category J } \\
\text { Appendix VI } \\
\text { Category A } \\
\text { Category D } \\
\text { Category H } \\
\text { Category I } \\
\text { Category G } \\
\text { Category I } \\
\text { Category C } \\
\text { Introduction } \\
\text { Introduction } \\
\text { Category B } \\
\text { Category F } \\
\text { Category G } \\
\text { Category E } \\
\text { Category C } \\
\text { Category H } \\
\text { Category I } \\
\text { Category D } \\
\text { Category E } \\
\text { Category I } \\
\text { Category A } \\
\text { Category B } \\
\text { Category I } \\
\text { Category I }\end{array}$ \\
\hline
\end{tabular}




\title{
CATEGORY A: DIABETES MELLITUS AND OTHER METABOLIC CONDITIONS
}

\author{
Revised 11-18-98
}

1. Disturbances in function of the endocrine glands cause many symptoms from generalized asthenia, muscle weakness, and spasm or tetany to sudden episodes of dizziness or unconsciousness. Individuals so afflicted should not drive a motor vehicle until these symptoms have been controlled by appropriate therapy.

2. Problems associated with metabolic diseases such as muscular weakness, muscular pain, visual disturbances, dizziness, intractable headaches, and/or fatigue propensity should also be shown under other appropriate profile categories.

3. Since persons with metabolic disorders may be affected in very different ways, the health care professional should counsel with the patient about any special precautions, limitations or recommendations appropriate to their case. These should be reported by the health care professional.

4. DIABETES MELLITUS: In the past, diabetics have been involved in almost twice as many motor vehicle accidents as the medically normal driving population. Careful evaluation and medical management can increase their safety. Even diabetics whose disease is well controlled with insulin or oral hypoglycemic drugs may occasionally suffer a hypoglycemic episode. It is important that the health care professional ascertain the cause of these occasional episodes and change management of the patient. Before deciding the patient's condition is again stable enough for them to drive a motor vehicle, the health care professional should observe the patient under the new program to be sure that it is effective.

5. Certain insulin requiring individuals with diabetes are much more likely than average to have altered consciousness from hypoglycemic episodes. These individuals have "hypoglycemic unawareness"...that is, a lack of the adrenergic warning signs of nervousness and sweating which should alert the person to eat sugar and reverse the insulin reaction.

6. A typical profile of such individuals includes previous episodes of hypoglycemia induced unconsciousness, long duration diabetes and possibly autonomic neuropathy or beta blocker therapy. The health care professional should take these factors into account when profiling. Also, many episodes of altered consciousness (requiring the assistance of another person to reverse) are treated outside of health care facilities and may not come to the health care professional's attention. Inquiry into such events should be made.

7. It is strongly recommended that health care professionals counsel all insulin or oral antidiabetic medication requiring individuals to store in their vehicles, at all times, a source of rapidly absorbed carbohydrate. Further, blood glucose monitoring just prior to driving should be urged for any diabetic driver with a history of limited awareness of hypoglycemia.

8. Visual acuity decreases with marked increase in blood glucose concentrations, due to osmotic swelling of the lens. The patient should not drive until the blood glucose level is brought under control. Diabetic retinopathy may affect visual acuity and should be checked by the primary care health care professional, ophthalmologist or optometrist and be reported under appropriate profile categories.

9. PARATHYROID DISORDERS: Hyperparathyroidism with muscular weakness and hypotonia is a contraindication to driving any motor vehicle, unless symptoms are mild or well controlled by therapy. Individuals suffering from acute hypoparathyroidism with increased neuromuscular excitability, cramps, spasm, and generalized tetany should not drive unless symptoms are mild.

10. THYROID DISORDERS: Hyperthyroidism or hypothyroidism may be accompanied by severe psychic disturbance, lethargy, muscular weakness, extreme restlessness, and/or tremors, which would preclude any driving. Depending upon the degree of impairment, operation of a private vehicle may be permissible. No medical follow-up is necessary for a thyroid only. 
11. HYPOGLYCEMIA: Individuals suffering from recurring spontaneous attacks of hypoglycemia causing faintness or unconsciousness should be carefully evaluated as to cause before being given a profile comparable to those under diabetes.

12. COMMERCIAL DRIVERS: Health care professional should refer to Appendix III in this manual for information regarding special qualifications for Commercial Driver 


\section{CATEGORY A: DIABETES MELLITUS AND OTHER METABOLIC CONDITIONS}

\begin{tabular}{|c|c|c|c|c|c|}
\hline $\begin{array}{l}\text { Profile } \\
\text { Level }\end{array}$ & Diabetes Mellitus & $\begin{array}{l}\text { Thyroid, Parathyroid, Pituitary and Other } \\
\text { Metabolic Conditions }\end{array}$ & $\begin{array}{l}\text { Med } \\
\text { Conf } \\
\text { Req }\end{array}$ & $\begin{array}{l}\text { Interval for } \\
\text { Review }\end{array}$ & License Class and Restrictions \\
\hline \multirow[t]{2}{*}{1} & \multirow{2}{*}{$\begin{array}{l}\text { No history of diabetes mellitus or elevated } \\
\text { blood sugar }\end{array}$} & \multirow[t]{2}{*}{ No history of metabolic condition } & Yes & 2 Years & Commercial Unlimited \\
\hline & & & No & N/A & Private Vehicles \\
\hline \multirow[t]{2}{*}{2} & \multirow{2}{*}{$\begin{array}{l}\text { History of elevated blood sugar. No positive } \\
\text { diagnosis of diabetes }\end{array}$} & \multirow{2}{*}{$\begin{array}{l}\text { Abnormal laboratory findings. No } \\
\text { diagnosis made. }\end{array}$} & \multirow[t]{2}{*}{ Yes } & 2 Years & Commercial Unlimited \\
\hline & & & & $\begin{array}{l}\text { Upon } \\
\text { Renewal }\end{array}$ & Private Vehicles \\
\hline \multirow[t]{2}{*}{3} & \multirow{2}{*}{$\begin{array}{l}\text { Any diabetes stable on diet; adult onset of } \\
\text { diabetes stable on oral agents }\end{array}$} & \multirow{2}{*}{$\begin{array}{l}\text { Stabilized under treatment or recovered } \\
\text { after surgery without symptoms for one } \\
\text { month }\end{array}$} & \multirow[t]{2}{*}{ Yes } & 1 Year a. & Commercial Unlimited \\
\hline & & & & 1 Year a. & Private Vehicles \\
\hline \multirow[t]{2}{*}{4} & \multirow[t]{2}{*}{$\begin{array}{l}\text { Stabilized diabetes with insulin with no } \\
\text { episodes of ketosis or altered consciousness } \\
\text { for } 1 \text { yr c. }\end{array}$} & \multirow[t]{2}{*}{$\begin{array}{l}\text { Stabilized under treatment with minimal } \\
\text { symptoms not affecting driving }\end{array}$} & \multirow[t]{2}{*}{ Yes } & 6 Months & $\begin{array}{l}\text { Commercial Intrastate (may be issued for } \\
\text { diabetes only if special qualifications listed in } \\
\text { Appendix III are met. Health care professional } \\
\text { approval required). }\end{array}$ \\
\hline & & & & 1 Year a. & Private Vehicles \\
\hline 5 & $\begin{array}{l}\text { Stabilized diabetes with no episodes of } \\
\text { ketosis or altered consciousness for } 6 \text { mths }\end{array}$ & \multirow{4}{*}{$\begin{array}{l}\text { Stabilized under treatment with minimal } \\
\text { or slight persisting or intermittent } \\
\text { symptoms. Profile recommendations } \\
\text { should be based on anticipated effect on } \\
\text { driving. }\end{array}$} & Yes & 1 Year a. & Private Vehicles \\
\hline 6 & $\begin{array}{l}\text { Stabilized diabetes with no episodes of } \\
\text { ketosis or altered consciousness for } 3 \text { mths }\end{array}$ & & Yes & 6 Months a. & Speed limitation \\
\hline 7 & \multirow{3}{*}{$\begin{array}{l}\text { Episodes of ketosis or altered consciousness } \\
\text { within } 3 \text { months. Profile recommendation } \\
\text { should be based on anticipated effect on } \\
\text { driving. b. }\end{array}$} & & Yes & 3 Months a. & Speed and area limitations \\
\hline 8 & & & Yes & 3 Months a. & Speed, area and time of day limits \\
\hline$\frac{9}{9}$ & & $\begin{array}{l}\text { Stabilized condition with unpredictable } \\
\text { temporary reoccurrence of more severe } \\
\text { symptoms. }\end{array}$ & Yes & 3 Months a. & $\begin{array}{l}\text { Any of above, as rec. by health care } \\
\text { professional if accompanied by licensed driver. }\end{array}$ \\
\hline 10 & $\begin{array}{l}\text { Special circumstances not listed above, } \\
\text { without episodes listed above }\end{array}$ & Special circumstances not covered above & Yes & $\begin{array}{l}\text { As } \\
\text { Recommende } \\
\text { d }\end{array}$ & $\begin{array}{l}\text { Special limitations not covered above } \\
\text { recommended by health care professional, } \\
\text { advise DLD }\end{array}$ \\
\hline 11 & Patient under evaluation & Patient under evaluation & Yes & $\begin{array}{l}\text { As } \\
\text { Recommende } \\
\text { d }\end{array}$ & $\begin{array}{l}\text { To be determined, health care professional } \\
\text { advise DLD }\end{array}$ \\
\hline 12 & $\begin{array}{l}\text { Severe unstable insulin dependent diabetes } \\
\text { or persisting ketosis }\end{array}$ & $\begin{array}{l}\text { Severe disorder not responsive to } \\
\text { treatment }\end{array}$ & & & No driving \\
\hline
\end{tabular}

a. Or as recommended by health care professional, longer or shorter according to stability.

b. Driving only with specific recommendation by health care professional.

c. If driver is a commercial applicant profiled at level 4 for diabetes, a written health care professional approval must accompany evaluation (see special qualifications in Appendix III) 


\section{CATEGORY B: CARDIOVASCULAR}

1. Cardiovascular disease may affect a driver's ability in a variety of ways. For this reason, profile guidelines and standards are șhown for four of the more common circumstances. Although an individual may have more than one abnormality, the one which causes the most limitation is the one under which they should be profiled for this category. It is essential that all aspects of their condition be evaluated in an appropriate profile.

2. GENERAL HEART DISEASE: This profile is made for any patient having had any diagnosis of heart disease. The levels are based on the functional classification of the American Heart Association.

Class I. Patients with heart disease but with no limitations of physical activity. Ordinary physical activity causes no undue dyspnea, anginal pain, fatigue or palpitation.

Class II. Patients with slight limitations of physical activity. They are comfortable at rest and with mild exertion. They experience symptoms only with the more strenuous grades of ordinary activity.

Class III. Patients with marked limitation of physical activity. They are comfortable at rest, but experience symptoms even with the milder forms of ordinary activity.

Class IV. Patients with inability to carry on any physical activity without discomfort. Symptoms of cardiac insufficiency or of the anginal syndrome may be present, even at rest, and are intensified by activity.

3. RHYTHM: Patients with rhythm disturbances should not be given profile levels 2 or 3 , except when the arrhythmia has been so remote and well controlled, or of such a minor nature, that the patient is expected to drive without presenting a risk to the public.

4. AFTER MYOCARDIAL INFARCTION OR CARDIAC SURGERY: No patient in these categories should drive until six weeks after the event or until the condition is stable, as determined by a health care professional. Because of the risk of infarction, recurrence or other cardiovascular events, such as arrhythmia, after infarction or surgery if the health care professional believes a patient has an unusually mild condition, a profile 3 may be given on his recommendation. A treadmill stress test should be repeated after six months.

5. HYPERTENSION: Apart from its complications, hypertension is largely an asymptomatic condition and in itself does not impair fitness to drive. Medications which may have a sedative side effect or cause unexpected orthostatic hypotension must be assessed by the health care professional as to their effect on the profile (see Appendix IV). Visual, neurological or cardiovascular complications should also be profiled under other categories. Usually, mild and stable hypertension may qualify for a profile 3 even if on medication upon recommendation of the examining health care professional.

6. Other less common cardiovascular conditions such as fistula, coarctation, cardiogenic syncope, severe peripheral arterial or venous vascular disease etc., should be profiled in a fashion comparable to those listed, based upon anticipated functional ability while driving.

7. COMMERCIAL DRIVERS: If initial blood pressure is 161-180 systolic and/or 91-104 diastolic, the commercial applicant can be medically certified for a period of three months. The driver is given this 3 month period to reduce their blood pressure to less than or equal to $160 / 90$. If the driver is subsequently found qualified with a blood pressure less than or equal to $160 / 90$, the certificate may be issued for a one year period but the continuing acceptable blood pressure of $160 / 90$ or less must be confirmed during the third month of this one year period. The individual requires annual certification thereafter.

If the initial blood pressure is $181 / 105$ or greater, the driver cannot be certified for commercial driving even temporarily, until their blood pressure has been reduced to less than 181/105. The examining health care professional may temporarily certify the individual once their blood pressure is below 181/105. The driver would then be given the three month period of time to reduce their blood pressure to below $160 / 90$ as stated above. If the driver is subsequently found qualified with a blood pressure less than or equal to $160 / 90$, they may be certified for a six month period. Documentation of continued control should be made every 6 months (biannually) thereafter.

Please refer to Profile Level Charts when completing Functional Ability Evaluation and Certificate of Visual Examination forms. 


\section{CATEGORY B: CARDIOVASCULAR}

\begin{tabular}{|c|c|c|c|c|c|c|c|}
\hline $\begin{array}{l}\text { Profile } \\
\text { level }\end{array}$ & General Heart Disease & Rhythm & After Myocardial Infarct or Surgery & Hypertension & $\begin{array}{l}\text { Med } \\
\text { Conf } \\
\text { Req }\end{array}$ & $\begin{array}{l}\text { Interval for } \\
\text { Review }\end{array}$ & $\begin{array}{l}\text { License Class and } \\
\text { Restrictions }\end{array}$ \\
\hline \multirow[t]{2}{*}{1} & \multirow[t]{2}{*}{ No history } & \multirow[t]{2}{*}{ No history } & \multirow[t]{2}{*}{ No history } & \multirow[t]{2}{*}{ No past or present hypertension } & Yes & 2 Years & $\begin{array}{l}\text { Commercial } \\
\text { Unlimited }\end{array}$ \\
\hline & & & & & No & N/A & Private Vehicles \\
\hline \multirow[t]{2}{*}{2} & \multirow[t]{2}{*}{ Past heart disease, fully recovered } & \multirow[t]{2}{*}{ Transient arrhythmia in childhood. } & \multirow[t]{2}{*}{ No history } & \multirow[t]{2}{*}{$\begin{array}{l}\text { Past hypertension now normal without } \\
\text { medication }\end{array}$} & Yes & 2 Years & $\begin{array}{l}\text { Commercial } \\
\text { Untimited }\end{array}$ \\
\hline & & & & & No & N/A & Private Vehicles \\
\hline 3 & $\begin{array}{l}\text { Heart disease AHA Class I, no limits. } \\
\text { No symptoms on ordinary activity }\end{array}$ & $\begin{array}{l}\text { Transient isolated anthythmia without } \\
\text { recurrence in past } 5 \text { yrs }\end{array}$ & Unusually mild condition b. & $\begin{array}{l}\text { Hypertension controlled on medication } \\
\text { c. }\end{array}$ & Yes & $\begin{array}{l}\text { Upon } \\
\text { Renewal }\end{array}$ & Private Vehicles \\
\hline \multirow[t]{2}{*}{4} & \multirow{2}{*}{$\begin{array}{l}\text { AHA Class I. No undue symptoms on } \\
\text { ordinary activity }\end{array}$} & \multirow{2}{*}{$\begin{array}{l}\text { Past arrhythmia, normal mythm. Stable with } \\
\text { pace-maker for } 6 \text { months }\end{array}$} & \multirow{2}{*}{$\begin{array}{l}1 \text { yr min. Symptoms only with } \\
\text { strenuous activity. a. }\end{array}$} & $\begin{array}{l}\text { Hypertension controlled on medication } \\
\text { c. }\end{array}$ & Yes & 1 Year a. & Private Vehicles \\
\hline & & & & Same but press.less than $161 / 91$ & Yes & 1 Year a. & $\begin{array}{l}\text { Commercial } \\
\text { Unlimited }\end{array}$ \\
\hline \multirow[t]{2}{*}{5} & \multirow[t]{2}{*}{$\begin{array}{l}\text { AHA Class II. Slight limit on activity. } \\
\text { Comfortable on mild exertion. d. }\end{array}$} & \multirow[t]{2}{*}{ Arthythmias controlled or stable for 3 months } & \multirow[t]{2}{*}{$\begin{array}{l}3 \text { months minimum, no symptoms } \\
\text { at rest a. }\end{array}$} & $\begin{array}{l}\text { Hypertension partially controlled by } \\
\text { medication. Diastolic less than } 120 \\
\text { mm.Hg. c. }\end{array}$ & Yes & 6 Mths a. & Private Vehicles \\
\hline & & & & Same but press.less than $181 / 105$ & Yes & 3 Mths f. & $\begin{array}{l}\text { Commercial } \\
\text { Unlimited }\end{array}$ \\
\hline 6 & $\begin{array}{l}\text { Class III, Itd activity with symptoms on } \\
\text { mild activity; anticipated aggravation } \\
\text { by unlimited driving }\end{array}$ & $\begin{array}{l}\text { Unstable thythm profile; supraventricular } \\
\text { tachycardia which is hemodynamically } \\
\text { unstable; recurring ventricular armythmias } \\
\text { proven by Holter monitor. Driving limitations } \\
\text { and health care professional's } \\
\text { recommendations should be based upon } \\
\text { anticipated degree of instability of inythm. e. }\end{array}$ & $\begin{array}{l}\text { Recovery timeframe and } \\
\text { restrictions to be determined by } \\
\text { health care professional and } \\
\text { appropriate profile level } \\
\text { determined. See narrative } \\
\text { paragraph } 4 \text {. }\end{array}$ & $\begin{array}{l}\text { Hypertension with diastolic persistently } \\
\text { above } 120 \mathrm{~mm} \text {. Hg. and/or systolic over } \\
200 \mathrm{~mm} . \mathrm{Hg} \text {. Functional profile to be } \\
\text { based upon anticipated effects on } \\
\text { driving with appropriate limitations on } \\
\text { speed, area, time of day, etc. c. }\end{array}$ & Yes & 3 Mins a. & $\begin{array}{l}\text { Private Vehicles } \\
\text { Speed limitations }\end{array}$ \\
\hline 7 & $\begin{array}{l}\text { Class III Itd activity with symptoms on } \\
\text { mild exertion slightly increased by } \\
\text { fatigue }\end{array}$ & & & & Yes & 3 Mths a. & $\begin{array}{l}\text { Private Vehicles } \\
\text { Speed \& area } \\
\text { limitations }\end{array}$ \\
\hline 8 & $\begin{array}{l}\text { Class III itd activity with symptoms on } \\
\text { mild exertion moder. increased by } \\
\text { fatigue }\end{array}$ & & & & Yes & 3 Mths a. & $\begin{array}{l}\text { Private Vehicles } \\
\text { Speed, area and } \\
\text { time of day } \\
\text { limitations }\end{array}$ \\
\hline 9 & $\begin{array}{l}\text { Class III Itd activity and unpredictable } \\
\text { fluctuation in symptoms on exertion. }\end{array}$ & & & & Yes & 3 Mths a. & $\begin{array}{l}\text { Accompanied by } \\
\text { licensed driver, with } \\
\text { limitations } \\
\text { recommended by } \\
\text { HCP g. }\end{array}$ \\
\hline 10 & \multicolumn{4}{|l|}{ Special circumstances not covered above. } & Yes & As rec. & $\begin{array}{l}\text { HCP rec., advise } \\
\text { DLD g. }\end{array}$ \\
\hline 11 & \multicolumn{4}{|l|}{ Patient under evaluation } & Yes & As rec. & $\begin{array}{l}\text { HCP rec., advise } \\
\text { DLD g. }\end{array}$ \\
\hline 12 & $\begin{array}{l}\text { Heart disease. AHA Class IV } \\
\text { limitations with any activity. Symptoms } \\
\text { at rest }\end{array}$ & $\begin{array}{l}\text { Arrhythmias with history of loss of } \\
\text { consciousness in past }\end{array}$ & Recovery not sufficient to drive & $\begin{array}{l}\text { Diastolic over } 120 \mathrm{mmHg} \text {. w/limiting } \\
\text { complication/side effects of } \\
\text { medications }\end{array}$ & & & No driving \\
\hline
\end{tabular}

a. Or as recommended by health care professional, longer or shorter according to stability. b. See narrative for consideration of unusually mild or stable cases. c. If medication does not interfere with alertness or coordination (See Appendix IV). d. Or Class III with long term stability. e. Levels 8 and 9: Type II second degree heart block or trivascular block. f. See narrative to establish expiration dates for medical certification. g. HCP = Health Care Professional

Appendix A. Guidelines and Standards

Page A15 


\section{CATEGORY C: PULMONARY \\ Last update 05/22/00}

1. Although impaired pulmonary function is seldom the cause of sudden death, it may seriously affect operators of vehicles in the following ways:

* Sudden severe coughing while driving may result in an accident

* Cough syncope may occur while driving

* Impaired cerebral oxygenation caused by impaired pulmonary function may result in mental confusion and/or impaired judgement.

2. For these and similar reasons, it is important to obtain an accurate picture of the pulmonary status of all applicants for driver licenses who have a history of problems or are observed to have respiratory difficulties at the time of examination.

3. In assessing the severity of pulmonary impairment, effort is made to limit the tests to those found in most medical offices, although occasionally more sophisticated studies may be needed (e.g. arterial blood gases, maximal voluntary ventilation, etc.).

4. The objective of classification according to pulmonary capacity, as in other functional categories, is to allow as much latitude as is consistent with the safe operation of a motor vehicle.

5. The basic function tests (FVC and FEV) are the principal guidelines and standards currently recommended. These are subjective/objective tests. When they are required, three graphs should be made and every effort should be made to elicit the full cooperation of the examinee. A bronchodilator may be used if the examiner feels it is safe and justifiable. The best reading, with or without bronchodilators, should be used.

6. In more severe cases of pulmonary impairment, measurement of arterial blood gases may be needed. If there is any question about the need for arterial gas measurements, the applicant usually would not qualify for profile levels 1 through 4 , but the blood gas determinations may support a higher functional level than might otherwise appear indicated. They may also help in defining profiles appropriate to limited private driving.

7. COMMERCIAL DRIVERS: A commercial driver meeting the requirements of profile level $1,2,3$ or 4 will qualify for a license or medical certificate except that in level 3 and 4 one year re-evaluations are required. If oxygen is required, even intermittently, the driver will be limited to a Class $C$ or $D$ license and may not carry hazardous material. If the driver is carrying passengers a NO SMOKING sign must be prominently displayed in their vehicle.

Please refer to Profile Level Charts when completing Functional Ability Evaluation and Certificate of Visual

forms 


\section{CATEGORY C: PULMONARY}

\begin{tabular}{|c|c|c|c|c|}
\hline $\begin{array}{l}\text { Profile } \\
\text { Level }\end{array}$ & Circumstances & Med Conf Req & $\begin{array}{l}\text { Interval } \\
\text { for } \\
\text { Review }\end{array}$ & $\begin{array}{l}\text { License Class and } \\
\text { Restrictions }\end{array}$ \\
\hline \multirow[t]{2}{*}{1} & \multirow{2}{*}{$\begin{array}{l}\text { No past history or current } \\
\text { pulmonary disease }\end{array}$} & Yes & 2 Years & Commercial Unlimited \\
\hline & & No & N/A & Private Vehicles \\
\hline \multirow[t]{2}{*}{2} & \multirow{2}{*}{$\begin{array}{l}\text { Past history, fully recovered. No } \\
\text { current medication use. }\end{array}$} & Yes & 2 Years & Commercial Unlimited \\
\hline & & No & N/A & Private Vehicles \\
\hline 3 & $\begin{array}{l}\text { Minimal pulmonary symptoms. } \\
\text { Sporadic use of medication (no } \\
\text { steroids), } \mathrm{FVC} \text { and } \mathrm{FEV}>70 \% \text { of } \\
\text { predicted normal. } \mathrm{PO}_{2} \text { within } \\
\text { normal range }\end{array}$ & Yes & 1 Year & $\begin{array}{l}\text { Commercial Unlimited Private } \\
\text { Vehicles }\end{array}$ \\
\hline 4 & $\begin{array}{l}\text { Pulmonary symptoms only with } \\
\text { greater than ordinary activity. May } \\
\text { be on steroids intermittently. FVC } \\
\text { and FEV }>50 \% \text { of predicted } \\
\text { normal. } \\
\end{array}$ & Yes & 1 Year & $\begin{array}{l}\text { Commercial Intrastate } \\
\text { Private Vehicles }\end{array}$ \\
\hline 5 & $\begin{array}{l}\text { Stable pulmonary disease on or } \\
\text { off treatment, including } \\
\text { intermittent } \mathrm{O}_{2} \text { or steroids, with } \\
\text { dyspnea only on exertion. No } \\
\text { cough syncope for } 6 \text { months. }\end{array}$ & Yes & 1 Year a. & $\begin{array}{l}\text { Commercial Intrastate Light } \\
\text { Vehicles HAZMAT appeal to } \\
\text { Medical Advisory Board } \\
\text { Private Vehicles }\end{array}$ \\
\hline 6 & Not Used & & & \\
\hline 7 & $\begin{array}{l}\mathrm{PO}_{2} \text { over } 50 \text {. Moderate dyspnea } \\
\text { or other symptoms with ordinary } \\
\text { activity. No cough syncope within } \\
3 \text { months. b. }\end{array}$ & Yes & 6 Mos a. & Speed and area limitations \\
\hline 8 & Not Used & & & \\
\hline 9 & $\begin{array}{l}\text { Unpredictable more severe } \\
\text { temporary dyspnea or other } \\
\text { symptoms. Cough syncope within } \\
3 \text { months. }\end{array}$ & Yes & 6 Mos a. & $\begin{array}{l}\text { Accompanied by licensed } \\
\text { driver, with speed, area } \\
\text { and/or time of day limitations } \\
\text { recommended by health care } \\
\text { professional }\end{array}$ \\
\hline 10 & $\begin{array}{l}\text { Special circumstances not } \\
\text { covered above }\end{array}$ & Yes & $\begin{array}{l}\text { As } \\
\text { recom. }\end{array}$ & $\begin{array}{l}\text { Special limitations not } \\
\text { covered above } \\
\text { recommended by health care } \\
\text { professional, advise DLD }\end{array}$ \\
\hline 11 & $\begin{array}{l}\text { Pulmonary symptoms or signs } \\
\text { under evaluation }\end{array}$ & Yes & $\begin{array}{l}\text { As } \\
\text { recom. }\end{array}$ & $\begin{array}{l}\text { To be determined, health } \\
\text { care professional advise DLD }\end{array}$ \\
\hline 12 & $\begin{array}{l}\text { Severe dyspnea with any activity } \\
\text { and/or cyanosis and/or } \mathrm{PCO}_{2}>50 \\
\text { or } \mathrm{PO}_{2}<50 \text {. Cough syncope } \\
\text { and/or untreated sleep apnea. }\end{array}$ & & & No driving \\
\hline
\end{tabular}

- Or as recommended by health care professional, longer or shorter according to stability.

- If supplemental oxygen is required to maintain $\mathrm{PO}_{2}$ over 50 , constant use of oxygen is required while driving. 


\section{CATEGORY D: NEUROLOGIC}

1. A wide variety of neurological conditions may affect driving safety. A partial list includes: strokes, head injuries, Cerebral Palsy, Multiple Sclerosis, Parkinson's disease, progressive conditions such as muscular atrophies and dystrophies, myasthenia gravis and other spinal cord and brain diseases. Epilepsy is considered as a separate category.

2. The common element in all of these is the disturbance of sensory, motor or coordinating functions sufficient to affect driving. Some of them will be considered as stable conditions for which a driving test showing adequate performance in the type of vehicle to be driven will be sufficient. However, other conditions that have not yet stabilized or have a probability of progression or need for medication may require a medical report initially or at intervals. The usual interval for reconfirmation is as shown or may be increased up to the time interval since the last significant change in status. No medical confirmation will be needed after the condition has been stable for three years if the health care professional so recommends.

3. In general, those impairments shown in the AMA Guide to Evaluation of Permanent Impairment for 5 to $15 \%$ impairment relate-to profile levels 4 and 5 , for $20-45 \%$ impairment to profiles 6 through 10 calling for limitations on driving and for over $45 \%$ to profile 12 for no driving, unless skill with compensating devices is demonstrated, in which case an appropriate suffix will follow the profile number.

4. Persons with neurological disorders with motor impairment will also be given a profile as appropriate under Category $\mathrm{K}$, (Functional Motor Impairment) in relation to driving, regardless of whether function is restored by use of compensatory devices. The health care professional should indicate by checking the appropriate box on the Functional Ability Evaluation form if a driving skills test should be given.

5. In some neurological disorders, there may be other problems which impair driving. For example, a head injury may not only result in paralysis, but in visual field loss and impairment of learning and memory. These should be shown as profiles in the other appropriate categories as well. In evaluating late effects of head injuries, careful inquiry into the duration of coma or amnesia will be found helpful in evaluating the likelihood of persisting effects which may impair reaction time and thus be important in considering limitations on driving speeds. Similar considerations may apply in the use of a variety of medications which affect neuro-motor functions.

6. COMMERCIAL DRIVERS: Drivers given a profile 5 may or may not be successful in passing a road test, but should have an opportunity to do so if their conditions are stable. The health care professional should check the driving skills test box at the bottom of the form.

Please refer to Profile Level Charts when completing Functional Ability Evaluation and Certificate of Visual 


\section{CATEGORY D: NEUROLOGIC}

\begin{tabular}{|c|c|c|c|c|}
\hline $\begin{array}{l}\text { Profile } \\
\text { Level }\end{array}$ & Circumstances & $\begin{array}{l}\text { Med } \\
\text { Conf } \\
\text { Req }\end{array}$ & $\begin{array}{l}\text { Interval } \\
\text { for } \\
\text { Review }\end{array}$ & $\begin{array}{l}\text { License Class and } \\
\text { Restrictions }\end{array}$ \\
\hline \multirow[t]{2}{*}{1} & \multirow{2}{*}{$\begin{array}{l}\text { No history of strength, sensory or } \\
\text { coordination impairment }\end{array}$} & Yes & 2 Years & Commercial Unlimited \\
\hline & & No & N/A & Private Vehicles \\
\hline \multirow[t]{2}{*}{2} & \multirow{2}{*}{$\begin{array}{l}\text { History of strength, sensory or } \\
\text { coordination impairment with full } \\
\text { functional recovery }\end{array}$} & Yes & 2 Years & Commercial Unlimited \\
\hline & & No & N/A & Private Vehicles \\
\hline 3 & $\begin{array}{l}\text { Impairment but able to control } \\
\text { equipment, walk, lift and carry }\end{array}$ & Yes & 1 Year $a$. & $\begin{array}{l}\text { Commercial Unlimited Private } \\
\text { Vehicles }\end{array}$ \\
\hline 4 & $\begin{array}{l}\text { Minimal neurologic impairment but able } \\
\text { to control equipment in conventional } \\
\text { manner }\end{array}$ & Yes & 1 Year a. & $\begin{array}{l}\text { Commercial Unlimited Private } \\
\text { Vehicles }\end{array}$ \\
\hline 5 & $\begin{array}{l}\text { Slight neurologic impairment but able to } \\
\text { control equipment }\end{array}$ & Yes & 1 Year a. & $\begin{array}{l}\text { Commercial Intrastate--Must } \\
\text { Pass Road TestPrivate } \\
\text { Vehicles }\end{array}$ \\
\hline 6 & $\begin{array}{l}\text { Moderate impairment of dexterity } \\
\text { affecting safe driving speeds }\end{array}$ & Yes & 1 Year a. & Speed limitation \\
\hline 7 & $\begin{array}{l}\text { Moderate impairment of dexterity and } \\
\text { decreased stamina }\end{array}$ & Yes & 1 Year a. & Speed and area limitations \\
\hline 8 & Not used & & & \\
\hline 9 & $\begin{array}{l}\text { Significant neurologic impairment } \\
\text { expected to be temporary } b \text {. }\end{array}$ & Yes & 6 Mos & $\begin{array}{l}\text { Accompanied by licensed } \\
\text { driver, with speed, area and/or } \\
\text { time of day limitations } \\
\text { recommended by health care } \\
\text { professional }\end{array}$ \\
\hline 10 & $\begin{array}{l}\text { Special circumstances not covered } \\
\text { above }\end{array}$ & Yes & As recom. & $\begin{array}{l}\text { Special limitations } \\
\text { recommended by health care } \\
\text { professional, advise DLD }\end{array}$ \\
\hline 11 & Patient under evaluation & Yes & As recom. & $\begin{array}{l}\text { To be determined, health care } \\
\text { professional advise DLD }\end{array}$ \\
\hline 12 & $\begin{array}{l}\text { Strength, sensory or coordination } \\
\text { impairment incompatible with any driving }\end{array}$ & & & No Driving \\
\hline
\end{tabular}

a. Or as recommended by health care professional, longer or shorter according to stability.

b. For example, as in recovery from strokes, head injuries, etc., where skill developed under supervision may be therapeutic. 


\section{CATEGORY E: EPILEPSY AND OTHER EPISODIC CONDITIONS}

1. Epilepsy includes any recurrent loss of consciousness or conscious control arising from intermittent change in brain function. Because of the similarity of consequences, other disorders affecting consciousness or control such as syncope, cataplexy, narcolepsy, hypoglycemia, episodic vertigo interfering with function, etc., have been included in this section, to be considered in a similar fashion.

2. Since all forms of epilepsy (tonic-clonic or grand mal, partial complex or psychomotor, partial, with or without spread, and absence or petit mal) may interfere with safe driving, they will affect the level of driving recommended and will require initial and follow-up reports.

3. A non-commercial operator's license, with or without limitations, may be issued after a suitable interval in the following circumstances confirmed by a medical report:

A single seizure or cluster of seizures (profile 12 until evaluation completed).

Seizures occurring only in sleep over a period of three or more years.

Seizures so limited as not to interfere with control, if stable for a period of one year.

Seizures recurring when medication has been reduced on a health care professional's advice to change or continue medication and a corrective change has been made as recommended by the health care professional.

A seizure provoked by a clearly identified cause which is not likely to recur.

4. To qualify for a profile based upon freedom from seizures, a person should be free from side effects of medications which affect driving. Anyone taking medication is responsible to refrain from driving if it affects their alertness and coordination, until the health care professional approves resumption of driving and believes the patient can drive safely. Side effects such as skin or gum changes which do not affect driving may be disregarded. In individual cases where anticonvulsant medication effects cause a slowing of reaction time, consideration should be given to limitations on speed as suggested in Neurologic Category D.

5. Persons experiencing seizures may have associated problems which may affect driving safety and these should be reported under the appropriate profile.

6. Persons with past seizures may qualify for a higher risk responsibility level by making sure they faithfully take their prescribed medication and use other means of control. In time, they may qualify for an unrestricted license. Under these guidelines and standards it is possible for a person to resume driving after a seizure free interval of only three months. Each case should be considered carefully to balance possible risk against the person's need to get to and from work, etc.

7. COMMERCIAL DRIVERS: Federal DOT guidelines require any patient with a history of epileptic seizures (other than childhood febrile seizures or symptomatic seizures) to be disqualified for a commercial interstate license or medical certificate. An. intrastate license or medical certificate may be granted under profiles 2,3 and 4 depending upon the degree of seizure control.

Please refer to Profile Level Charts when completing Functional Ability Evaluation and Certificate of Visual Examination forms. 


\section{CATEGORY E: EPILEPSY AND OTHER EPISODIC CONDITIONS}

\begin{tabular}{|c|c|c|c|c|}
\hline $\begin{array}{l}\text { Profile } \\
\text { Level }\end{array}$ & Circumstances & $\begin{array}{l}\text { Med } \\
\text { Conf } \\
\text { Req }\end{array}$ & $\begin{array}{l}\text { Interval for } \\
\text { Review }\end{array}$ & $\begin{array}{l}\text { License Class and } \\
\text { Restrictions }\end{array}$ \\
\hline \multirow[t]{2}{*}{1} & \multirow[t]{2}{*}{ No history of epileptic seizures } & Yes & 2 Years & Commercial Unlimited \\
\hline & & No & N/A & Private Vehicles \\
\hline \multirow[t]{2}{*}{2} & \multirow{2}{*}{$\begin{array}{l}\text { History of seizures or episodes but none } \\
\text { in past } 5 \text { years without medication }\end{array}$} & Yes & 2 Years & Commercial Intrastate \\
\hline & & No & N/A & Private Vehicles \\
\hline \multirow[t]{2}{*}{3} & \multirow{2}{*}{$\begin{array}{l}\text { Seizure or episode free } 5 \text { years and } \\
\text { subsequently off medication } 3 \text { years with } \\
\text { health care professional's } \\
\text { recommendation }\end{array}$} & Yes & 2 Years & $\begin{array}{l}\text { Commercial Intrastate with } \\
\text { health care professional } \\
\text { approval }\end{array}$ \\
\hline & & Yes & $\begin{array}{l}\text { Upon } \\
\text { Renewal }\end{array}$ & Private Vehicles \\
\hline 4 & $\begin{array}{l}\text { Seizure or episode free } 1 \text { year off or on } \\
\text { medication without side effects }\end{array}$ & Yes & 1 year a. b. & $\begin{array}{l}\text { Commercial Intrastate, Light } \\
\text { Vehicles Appeal larger } \\
\text { vehicles to Medical Advisory } \\
\text { Board Private Vehicles }\end{array}$ \\
\hline 5 & $\begin{array}{l}\text { Seizure or episode free } 6 \text { months, off or } \\
\text { on medication without side effects }\end{array}$ & Yes & 6 mos a. b. & Private Vehicles \\
\hline 6 & $\begin{array}{l}\text { Seizure or episode free } 5 \text { months, off or } \\
\text { on medication without side effects }\end{array}$ & Yes & 6 mos a. c. & Speed limitation \\
\hline 7 & $\begin{array}{l}\text { Seizure or episode free } 4 \text { months, off or } \\
\text { on medication without side effects }\end{array}$ & Yes & 6 mos a. c. & Speed and area limitation \\
\hline 8 & $\begin{array}{l}\text { Seizure or episode free } 3 \text { months, off or } \\
\text { on medication without side effects }\end{array}$ & Yes & 6 mos a. c. & $\begin{array}{l}\text { Speed, area and time of day } \\
\text { limitations }\end{array}$ \\
\hline 9 & Not Used & & & \\
\hline 10 & $\begin{array}{l}\text { Special circumstances not covered above } \\
\text { e.g. single recurrence after long interval } \\
\text { (over } 2 \text { years) of seizure freedom }\end{array}$ & Yes & 6 mos a. c. & $\begin{array}{l}\text { Special limitations } \\
\text { recommended by health care } \\
\text { professional, advise DLD }\end{array}$ \\
\hline 11 & $\begin{array}{l}\text { Single seizure or episode, suspected } \\
\text { seizure or cluster or seizures in process } \\
\text { of evaluation, or other special } \\
\text { circumstances }\end{array}$ & Yes & As recom. & $\begin{array}{l}\text { To be determined, health care } \\
\text { professional advise DLD }\end{array}$ \\
\hline 12 & $\begin{array}{l}\text { Seizure or episodes not controlled, or } \\
\text { medication effects interfering with } \\
\text { alertness or coordination }\end{array}$ & & & No Driving \\
\hline
\end{tabular}

1) Or shorter if recommended by health care professional, according to stability.

2) Or interval since last seizure or episode, up to renewal interval.

3) Or interval to qualify for higher profile. 


\section{CATEGORY F: LEARNING, MEMORY AND COMMUNICATION}

1. Driving a motor vehicle is a complex operation which requires the ability to learn from experience, to remember facts related to driving situations, to communicate intentions by appropriate signals and to receive communications by interpretation of signs and in other ways. Greater demands for verbal communication are imposed when passengers are carried.

2. These functional profile levels are intended as guides for health care professionals in advising appropriate driving for their patients. In stable situations, such as retardation, a single medical confirmation will be sufficient, but in other circumstances, reconfirmation of the profile should be based upon medical judgement as to the likelihood of future changes. For example, a person who is improving after a head injury may be reviewed after an appropriate interval and receive increased privileges. Similarly, a person with increasing difficulties should be reviewed and greater limitations advised as may be appropriate. A health care professional should use available information to make the best judgement possible in the interest of their patient's safety. This should include information from their family, driving incidents, habits and other medically pertinent data. In general, AMA impairment percentages from 0 to $15 \%$ may be appropriate for driving private vehicles, while higher percentages will usually call for limitations.

3. Intellectual function usually relates to age in younger individuals, but may be estimated for all ages in a common sense fashion. A person's ability to function may be affected by emotional factors or experience. A health care professional can often get a good indication of intelligence by learning how well a person handles school, work or activities of daily living. For example, a person who cannot figure change in making simple purchases may not be able to drive safely.

4. A very important component of any impairment of learning, memory, communication, or other intellectual functions is the element of emotional stability and maturity in social relations. A person with intellectual impairment who is impulsive or aggressive may be a dangerous driver. Hence, these factors must be considered in setting a profile level.

5. Most younger individuals with learning problems will have had testing done which may be used as a basis for recommendations. In other cases, estimates of abilities, including general intelligence, may be made using whatever resources are usually used by the health care professional. Since inappropriate driving may create risks for both the patient and the public, if there is uncertainty, psychometric testing or other referral should be considered. Individuals with I.Q.S below 70 are reported to have more accidents in emergency situations.

6. Ability may fluctuate in relation to effects of medications, alcohol, emotional stress or fatigue, etc. Hence, a person's age, habits, stability and related impairments as in head injuries, should be considered carefully. Recommendations should be conservative to take into account intervals when abilities may be less than usual.

7. Patients with closed head injury may have diffuse cognitive deficits, for example: impaired judgement, impulsiveness, distractibility, impaired attention, neglect, slowed reaction time or impaired cognitive endurance. If the patient has had a severe injury (defined as coma longer than 24 hours and/or post traumatic amnesia longer than 7 days) the patient should be required to be evaluated by a state driver license examiner.

8. Alzheimer's disease results in progressively impaired cognitive function and may require frequent review of driving abilities.

9. In special problems such as aphasia or inadequate language skills, the health care professional may indicate that a drive test should be given to make a careful final appraisal based upon special attention to learning and communication during the drive test. The health care professional should check the driving skills test box at the bottom of the form.

Please refer to Profile Level Charts when completing Functional Ability Evaluation and Certificate of Visual Examination forms. 


\section{CATEGORY F: LEARNING, MEMORY AND COMMUNICATION}

\begin{tabular}{|c|c|c|c|c|}
\hline $\begin{array}{l}\text { Profile } \\
\text { Level }\end{array}$ & Circumstances & $\begin{array}{l}\text { Med } \\
\text { Conf Req }\end{array}$ & $\begin{array}{l}\text { Interval for } \\
\text { Review }\end{array}$ & $\begin{array}{l}\text { License Class and } \\
\text { Restrictions }\end{array}$ \\
\hline \multirow[t]{2}{*}{1} & \multirow{2}{*}{$\begin{array}{l}\text { No history of impairment of learning, } \\
\text { memory, or communication. Normal } \\
\text { intelligence }\end{array}$} & Yes & 2 Years & Commercial Unlimited \\
\hline & & No & N/A & Private Vehicles \\
\hline \multirow[t]{2}{*}{2} & \multirow{2}{*}{$\begin{array}{l}\text { Past history of impairment of learning, } \\
\text { memory or communication, but fully } \\
\text { recovered at least one year. Normal } \\
\text { intelligence }\end{array}$} & Yes & 2 Years & Commercial Unlimited \\
\hline & & No & N/A & Private Vehicles \\
\hline \multirow[t]{2}{*}{3} & \multirow{2}{*}{$\begin{array}{l}\text { Residual minimal difficulties with } \\
\text { complex intellectual functions or } \\
\text { communication. Good social and } \\
\text { personal adjustment }\end{array}$} & Yes & 2 Years & Commercial Unlimited \\
\hline & & No & N/A & Private Vehicles \\
\hline \multirow[t]{2}{*}{4} & \multirow[t]{2}{*}{$\begin{array}{l}\text { Borderline cognitive impairment with } \\
\text { good socialization and emotional } \\
\text { control }\end{array}$} & Yes & 2 Years a. & $\begin{array}{l}\text { Commercial UnlimitedSkills test } \\
\text { if recommended by health care } \\
\text { professional }\end{array}$ \\
\hline & & & b. & Private Vehicles \\
\hline \multirow[t]{2}{*}{5} & \multirow[t]{2}{*}{$\begin{array}{l}\text { Mild intellectual or communication } \\
\text { impairment Good socialization and } \\
\text { emotional control }\end{array}$} & Yes & 2 Years a. & $\begin{array}{l}\text { Commercial Intrastate, Skills } \\
\text { Test RequiredHealth care } \\
\text { professional Recommendation }\end{array}$ \\
\hline & & & b. & \begin{tabular}{|l} 
Private Vehicles \\
\end{tabular} \\
\hline 6 & $\begin{array}{l}\text { Not Used } \\
\end{array}$ & & & \\
\hline 7 & Not Used & & & \\
\hline 8 & Not Used & & & \\
\hline 9 & Not Used & & & \\
\hline 10 & $\begin{array}{l}\text { Impairment of learning, memory, } \\
\text { judgement or communication } \\
\text { involving special circumstances (see } \\
\text { paragraphs } 6,7 \text { and } 8 \text { in narrative) } \\
\end{array}$ & Yes & As recom. & $\begin{array}{l}\text { Special limitations as } \\
\text { recommended by health care } \\
\text { professional, advise DLD }\end{array}$ \\
\hline 11 & Patient under evaluation & Yes & As recom. & $\begin{array}{l}\text { To be determined, health care } \\
\text { professional advise DLD }\end{array}$ \\
\hline 12 & $\begin{array}{l}\text { Moderate, severe and profound } \\
\text { mental retardation or impairment of } \\
\text { intellectual functions or } \\
\text { communication; or lesser impairment } \\
\text { but with poor socialization and/or } \\
\text { emotional control }\end{array}$ & & & No Driving \\
\hline
\end{tabular}

a. Or shorter interval, as recommended by health care professional.

b. Initial medical confirmation only needed for static conditions. Otherwise intervals from three months up to renewal interval according to the health care professional's judgement regarding probability of change. 


\section{CATEGORY G: PSYCHIATRIC OR EMOTIONAL CONDITIONS}

1. There is no certain way of predicting which person with psychiatric illness will have accidents, but many high risk drivers are such because of psychiatric conditions. Consistent application of the point system reflecting accident involvement and reckless driving with imposition of appropriate driving restrictions will help to identify and control many of the psychiatric population at risk.

2. The involuntary hospitalization or commitment law presently in effect in the State of Utah requires that the individual to be committed must have a major mental illness, lack insight into their condition, be untreatable in programs involving less restriction of personal freedom, be an imminent danger to themselves or others, or be incapable of self care. The coincidence of these four criteria adjudicated at a court hearing would be strong grounds for the withholding of the driving privilege during the duration of the commitment. Termination of committed status does not mean that the patient is necessarily mentally well but merely improved. Such individuals should be medically screened before resuming driving privileges.

3. There is a large population of individuals with psychotic illness who are being maintained on antipsychotic medications in an ambulatory status in the community. All of these drugs, as well as the tricyclic anti-depressants, have varying degrees of sedative side effects and potentiate other CNS depressants. Most of these are individuals with a clinical diagnosis of "schizophrenia". The quality of the remission being maintained by medication varies widely. Some of the individuals continue to have significant mental disability. These persons should be screened in terms of severity of side effects incident to medication and the adequacy of the remission in terms of a reasonably stable, reality oriented, socially responsible and impulse controlled adjustive style.

4. Benzodiazepines have been implicated in automobile fatalities to a degree comparable with alcohol. Research shows the major period of risk is the first three weeks, after which tolerance generally develops to the sedation and dysfunctional effects on coordination.

5. There are a variety of behavioral conditions, extremes of mood and impairments in thinking associated with psychiatric disorders which may correlate with accident proneness or driver risk. These include:

a. Inattentiveness which may accompany even minor mental disturbances;

b. Impulsivity, explosive anger, and impaired social judgement characteristic of personality disorders, especially antisocial personality;

c. Suicidality, perceptual distortions, psychomotor retardation or frank irrationality in addition to the previously described symptoms which are common features of major psychiatric illnesses such as schizophrenia, major depressive disorder, bipolar (manic depressive) disorder and organic brain syndromes.

6. The applicant's prior accident and violation records are more valid "predictors" of driver risk than psychiatric status. This record should be a major factor in placing restrictions upon driving. The combination of a bad driving record and mental disability could be a particularly lethal combination. If an applicant reports accidents or moving violations the health care professional should be alert to possible psychiatric problems. The health care professional may call 965-4437 for further information retained on the patient's driving record.

7. If a health care professional believes there may be a problem, but is not sufficiently familiar with the patient's psychiatric status to make a valid judgement, they should refrain from doing so until they gain access to current psychiatric information or records or makes an appropriate referral for evaluation.

Please refer to Profile Level Charts when completing Functional Ability Evaluation and Certificate of Visual Examination forms. 


\section{CATEGORY G: PSYCHIATRIC OR EMOTIONAL CONDITION}

\begin{tabular}{|c|c|c|c|c|}
\hline $\begin{array}{l}\text { Profile } \\
\text { Level }\end{array}$ & Circumstances & $\begin{array}{l}\text { Med Conf } \\
\text { Req }\end{array}$ & $\begin{array}{l}\text { Interval for } \\
\text { Review }\end{array}$ & $\begin{array}{l}\text { License Class and } \\
\text { Restrictions }\end{array}$ \\
\hline \multirow{2}{*}{1} & \multirow{2}{*}{$\begin{array}{l}\text { No history of psychiatric or emotional } \\
\text { condition }\end{array}$} & Yes & 2 Years & Commercial Unlimited \\
\hline & & No & N/A & Private Vehicles \\
\hline \multirow{2}{*}{2} & \multirow{2}{*}{$\begin{array}{l}\text { Past history of psychiatric or } \\
\text { emotional condition, asymptomatic } \\
\text { for } 5 \text { years }\end{array}$} & Yes & 2 Years & Commercial Unlimited \\
\hline & & No & N/A & Private Vehicles \\
\hline \multirow[b]{2}{*}{3} & \multirow{2}{*}{$\begin{array}{l}\text { Psychiatric or emotional condition } \\
\text { stable for } 1 \text { year with symptoms } \\
\text { controlled without medication or with } \\
\text { medications which do not interfere } \\
\text { with alertness or coordination }\end{array}$} & \multirow[b]{2}{*}{ Yes } & 1 Year & Commercial Unlimited \\
\hline & & & 1 year $\mathbf{a}$. & Private Vehicles \\
\hline \multirow[t]{2}{*}{4} & \multirow{2}{*}{$\begin{array}{l}\text { Psychiatric or emotional condition } \\
\text { stable for } 3 \text { months with symptoms } \\
\text { controlled without medication or with } \\
\text { medications which do not interfere } \\
\text { with alertness or coordination }\end{array}$} & \multirow[t]{2}{*}{ Yes } & 1 Year & $\begin{array}{l}\text { Commercial Intrastate with } \\
\text { health care professional } \\
\text { recommendation c. } \\
\end{array}$ \\
\hline & & & 1 year $\mathbf{a}$. & Private Vehicles c. \\
\hline 5 & $\begin{array}{l}\text { Psychiatric or emotional condition } \\
\text { stable for } 1 \text { month with symptoms } \\
\text { controlled by medications which do } \\
\text { not interfere with alertness or } \\
\text { coordination }\end{array}$ & Yes & 6 mos b. & Private Vehicles c. \\
\hline 6 & $\begin{array}{l}\text { Psychiatric or emotional condition } \\
\text { with medications which minimally } \\
\text { interfere with coordination, as in } \\
\text { dyskinesia etc }\end{array}$ & Yes & 6 mos b. & Speed limitation c. \\
\hline 7 & Not Used & & & \\
\hline 8 & Not Used & & & \\
\hline 9 & \begin{tabular}{|l|} 
Psychiatric or emotional condition \\
with variable symptoms where \\
driving under direct supervision of a \\
responsible licensed driver may be \\
therapeutic
\end{tabular} & Yes & 6 mos b. & $\begin{array}{l}\text { Accompanied by licensed driver } \\
\text { with speed, area and/or time of } \\
\text { day limitations recommended by } \\
\text { health care professional }\end{array}$ \\
\hline 10 & $\begin{array}{l}\text { Special circumstances not covered } \\
\text { above }\end{array}$ & Yes & 6 mos b. & $\begin{array}{l}\text { Special limitations } \\
\text { recommended by health care } \\
\text { professional, advise DLD } \\
\end{array}$ \\
\hline 11 & $\begin{array}{l}\text { Psychiatric or behavioral symptoms } \\
\text { under evaluation }\end{array}$ & Yes & As recom. & $\begin{array}{l}\text { To be determined, health care } \\
\text { professional advise DLD }\end{array}$ \\
\hline 12 & $\begin{array}{l}\text { Active psychiatric or emotional } \\
\text { condition with indications of risk to } \\
\text { self or others; or with treatment with } \\
\text { medications which interfere with } \\
\text { alertness or coordination; and/or with } \\
\text { commitment status }\end{array}$ & & & No Driving \\
\hline
\end{tabular}

a. Or as recommended by health care professional, longer or shorter according to stability.

b. Or interval up to 1 year if recommended by health care professional.

c. Drivers with impulsivity, explosive anger, and impaired social judgement characteristic of personality disorders such as antisocial personality must have a recommendation from their health care professional as well as approval of the Medical Advisory Board. 


\section{CATEGORY H: ALCOHOL AND OTHER DRUGS}

(Revised 4/98)

1. It is generally known that one-half or more of the highway accidents, injuries and fatalities are related to the use of alcohol. Chronic users of alcohol cause more fatal accidents than the combination of all other drivers with medical problems. Hence, an awareness of problems caused by alcohol is essential to the proper granting of driving privileges.

2. Use of other problem causing drugs can impair a person's driving ability. The nature of these substances is such that continued use creates problems which are recognizable and require special attention in licensing drivers.

3. Users of alcohol and other drugs are well known for their tendency to not report or under-report amounts used. There is a wide individual variation in the effects of such substances. Hence, about the only valid basis for evaluating an applicant's probable safety as a driver is careful appraisal of the person's history including, but not limited to, the past effect upon driving.

4. Adverse personal consequences of alcohol and drug use include (1) physical dependence or withdrawal symptoms, (2) medical or neurological findings associated with effects of alcohol or drug use upon the nervous system or other organs, (3) a history of alcohol or drug related behavioral change indicated by fighting, physical abuse or mood and personality instability, (4) history of alcohol or drug related vehicular accidents or trauma, and (5) convictions involving alcohol.

5. The interaction of psychoactive medications (antidepressants, benzodiazepines, neuroleptics, sedatives, hypnotics) taken in appropriate doses with alcohol or illicit drugs may hamper driving ability.

6. Users of mood altering and hallucinogenic drugs are next to users of alcohol in traffic violations. In addition, untoward drug-related experiences, such as flashbacks, or substance withdrawal seizures may be hazardous to driving. Not only "street" drugs (cannabis, amphetamines, LSD, cocaine, PCP, inhalants, ETC), but also inappropriately used prescription drugs (benzodiazepines, barbiturates, antihistamines, antipsychotics, antidepressants, sedative hypnotics, muscle relaxants, opiates, ETC) increase accident rates, especially when used in combination with alcohol.

7. There is increasing evidence that marijuana may affect driving by causing changes in depth perception, unpredictable alteration of reaction time, illusions of distance, impairment of accuracy of sensory perception, impairment of judgement and periodic lapses of attention, acutely as well as after chronic use. Marijuana may impair driving even several days after cessation of use.

8. Health care professionals should be alert to the fact that those with substance problems tend to visit them more often than the average. Patterns that suggest substance abuse include: gastrointestinal symptoms, often atypical; injuries or burns of vague causation; neurologic symptoms; general medical or flu-like symptoms, hypertension or skin problems; psychiatric symptoms, including depression; social maladjustment and interpersonal and work difficulties; and family health problems. Inquiry may lead to a clearer picture of the problem and temporary limiting of driving for the benefit of the public as well as the patient. Persons who have been stabilized by methadone treatment in a recognized clinic may qualify to drive a non-commercial vehicle as long as they remain under supervision.

9. Many young or inexperienced drivers are unaware of the high risks of driving associated with the use of alcohol, especially when mixed with other substances. Making factual information regarding drugs and alcohol and their effects on driving available to young drivers may help them to make safer choices. Health care professionals can effectively help in these educational efforts.

10. Since many persons rely on their automobiles for transportation to and from work, pressure may be brought to bear to make exceptions. Since the guidelines provide for limitations on speed, areas, time of day, etc., these should be used as appropriate to facilitate driving to and from work until the person has demonstrated sustained responsibility for unlimited privileges. 21

Please refer to Profile Level Charts when completing Functional Ability Evaluation and Certificate of Visual Exammination forms. 


\section{CATEGORY H: ALCOHOL AND OTHER DRUGS}

\begin{tabular}{|c|c|c|c|c|c|}
\hline $\begin{array}{l}\text { Profile } \\
\text { Level }\end{array}$ & Circumstances ALCOHOL USE & $\begin{array}{l}\text { Circumstances } \\
\text { DRUG USE }\end{array}$ & $\begin{array}{l}\text { Med } \\
\text { Conf } \\
\text { Req }\end{array}$ & $\begin{array}{l}\text { Interval } \\
\text { for Review }\end{array}$ & License Class and Restrictions \\
\hline \multirow[t]{2}{*}{1} & \multirow[t]{2}{*}{ No history of use of alcoholic beverages } & \multirow[t]{2}{*}{ No history of inappropriate use of drugs } & Yes & 2 Years & Commercial Unlimited \\
\hline & & & No & N/A & Private Vehicles \\
\hline \multirow[t]{2}{*}{2} & \multirow{2}{*}{$\begin{array}{l}\text { Alcohol use but no adverse personal or } \\
\text { social consequences b. }\end{array}$} & \multirow{2}{*}{$\begin{array}{l}\text { Drug use (schedule } \| \text { to } V \text { ) and } \\
\text { nonprescription medications }\end{array}$} & Yes & 2 Years & Commercial Unlimited \\
\hline & & & No & N/A & Private Vehicles \\
\hline \multirow[t]{2}{*}{3} & \multirow{2}{*}{$\begin{array}{l}\text { Alcohol use with no adverse personal or } \\
\text { social consequences within past } 5 \text { years b. }\end{array}$} & \multirow{2}{*}{$\begin{array}{l}\text { History of drug abuse, but not within past } 5 \\
\text { years c. }\end{array}$} & \multirow[t]{2}{*}{ Yes } & 2 Years & Commercial Unlimited \\
\hline & & & & \begin{tabular}{|l|} 
Upon \\
Renewal \\
\end{tabular} & Private Vehicles \\
\hline \multirow[t]{2}{*}{4} & \multirow{2}{*}{$\begin{array}{l}\text { Alcohol use with no adverse personal or } \\
\text { social consequences within the last one } \\
\text { year b. }\end{array}$} & \multirow{2}{*}{$\begin{array}{l}\text { History of drug abuse, but not within the last } \\
\text { one year } c \text {. }\end{array}$} & \multirow[t]{2}{*}{ Yes } & \multirow[b]{2}{*}{1 Year } & Commercial Unlimited \\
\hline & & & & & Private Vehicles \\
\hline \multirow[t]{2}{*}{5} & \multirow{2}{*}{$\begin{array}{l}\text { Alcohol use with no adverse personal or } \\
\text { social consequences within past } 6 \text { months } \\
\text { b. }\end{array}$} & \multirow{2}{*}{$\begin{array}{l}\text { History of drug abuse, but not within past } 6 \\
\text { months } c \text {. }\end{array}$} & \multirow[t]{2}{*}{ Yes } & 6 mos & Commercial Intrastate with MAB Review Only d. \\
\hline & & & & 6 mos a. & $\begin{array}{l}\text { Private Vehicles with demonstration of drug or alcohol } \\
\text { abstinence by recognized medical test if use led to illegal } \\
\text { consequences d. }\end{array}$ \\
\hline 6 & $\begin{array}{l}\text { Alcohol use with no adverse personal or } \\
\text { social consequences within the past } 3 \\
\text { months }\end{array}$ & $\begin{array}{l}\text { History of drug abuse, but not within past } 3 \\
\text { months c. }\end{array}$ & Yes & 3 mos a. & $\begin{array}{l}\text { Private Vehicles with demonstration of drug or alcohol } \\
\text { abstinence by recognized medical test } d \text {. }\end{array}$ \\
\hline 7 & $\begin{array}{l}\text { Alcohol use with no adverse personal or } \\
\text { social consequences within the past } 1 \\
\text { month }\end{array}$ & $\begin{array}{l}\text { History of drug abuse, but not within past one } \\
\text { month c. }\end{array}$ & Yes & 6 mo a. & $\begin{array}{l}\text { Private Vehicles with demonstration of drug or alcohol } \\
\text { abstinence by recognized medical test } d \text {. }\end{array}$ \\
\hline 8 & $\begin{array}{l}\text { Use of alcohol with intermittent impairment } \\
\text { of function but not during driving or working } \\
\text { hours }\end{array}$ & $\begin{array}{l}\text { Use of drugs as medically prescribed with } \\
\text { intermittent impairment of function but not } \\
\text { during driving or working hours }\end{array}$ & Yes & 6 mos a. & Speed, area and time of day limitations \\
\hline 9 & $\begin{array}{l}\text { Use of alcohol with intermittent impaiment } \\
\text { of function but where driving under } \\
\text { supervision of responsible licensed driver } \\
\text { may be therapeutic }\end{array}$ & $\begin{array}{l}\text { Use of drugs as medically prescribed with } \\
\text { intermittent impairment of function but where } \\
\text { driving under supervision of responsible } \\
\text { licensed driver may be therapeutic } \\
\end{array}$ & Yes & 6 mos a. & $\begin{array}{l}\text { Accompanied by licensed driver with speed, area and/or time } \\
\text { of day limitations recommended by health care professional. }\end{array}$ \\
\hline 10 & Special situations not covered above & Special situations not covered above & Yes & As recom. & $\begin{array}{l}\text { Special limitations recommended by health care professional, } \\
\text { advise DLD }\end{array}$ \\
\hline 11 & Patient's alcohol use under evaluation & Patient's drug use under evaluation & Yes & As recom. & To be determined, health care professional advise DLD \\
\hline 12 & $\begin{array}{l}\text { Chronic use of alcohol with impairment of } \\
\text { motor and/or intellectural functions }\end{array}$ & $\begin{array}{l}\text { Chronic use of drugs with impairment of } \\
\text { motor and/or intellectual functions }\end{array}$ & & & No Driving \\
\hline
\end{tabular}

a. Or as recommended by health care professional, shorter or longer up to 1 year.

b. See narrative for examples of adverse consequences

c. Drug Abuse means any use of illicit drugs or inappropriate use of prescription or non-prescription drugs.

d. Random blood alcohol, random urine or hair drug analysis, or documented compliance with requirements of an approved treatment program at time of profiling. 


\section{CATEGORY I: VISUAL ACUITY}

1. Visual acuity and peripheral vision guidelines for functional ability profiles are as shown.

2. Correction of vision may be either with regular glasses or with contact lenses, provided they are used at all times when driving. With spectacles, the correction must be less than 10 diopters to qualify for profile level 1. Profiles based upon use of a visual correction should be identified by the suffix " $\mathrm{C}$ ".

3. Some of the eye conditions requiring special consideration, but which have no set standards, are listed below. Persons with these conditions may drive if they meet the criteria for acuity and fields.

4. COLOR VISION: People who are completely color blind usually suffer from poor visual acuity and possible associated visual field loss. Red-green color discrimination is not important because of traffic light standardization, except in the case of commercial drivers, who must be able to recognize standard colors of red, green and amber.

5. DARK ADAPTATION: Dark adaptation and glare tolerance are important for safe twilight and night driving, but methods of measurement and standards are not well established. However, individuals with cataracts, retinal abnormalities, chronic pupillary constriction, or other known causes of glare intolerance or poor dark adaptation should be carefully evaluated before being recommended for unrestricted licensure. Under certain conditions, a profile for daytime driving only may be recommended.

6. HETEROPHORIA can occasionally be a cause of driver fatigue. In more severe conditions, it may lead to blurred vision, diplopia or suppression of vision in one eye. A strabismic person, if diplopia (double vision) is not present, may be regarded as a one-eyed driver. A person with persisting diplopia may be licensed only on the basis of specific medical recommendations.

7. STEREOPSIS is only important in distances up to 75 feet and therefore relates more to parking, backing and following closely in city traffic. The best method for testing depth perception on the highway is the driver license examiner's road test.

8. MONOCULAR VISION: A person with vision with one eye or correctable vision in one eye to 20/40 may drive non-commercial vehicles. Side mirrors are not required because they are not considered adequate compensatory devices. In certain circumstances a driver with monocular vision may be approved by the Medical Advisory Board for a commercial intrastate license or medical certificate.

9. REFRACTIVE STATES: Myopia (near-sightedness), hyperopia (far-sightedness) and astigmatism (distorted, but constant for all viewing distances) can usually be compensated and need not be considered as problems. Likewise, presbyopia (inability to focus clearly at near) is natural to aging and is not of licensing concern if compensated.

10. TELESCOPIC LENS: When a person puts on a telescopic lens, the visual field is decreased to an extent that the wearer is not qualified to drive.

11. CHRONIC AND RECURRENT DISEASE, including nystagmus, glaucoma, cataracts, ptosis, corneal disorders, pupillary action, retinal changes and aphakia, are significant in that they usually produce changes in the visual acuity or visual fields.

12. VISUAL FIELDS: Recent research demonstrates that intact peripheral vision is important for safe driving. An adequate visual field for passenger vehicles is defined as 120 degrees on the horizontal meridian and 20 degrees on the vertical meridian both above and below fixation. If the patient has pathology that may affect the visual fields, such as glaucoma, retinitis pigmentosa, post panretinal photocoagulation, or cataracts, formal visual field testing using a Goldmann III-4-e object or its equivalent for automated perimetry may be helpful in determining the extent of visual field impairment. A person with a homonymous hemianopia is at increased risk for accidents and should be reviewed by the Medical Advisory Board.

Please refer to Profile Level Charts when completing Functional Ability Evaluation and Certificate of Visual Examination forms. 


\section{CATEGORY I: VISUAL ACUITY}

\begin{tabular}{|c|c|c|c|c|c|c|}
\hline $\begin{array}{l}\text { Profile } \\
\text { Levels }\end{array}$ & Vision & Visual Fields c. & $\begin{array}{l}\text { Color } \\
\text { Vision } \\
\text { CDL Only }\end{array}$ & $\begin{array}{l}\text { Med } \\
\text { Conf } \\
\text { Req }\end{array}$ & $\begin{array}{l}\text { Interval for } \\
\text { Review }\end{array}$ & License Class and Restrictions \\
\hline \multirow[t]{2}{*}{1} & \multirow[t]{2}{*}{$20 / 25$ vision each eye } & \multirow{2}{*}{$\begin{array}{l}\text { Monocular visual fields } 120 \text { degrees in each } \\
\text { eye, binocular visual fields } 70 \text { degrees to the } \\
\text { right and to the left in the horizontal } \\
\text { meridian. }\end{array}$} & Normal & Yes & 2 Years & Commercial Unlimited \\
\hline & & & $N / A$ & No & N/A & Private Vehicles \\
\hline \multirow[t]{2}{*}{2} & \multirow[t]{2}{*}{$20 / 40$ in each eye } & & Normal & Yes & 2 Years & Commercial Unlimited \\
\hline & & & N/A & No & N/A & Private Vehicles \\
\hline \multirow[t]{2}{*}{3} & \multirow[t]{2}{*}{$20 / 40$ in better eye, stable pathology } & \multirow[t]{2}{*}{ At least 120 degrees in each eye } & Normal & Yes & 1 Year a. & Commercial Intrastate, with approval by MAB d. \\
\hline & & & N/A & No & $\begin{array}{l}\text { Upon renewal } \\
\text { a. }\end{array}$ & Private Vehicles \\
\hline \multirow[t]{2}{*}{4} & \multirow[t]{2}{*}{$20 / 40$ in better eye, stable pathology } & \multirow[t]{2}{*}{ At least 120 degrees total for both eyes } & Normal & Yes & 1 Year a. & $\begin{array}{l}\text { Commercial Intrastate, renewal only, with approval } \\
\text { by the MAB d. }\end{array}$ \\
\hline & & & N/A & No & $\begin{array}{l}\text { Upon } \\
\text { Renewal a. }\end{array}$ & Private Vehicles \\
\hline 5 & $20 / 40$ in better eye, unstable pathology & & N/A & Yes & 2 years a. & Private Vehicles \\
\hline 6 & $\begin{array}{l}20 / 50 \text { to } 20 / 70 \text { in better eye, stable } \\
\text { pathology }\end{array}$ & & N/A & Yes & $\begin{array}{l}\text { Upon } \\
\text { Renewal a. }\end{array}$ & Speed limitations \\
\hline 7 & $\begin{array}{l}20 / 50 \text { to } 20 / 70 \text { in better eye, unstable } \\
\text { pathology }\end{array}$ & & N/A & Yes & 1 Year $\mathbf{a}$. & Speed limitations and area $\mathbf{b}$. \\
\hline 8 & $\begin{array}{l}20 / 80 \text { to } 20 / 100 \text { in better eye, stable } \\
\text { pathology }\end{array}$ & At least 90 degrees total for both eyes e. & N/A & Yes & 1 Year a. & $\begin{array}{l}\text { Speed, area and time of day restrictions as } \\
\text { recommended by health care professional and } \\
\text { approved by MAB }\end{array}$ \\
\hline 9 & $\begin{array}{l}20 / 80 \text { to } 20 / 100 \text { in better eye, unstable } \\
\text { pathology }\end{array}$ & & N/A & Yes & $6 \mathrm{moa}$. & $\begin{array}{l}\text { Speed, area and time of day restrictions as } \\
\text { recommended by health care professional and } \\
\text { approved by MAB }\end{array}$ \\
\hline 10 & $\begin{array}{l}\text { Special circumstances not covered by } \\
\text { any of the above }\end{array}$ & $\begin{array}{l}\text { Special circumstances not covered by any of } \\
\text { the above }\end{array}$ & N/A & Yes & As recom. & $\begin{array}{l}\text { Special limitations recommended by health care } \\
\text { professional, advise DLD f. }\end{array}$ \\
\hline 11 & Patient under evaluation & Patient under evaluation & N/A & Yes & As recom. & $\begin{array}{l}\text { To be determined by health care professional, advise } \\
\text { DLD }\end{array}$ \\
\hline 12 & No Driving & Less than 90 degrees total for both eyes & N/A & & & No Driving \\
\hline
\end{tabular}

a. Or as recommended by health care professional, shorter or longer according to stability.

b. Speed, area and time of day restrictions as recommended by health care professional.

c. An adequate visual field is defined as 90 degrees on the horizontal meridian and 20 degrees on the vertical meridian both above and below fixation.

If there is any question concerning the visual fields on confrontation testing or because of ophthalmic pathology, formal visual field testing by perimetry using a

III-4-e Goldmann target (or its equivalent on automated perimetry) should be performed.

d. May be modified subject to Federal Rulemaking.

e. Patients with a homonymous hemianopia must be reviewed by the Medical Advisory Board.

f. Profile should be indicated by health care professional with recommendations and indicate on the Visual Exam Form if a driving skills test is required. 


\section{CATEGORY J: MUSCULOSKELETAL ABNORMALITY OR CHRONIC MEDICAL DEBILITY}

1. The preceding categories have been developed to cover most of the more common conditions which may affect driving safety. Category $\mathrm{J}$ includes a variety of chronic conditions not included elsewhere, which have in common their potential effect upon driving safety. In some of them, medical judgement may be of primary importance in determining limitations on driving, such as, osteoporosis or active infectious disease, including HIV, as they affect the safety of the driver or passengers or other vehicles. In others, the basis for limitation of driving privileges will be the functional motor impairment for the specific acts of operating a vehicle, such as amputations or congenital abnormalities, unless compensatory devices are used as outlined in Category $\mathrm{K}$.

2. In case of obvious paralysis or absence or abnormality of limbs, etc., where an applicant is able to pass the driving test without compensatory aids, no medical confirmation is required. Otherwise, a provisional profile level may be based on the health care professional's recommendations and a final one upon the functional motor profile in Category K. For stable conditions, the interval for revalidation will be normal, but in unstable situations, the health care professional should recommend shorter intervals depending upon the nature of the problem.

3. Many persons with chronic illness require medications for pain and other symptoms which may interfere with alertness or coordination. Use of such medications should be taken into consideration in assigning a profile level. The individual should be cautioned that they are responsible to refrain from driving when their condition or medications seem to affect driving ability.

4. COMMERCIAL DRIVERS: The health care professional may indicate a profile 4 , subject to confirmation by passing a road test to indicate their ability to control and operate a commercial motor vehicle safely. The health care professional should check the skills test box at bottom of form.

Please refer to Profile Level Charts when completing Functional Ability Evaluation and Certificate of Visual Examination forms. 


\section{CATEGORY J: MUSCULOSKELETAL ABNORMALITY OR CHRONIC DEBILITY}

\begin{tabular}{|c|c|c|c|c|c|}
\hline $\begin{array}{l}\text { Profile } \\
\text { Level }\end{array}$ & Musculoskeletal Abnormality & General Debility or Impairment & $\begin{array}{l}\text { Med } \\
\text { Conf } \\
\text { Req }\end{array}$ & $\begin{array}{l}\text { Interval } \\
\text { for } \\
\text { Review }\end{array}$ & License Class and Restrictions \\
\hline \multirow[t]{2}{*}{1} & \multirow[t]{2}{*}{ No history } & \multirow[t]{2}{*}{ No history } & Yes & $2 Y r s$ & Commercial Unlimited \\
\hline & & & No & N/A & Private Vehicles \\
\hline \multirow[t]{2}{*}{2} & \multirow[t]{2}{*}{ Full recovery one year } & \multirow[t]{2}{*}{ Full recovery one year } & Yes & 2 Yrs & Commercial Unlimited \\
\hline & & & No & N/A & Private Vehicles \\
\hline \multirow[t]{2}{*}{3} & \multirow[t]{2}{*}{ Minimal residual loss of function } & \multirow[t]{2}{*}{ Minimal residual loss of function } & Yes & 2 Yrs & Commercial Unlimited \\
\hline & & & No & N/A & Private Vehicles \\
\hline \multirow[t]{2}{*}{4} & \multirow[t]{2}{*}{$\begin{array}{l}\text { Mild residual loss of function with or without } \\
\text { compensatory device a. }\end{array}$} & \multirow[t]{2}{*}{ Mild residual loss of function a. } & Yes & $2 Y r s$ & $\begin{array}{l}\text { Commercial Unlimited (Waiver } \\
\text { Reg'd)Must have MAB Approval }\end{array}$ \\
\hline & & & No & N/A & Private Vehicles \\
\hline \multirow[t]{2}{*}{5} & \multirow{2}{*}{$\begin{array}{l}\text { Congenital absence or deformity of a limb or the spine, } \\
\text { traumatic or surgical amputations, or limitations of joint } \\
\text { motion by fusion, anthritis, contractures, etc. a. b. }\end{array}$} & \multirow[t]{2}{*}{ Moderate residual loss of function a. } & Yes & 1 yrd. & $\begin{array}{l}\text { Commercial Unlimited (Waiver Req'd) } \\
\text { Must have MAB Approval }\end{array}$ \\
\hline & & & c. & 1 yrd. & Private Vehicles \\
\hline 6 & $\begin{array}{l}\text { Congenital absence or deformity of a limb or the spine, } \\
\text { traumatic or surgical amputations, or limitations of joint } \\
\text { motion by fusion, arthritis, contractures, etc. b. }\end{array}$ & $\begin{array}{l}\text { General debility or impaiment from cancer, aging, } \\
\text { chronic infections such as HIV, malnutrition, } \\
\text { chemotherapy, drugs or other treatment, chronic pain } \\
\text { syndromes, etc. b. }\end{array}$ & c. & 1 yrd. & Speed limitations \\
\hline 7 & & & c. & 1 yrd. & Speed and area limitations \\
\hline 8 & & & c. & 1 yrd. & Speed, area, time of day limitations \\
\hline 9 & \multicolumn{2}{|c|}{$\begin{array}{l}\text { Impaiment requiring assistance of responsible licensed driver, such as variable weakness, episodes of pain, } \\
\text { etc. b. }\end{array}$} & Yes & 1 yrd. & $\begin{array}{l}\text { Accompanied by licensed driver, with } \\
\text { speed, area, and time limits } \\
\text { recommended by health care } \\
\text { professional }\end{array}$ \\
\hline 10 & \multicolumn{2}{|l|}{ Circumstances not covered by any of the above $b$. } & Yes & 1 yrd. & $\begin{array}{l}\text { Special fimitations recommended by } \\
\text { health care professional, advise DLD }\end{array}$ \\
\hline 11 & \multicolumn{2}{|l|}{ Patient under evaluation } & Yes & 1 yr d. & $\begin{array}{l}\text { To be determined, health care } \\
\text { professional advise DLD }\end{array}$ \\
\hline 12 & \multicolumn{2}{|c|}{ Chronic conditions making driving unsafe. Not fully compensated for by restorative functional devices. } & & & No Driving \\
\hline
\end{tabular}

a. Commercial Unlimited license or medical certificate may be obtained with a waiver.

b. Profile should be indicated by the health care professional according to their best information, and should indicate on the form if a driving test is required. Additional functional motor evaluation will be done under Category $\mathrm{K}$.

c. If compensatory devices used on request of examiner or in case of chronic disease.

d. Longer interval or shorter as recommended by health care professional according to stability. 


\section{CATEGORY K: FUNCTIONAL MOTOR ABILITY}

1. Evaluation of functional motor ability, consists of an appraisal of an individual's abilities to operate a vehicle with reference to muscular strength; coordination; range of motion of joints; spinal movement and stability; amputations or the absence of body parts; and/or other abnormalities affecting motor control. In addition, there is the intangible element of the individual's ingenuity and skill in offsetting their limitations. Specific vehicles may vary greatly in the degree of strength and skill required.

2. Because of these factors, motor ability to operate a particular vehicle may be difficult to define with certainty in the health care professional's office. Nevertheless, the health care professional confirming an applicant's profile should indicate in their best judgement a provisional profile level without and with compensating devices. This will help the driver examiner who tests the applicant (in the vehicle using compensatory devices) and makes the final determination of the functional motor ability profile level. In the event of differences of opinion or where the applicant may feel their case is not well understood, consultation between the driver examiner and the health care professional is encouraged. If there is a continuing uncertainty, a request may be made for review by the Medical Advisory Board as in other cases.

3. If a person demonstrates ability to perform all motor functions necessary to operate a specific type of vehicle without compensating or assistive devices of any sort their motor ability profile will be without a suffix. If any of these devices are used, a suffix will be added as appropriate:

CPD - Compensating Personal Devices

CSA - Compensating Standard Accessories

CNA - Compensating Non-standard Adaptations

4. The suffix CPD (Compensating Personal Devices) will indicate use of personal devices by the person routinely throughout the day for other activities as well as for driving, such as back braces, limb prostheses, limb braces, neck braces, etc.

5. The profile suffix CSA (Compensating Standard Accessories) will indicate the ability to operate a vehicle using standard auto accessories, such as power steering, power brakes, automatic transmission, power windows, etc. A license based upon a profile followed by CSA will be limited to use of vehicles equipped as specified on the license.

6. The profile suffix CNA (Compensating Non-standard Adaptations) will be used to indicate an ability to operate the vehicle using non-standard shoulder and lap belts, special mirrors, special power equipment other than standard power brakes or steering, and other such devices. Any license based on a CNA profile will be valid only when the specified compensating adaptations(s) is (are) being used and are in good working order. A driving test may be required, by the Driver License Division, of drivers using CNAs.

7. If more than one compensating mechanism is used, each suffix will be added to the profile. Examining forms and licenses issued will indicate the levels of functional motor ability and compensating devices to be used. For testing of applicants who use more sophisticated or complex compensating devices, a specially trained examiner will be designated to insure the most knowledgeable evaluation possible. Periodic review of the safety status of such devices is recommended and may be required from time to time by designated examiners.

8. An applicant with a stable motor impairment who is able to pass a standard driving test to the examiner's satisfaction without use of compensating devices (other than standard accessories such as seat belts or power steering or brakes) will not generally need a medical confirmation of their profile. However, if other than standard accessories are used, if the profile has other indications of possible impairment, or if the examiner is not able to pass the applicant on all parts of the standard driving test, medical confirmation of the profile should be secured.

9. COMMERCIAL DRIVERS: All drivers with profiles 3 and 4 will be given a special driving test with the vehicles to be used and with compensatory devices and accessories used. The health care professional should add the appropriate suffix to the profile level to alert the driving test examiners. If there has been loss or impairment of a hand or finger, arm, foot or leg which may interfere with operating a motor vehicle, approval by the Medical Advisory Board is required.

Appendix A. Guidelines and Standards

Page A32 
CATEGORY K: FUNCTIONAL MOTOR ABILITY (WITH OR WITHOUT COMPENSATORY AIDS)

\begin{tabular}{|c|c|c|c|c|c|c|c|}
\hline $\begin{array}{l}\text { Profiles Without } \\
\text { Compensating } \\
\text { Aids }\end{array}$ & $\begin{array}{l}\text { Profiles With } \\
\text { Compensating } \\
\text { Personal } \\
\text { Devices } \\
\end{array}$ & $\begin{array}{l}\text { Profiles With } \\
\text { Compensating } \\
\text { Standard } \\
\text { Accessories } \\
\end{array}$ & $\begin{array}{l}\text { Profiles With } \\
\text { Compensating } \\
\text { Non-Standard } \\
\text { Accessories } \\
\end{array}$ & Circumstances & $\begin{array}{l}\text { Med } \\
\text { Conf } \\
\text { Req }\end{array}$ & $\begin{array}{l}\text { Interval } \\
\text { for } \\
\text { Review }\end{array}$ & License Class and Restrictions \\
\hline \multirow[t]{2}{*}{1} & & & & \multirow[t]{2}{*}{ No history of motor impairment } & Yes & 2 Years & Commercial Unlimited \\
\hline & & & & & No & N/A & Private Vehicles \\
\hline \multirow[t]{2}{*}{2} & & & & \multirow{2}{*}{ Past motor impairment, fully recovered } & Yes & 2 Years & Commercial Unlimited \\
\hline & & & & & No & N/A & Private Vehicles \\
\hline \multirow[t]{2}{*}{3} & \multirow[t]{2}{*}{ CPD } & \multirow[t]{2}{*}{ CSA } & \multirow[t]{2}{*}{ CNA } & \multirow{2}{*}{$\begin{array}{l}\text { Past motor impairment or incomplete } \\
\text { recovery with no driving limitation }\end{array}$} & Yes & 2 Years & Commercial Unlimited (Waiver Req'd) \\
\hline & & & & & Yes a. & Renewal & Private Vehicles \\
\hline \multirow[t]{2}{*}{4} & \multirow[t]{2}{*}{ CPD } & \multirow[t]{2}{*}{ CSA } & \multirow[t]{2}{*}{ CNA } & \multirow{2}{*}{$\begin{array}{l}\text { Present motor impairment or } \\
\text { demonstrates ability to operate } \\
\text { vehicle(s) to be driven }\end{array}$} & Yes & 2 Years & Commercial Intrastate (Waiver Req'd) \\
\hline & & & & & Yes a. & Renewal & Private Vehicles \\
\hline 5 & & & & Not Used & & & \\
\hline 6 & CPD & CSA & CNA & $\begin{array}{l}\text { Demonstrates ability to operate } \\
\text { vehicle(s) at reduced speeds }\end{array}$ & Yes a. & $\begin{array}{l}\text { Upon } \\
\text { Renewal }\end{array}$ & Speed limitation \\
\hline 7 & CPD & CSA & CNA & $\begin{array}{l}\text { Demonstrates ability to operate } \\
\text { vehicle(s) at reduced speeds in limited } \\
\text { areas }\end{array}$ & Yes a. & $\begin{array}{l}\text { Upon } \\
\text { Renewal }\end{array}$ & Speed and area limitations \\
\hline 8 & CPD & CSA & CNA & $\begin{array}{l}\text { Demonstrates ability to operate } \\
\text { vehicle(s) at reduced speeds, in limited } \\
\text { areas and daytime only }\end{array}$ & Yes a. & $\begin{array}{l}\text { Upon } \\
\text { Renewal }\end{array}$ & Speed, area and time of day limitations \\
\hline 9 & CPD & CSA & CNA & $\begin{array}{l}\text { Demonstrates ability to operate } \\
\text { vehicle(s) at reduced speed, area or } \\
\text { other limits, accompanied by } \\
\text { responsible driver }\end{array}$ & Yesa. & $\begin{array}{l}\text { Upon } \\
\text { Renewal } \\
\text { b. }\end{array}$ & $\begin{array}{l}\text { Accompanied by licensed driver with speed, } \\
\text { area and time of day limits recommended by } \\
\text { health care professional or examiner }\end{array}$ \\
\hline 10 & CPD & CSA & CNA & $\begin{array}{l}\text { Motor ability to operate vehicle with } \\
\text { special limits recommended by health } \\
\text { care professional and/or examiner }\end{array}$ & Yes a. & $\begin{array}{l}\text { Upon } \\
\text { Renewal } \\
\text { b. }\end{array}$ & $\begin{array}{l}\text { Speed limitations recommended by health } \\
\text { care professional (advise DLD) or examiner }\end{array}$ \\
\hline 11 & CPD & CSA & CNA & Patient under evaluation & Yes & $\begin{array}{l}\text { As } \\
\text { recom. }\end{array}$ & $\begin{array}{l}\text { To be determined, health care professional } \\
\text { advise DLD }\end{array}$ \\
\hline 12 & CPD & $\overline{C S A}$ & CNA & $\begin{array}{l}\text { Unable to operate vehicle safely with or } \\
\text { without compensatory devices }\end{array}$ & & & No Driving \\
\hline
\end{tabular}

a. At discretion of health care professional.

b. As recommended by health care professional if shorter than renewal interval, according to stability. 


\section{CATEGORY L: HEARING (COMMERCIAL DRIVERS ONLY)}

1. Drivers of private vehicles: No hearing requirements have been set up.

For Meniere's Disease, see Category E, Episodic Disorders.

2. Commercial drivers are required to pass a hearing test. They may be tested either without an aid or with a hearing aid if ordinarily used and are acceptable if:

(1) They perceive a forced whispered voice in the better ear at not less than five feet;

OR,

(2) If tested by use of an audiometric device, they do not have an average hearing loss in the better ear greater than 65 decibels at $500 \mathrm{~Hz}, 1000 \mathrm{~Hz}$ and $2000 \mathrm{~Hz}$. If tested by use of an audiometric device, etc., to $2000 \mathrm{~Hz}$ and for unlimited commercial driving nor an average hearing loss greater than 65 decibels for the same frequencies for intrastate driving of certain vehicles (American National Standard Z 24.5 - 1951).

It is suggested that, if a driver does not pass the whisper test and there is no correctable abnormality such as wax accumulation, arrangements be made for an audiogram.

Please refer to Profile Level Charts when completing Functional Ability Evaluation and Certificate of Visual Examination forms. 
CATEGORY L: HEARING (COMMERCIAL DRIVERS ONLY)

\begin{tabular}{|c|c|c|c|c|}
\hline $\begin{array}{l}\text { Profile } \\
\text { Level }\end{array}$ & Circumstances & $\begin{array}{l}\text { Med } \\
\text { Conf } \\
\text { Req }\end{array}$ & $\begin{array}{l}\text { Interval for } \\
\text { Review }\end{array}$ & $\begin{array}{l}\text { License Class and } \\
\text { Restrictions }\end{array}$ \\
\hline 1 & No past history or current hearing impairment & Yes $^{*}$ & 2 Years & Commercial Unlimited \\
\hline 2 & $\begin{array}{l}\text { Past history of hearing impairment, fully } \\
\text { recovered }\end{array}$ & Yes $^{*}$ & 2 Years & Commercial Unlimited \\
\hline 3 & $\begin{array}{l}\text { Hearing impairment - hears whisper at } 5 \text { feet or } \\
40 \text { decibel audiogram without hearing aid }\end{array}$ & Yes $^{*}$ & 2 Years & Commercial Unlimited \\
\hline 4 & $\begin{array}{l}\text { Hearing impairment - hears whisper at } 5 \text { feet or } \\
40 \text { decibel audiogram with hearing aid }\end{array}$ & Yes $^{*}$ & 2 Years & Commercial Unlimited \\
\hline 5 & $\begin{array}{l}\text { Hearing impairment - unable to hear whisper at } \\
5 \text { feet or } 40-65 \text { decibel loss }\end{array}$ & Yes $^{*}$ & 1 Year a. b. & $\begin{array}{l}\text { Commercial Intrastate } \\
\text { (light vehicles) }\end{array}$ \\
\hline 6 & More than 65 decibel loss & N/A & N/A & Private Vehicles \\
\hline 7 & Not Used & & & \\
\hline 8 & Not Used & & & \\
\hline 9 & Not Used & & & \\
\hline 10 & Not Used & & & \\
\hline 11 & Patient's hearing impairment under evaluation & & & $\begin{array}{l}\text { To be determined by } \\
\text { health care professional } \\
\text { Advise DLD. }\end{array}$ \\
\hline 12 & Not Used & & & \\
\hline
\end{tabular}

*For Commercial Drivers Only

a. Or sooner, if not stable, at discretion of health care professional.

b. Indicate with or without the use of hearing aids. 


\title{
APPENDIX I \\ PRINCIPLES USED IN DEVELOPING GUIDELINES AND STANDARDS FOR DEFINING DRIVING CAPABILITY
}

\author{
Last update 05/22/00
}

In cooperation with the Director of the Utah Driver License Division, the Medical Advisory Board has followed these ten principles in developing these guidelines and standards:

1. Guidelines and standards should be the least restrictive possible consistent with public safety.

2. Functional ability to operate a vehicle safely, rather than impairments, should receive emphasis.

3. Some impairments will permit driving safely under appropriate limitations as to speed, area, time of driving and use of compensating devices, etc.

4. Fairness should prevail in these ways: (a) medically impaired drivers should not be required to meet guidelines and standards of expected safety in excess of those expected of unimpaired drivers; and (b) drivers with different kinds of impairments, but with similar estimated increases in driving risk, should have as nearly the same limitations as possible.

5. A system for profiling all aspects of a person's health which may adversely affect driving either intermittently or continuously will be used by applicants for a driver license.

6. Health care professionals should not be expected to function as policemen, prosecutors or judges in the process of driver evaluation, but as individuals skilled in diagnosis and accurate reporting of functional ability, as well as teachers and advisers to their patients.

7. Since the ultimate responsibility for safety lies with all drivers, they should be involved in selfevaluation, with medical evaluations being used to confirm its accuracy or change it.

8. Every opportunity should be used to educate all drivers and applicants about the effects of physical and emotional health problems, use of drugs, etc. on their ability to drive safely.

9. If anything related to licensing can be simplified safely, this should be done.

10. Health care professionals are invited to help put into effect these principles of safety and fairness and of increasing driver awareness of health in relation to driving safety.

\section{Commercial Driver Licensing}

Regarding guidelines and standards for operators of commercial motor vehicles, Federal Fitness Standards have been integrated as written in the Federal Motor Carrier Safety Regulations, 49CFR, Part 391. 


\section{APPENDIX II \\ UTAH CRIMINAL AND TRAFFIC CODE \\ OPERATORS' LICENSE ACT \\ LICENSES IMPAIRED PERSONS \\ 53-3-303. Driver License Medical Advisory Board Membership Guidelines for licensing impaired persons Recommendations to division.}

(1) There is created within the division the Driver License Medical Advisory Board.

(2) (a) The board is comprised of three regular members appointed by the Commissioner of Public Safety to four-year terms.

(b) The board shall be assisted by expert panel members nominated by the board as necessary and as approved by the Commissioner of Public Safety.

(c) Notwithstanding the requirements of Subsection (a), the executive director shall, at the time of appointment or reappointment, adjust the length of terms to ensure that the terms of board members are staggered so that approximately half of the board is appointed every two years.

(d) When a vacancy occurs in the membership for any reason, the replacement shall be appointed for the unexpired term.

(e) The expert panel members shall recommend medical standards in the areas of the panel members' special competence for determining the physical, mental, and emotional capabilities of applicants for licenses and licensees.

(3) In reviewing individual cases, a panel acting with the authority of the board consists of at least two members, of which at least one is a regular board member.

(4) The director of the division or his designee serves as secretary to the board and its panels.

(5) Members of the board and expert panel members nominated by them shall be health care professionals.

(6) (a) (i) Members who are not government employees shall receive no compensation or benefits for their services, but may receive per diem and expenses incurred in the performance of the member's official duties at the rates established by the Division of Finance under Sections 63A-3-106 and 63A3-107.

(ii) Members may decline to receive per diem and expenses for their service.

(b) (i) State government officer and employee members who do not receive salary, per diem, or expenses from their agency for their service may receive per diem and expenses incurred in the performance of their official duties from the board at the rates established by the Division of Finance under Sections 63A-3-106 and 63A-3-107.

(ii) State government officer and employee members may decline to receive per diem and expenses for their service.

(7) The board shall meet from time to time when called by the director of the division.

(8) (a) The board shall recommend written guidelines and standards for determining the physical, mental, and emotional capabilities of applicants for licenses and for licensees. (b) The guidelines and standards are applicable to all Utah licensees and for all individuals who hold learner permits and are participating in driving activities in all forms of driver education.

(c) The guidelines and standards shall be published by the division.

(9) If the division has reason to believe that an applicant or licensee is an impaired person, it may:

(a) act upon the matter based upon the published guidelines and standards; or 
(b) convene a panel to consider the matter and submit written findings and a recommendation; the division shall consider the recommendation along with other evidence in determining whether a license should be suspended, revoked, denied, disqualified, canceled, or restricted.

(10) (a) If the division has acted under Subsection (9) to suspend, revoke, deny, disqualify, cancel, or restrict the driving privilege without the convening of a panel, the affected applicant or licensee may within ten days of receiving notice of the action request in writing a review of the division's action by a panel. (b) The panel shall review the matters and make written findings and conclusions.

(c) The division shall affirm or modify its previous action.

(11) (a) Actions of the division are subject to judicial review as provided in this part. (b) The guidelines, standards, findings, conclusions, and recommendations of the board or of a panel are admissible as evidence in any judicial review.

(12) Members of the board and its panels incur no liability for recommendations, findings, conclusions, or for other acts performed in good faith and incidental to membership on the board or a panel.

(13) The division shall provide forms for the use of health care professionals in depicting the medical history of any physical, mental, or emotional impairment affecting the applicant's or licensee's ability to drive a motor vehicle.

(14) (a) (i) Individuals who apply for or hold a license and have, or develop, or suspect that they have developed a physical, mental, or emotional impairment that may affect driving safety are responsible for reporting this to the division or its agent.

(ii) If there is uncertainty, the individual is expected to seek competent medical evaluation and advice as to the significance of the impairment as it relates to driving safety, and to refrain from driving until a clarification is made.

(b) Heath care professionals who care for patients with physical, mental, or emotional impairments that may affect their driving safety, whether defined by published guidelines and standards or not, are responsible for making available to their patients without reservation their recommendations and appropriate information related to driving safety and responsibilities.

(c) A health care professional or other person who becomes aware of a physical, mental, or emotional impairment that appears to present an imminent threat to driving safety and reports this information to the division in good faith has immunity from any damages claimed as a result of making the report.

\section{3-3-305.5 Driver License Medical Advisory Board.}

(1) The Driver license Medical Advisory Board shall:

(a) advise the director of the division, and

(b) establish and recommend written functional ability profile guidelines and standards for determining the physical, mental, and emotional capabilities of applicants for specific types of licenses, appropriate to various driving abilities.

(2) (a) The Driver License Medical Advisory Board shall establish fitness standards for issuing intrastate commercial driver licenses under Title 53, Chapter 3, Part 4, Uniform Commercial Driver License Act.

(b) The standards under this Subsection (2) may only be implemented if the United States Department of Transportation (USDOT) will not impose any sanctions, including funding sanctions, against the state of Utah.

(3) In case of uncertainty of interpretation of these guidelines and standards, or in special circumstances, applicants may request a review of any division decision by a panel of board members. All of the actions of the director and board are subject to judicial review. 
(4) (a) If the applicant for an intrastate commercial driver license under Subsection (2) applies for the license under a waiver program, the applicant shall bear any costs directly associated with the cost of administration of the waiver program, with respect to the applicant's application, in addition to any fees required under Section 53-3-105.

(b) The division shall establish any additional fee necessary to administer the license under this Subsection (4) in accordance with Section 63-38-3.2

53-3-304. Licensing of impaired persons - Medical review - Restricted license - Procedures.

(1) (a)If the division has reason to believe that an applicant for a license is an impaired person, the division may require one or both of the following:

(i)a physical examination of the applicant by a health care professional and the submittal by the health care professional of a signed medical report indicating the results of the physical examination;

(ii) follow-up medical review of the applicant by a health care professional and completion of a medical report at intervals established by the division under standards recommended by the board.

(b)The format of the medical report required under Subsection (a) shall be devised by the division with the advice of the board and shall elicit the necessary medical information to determine whether it would be a public safety hazard to permit the applicant to driver a motor vehicle on the highways.

(2) (a)The division may grant a restricted license to an impaired person who is otherwise qualified to obtain a license.

(b) The license continues in effect until its expiration date so long as the licensee complies with the requirements set forth by the division.

(c) The license renewal is subject to the conditions of this section.

(d) Any physical, mental, or emotional impairment of the applicant that in the opinion of the division does not affect the applicant's ability to exercise reasonable and ordinary control at all times in driving a motor vehicle upon the highway, does not prevent granting a license to the applicant.

(3) (a) If an examination is required under this section, the division is not bound by the recommendation of the examining health care professional but shall give fair consideration to the recommendation in acting upon the application. The criterion is whether upon all the evidence it is safe to permit the applicant to drive a motor vehicle.

(b) In deciding whether to grant or deny a license, the division may be guided by the opinion of experts in the fields of diagnosing and treating mental, physical, or emotional disabilities and may take into consideration any other factors that bear on the issue of public safety.

(4) Information provided under this section relating to physical, mental, or emotional impairment is classified under Title 63, Chapter 2, Government Records Access and Management Act. 


\section{APPENDIX III \\ SPECIAL QUALIFICATIONS FOR PERSONS WITH \\ DIABETES MELLITUS FOR COMMERCIAL DRIVER LICENSES}

\section{Last update 05/22/00}

Current federal commercial driver qualification requirements read:

"A person is physically qualified to drive a motor vehicle if that person has no established medical history or clinical diagnosis of Diabetes Mellitus currently requiring insulin for control." "If insulin is necessary to control a diabetic condition, the driver is not qualified to operate a motor vehicle. If mild diabetes is noted at the time of examination and it is stabilized by use of a hypoglycemia drug and a diet that can be obtained while the driver is on duty, it should not be considered disqualifying. However, the driver must remain under adequate medical supervision."

Some insulin taking diabetic individuals are clearly at minimal risk of severe hypoglycemia. These individuals are characterized by the following:

1) Easy recognition of hypoglycemic spells;

2) Willingness and ability to self blood glucose monitor on a frequent basis;

3) Trained in the management of their diabetes with an understanding of the balance of insulin, food, exercise and stress.

Physical qualifications for drivers: A person is physically qualified to drive a commercial motor vehicle if that person has no established medical history or clinical diagnosis of Diabetes Mellitus likely to interfere with that person's ability to safely operate a commercial motor vehicle and provided a person who requires insulin for control of the disease:

a. Has within the last five years

(1) An absence of a hypoglycemic reaction that resulted in loss of consciousness or seizure.

(2) An absence of seizure or coma without antecedent prodromal symptoms of hypoglycemia.

(3) An absence of recurrent diabetic ketoacidosis or hyperosmolar nonketotic coma.

b. Provides the following information (as a minimum) to the Board Certified Endocrinologist who examines them:

(1) A complete medical history including all hospitalization, consultation notes, diagnostic examinations, special studies and follow-up reports.

(2) A complete drivers record as reported by the State Licensing Agency which issued the person a drivers license (as may be available).

(3) Complete information regarding any motor vehicle or other accidents resulting in personal injury or property damage.

(4) Written signed authorization to permit the examining endocrinologist to obtain information from employers, work associates, health care professionals, or other health care workers, relevant to the person's medical condition.

c. Undergoes a complete medical evaluation by a Board Certified Endocrinologist who will assess the results of the following procedures prior to determining whether the person is qualified to operate a commercial motor vehicle:

(1) At least two results of glycolysated hemoglobins during the last 6 months, a lipid profile,urinalysis and $\mathrm{CBC}$. Blood pressure readings at rest, sitting and standing. Elevated blood pressure, medication for hypertension or other evidence of any cardiovascular abnormality will require a maximal exercise stress EKG.

(2) Ophthalmologic confirmation of absence of visually significant retinal disease. 
(3) Examination and tests to detect peripheral neuropathy and/or circulatory deficiencies of the extremities.

(4) A detailed evaluation of insulin dosages and types, diet utilized for control and any significant lifestyle factors, such as smoking, alcohol use and other medications or drugs taken.

The Board Certified Endocrinologist shall:

a. Certify that drivers have been educated in diabetes and its control and thoroughly informed of and have demonstrated the understanding of the procedures which must be followed to monitor and manage their diabetes and what actions should be followed if complications arise.

b. Ascertain that drivers have the ability, willingness, and equipment to properly monitor and manage their diabetes. A blood glucose monitor with electronic "memory" is required.

c. Determine that drivers with diabetes will not adversely affect their ability to safely operate a commercial motor vehicle. The methods of making that determination shall be established by the examining health care professional.

Special Qualifications For Persons With Diabetes Mellitus For Commercial Driver Licenses

The following monitoring and re-evaluation procedures shall be performed as a minimum by an insulin using diabetic who drives a commercial motor vehicle. These procedures may be supplemented with additional procedures and/or operational conditions by the examining health care professional:

a. One hour prior to driving and approximately every two hours while driving, drivers shall test their blood glucose concentration and record those concentrations electronically.

b. Upon request, make records of self blood glucose concentrations available to Federal or State enforcement personnel.

c. Annually, or more often as indicated by the endocrinologist, submit to complete medical reevaluation including readings of glycosylated hemoglobin to the examining endocrinologist. This requires the driver to submit any new data on the drivers medical condition, driving record or accident involvement and the glucose records. Use of a new examining endocrinologist will require the insulin using driver to follow the procedures set forth for a new applicant.

d. At each visit the endocrinologist will verify that the insulin using diabetic can demonstrate the accuracy of self blood glucose measurement within $20 \%$ of actual concentration.

e. Annually have ophthalmologic confirmation of the absence of visually significant retinal disease.

f. While driving, should circumstances preclude a particular blood glucose test, intake of an appropriate snack or other source of glucose is an acceptable alternative, however no two consecutive tests may be replaced by the ingestion of glucose or food.

g. The driver must carry necessary supplies on board the vehicle including as a minimum, blood sampling lancets, personal blood glucose monitor and strips, a plentiful source of rapidly absorbable glucose. All dated materials must be within their expiration dates.

h. It is suggested that for long distance trips a co-driver or a companion shall be made aware of the signs and symptoms of hypoglycemia and the appropriate treatment thereof. 


\section{APPENDIX IV ADDITIONAL INFORMATION FOR CATEGORY B: HYPERTENSION/CARDIOVASCULAR PROFILE}

\section{A. HYPERTENSION/CARDIOVASCULAR PROFILE}

Most antihypertensive agents have potential side effects which may affect driving capability. The examining health care professional should be alert to the following potential problems which may be more prominent or likely with certain antihypertensives as listed. Each hypertensive applicant who is receiving antihypertensive medication should be specifically questioned for these side effects.

\section{(1) ORTHOSTATIC HYPOTENSION}

Virtually any antihypertensive, especially when used in combinations including diuretics, ACE inhibitors, calcium channel blockers, alpha blockers, clonidine, especially Guanethidine and Guanadrel.

\section{(2) SYNCOPE}

Alpha Blockers

(3) DROWSINESSISEDATION

Methyldopa, Guanabenz, Guanadrel, Resperine, Clonidine

(4) DIZZINESS

Most beta blockers, alpha blockers, calcium channel blockers. Also, Apresoline may aggravate angina symptoms in individuals with pre-existing clinically significant coronary artery disease.

(5) OTHER AGENTS AFFECTING DRIVING SAFETY

Because of their greater tendency to produce side effects, the following agents are even more likely to affect driving safety: Guanethidine, Methyldopa, Reserpine, Guanabenz and Guanadrel. 


\section{APPENDIX V}

\section{Suggested Reading}

Decina, LE, Breton, ME, Staplin, L: Visual Disorders and Commercial Drivers. U.S. Department of Transportation, Federal Highway Administration, November 1991.

Epilepsy and Life Performance. Rodin et al. Rehabilitation Literature. 38:2:34 (Feb. 1977).

Federal Highway Administration: Federal Guidelines On Monocular Drivers, Diabetes, Ophthalmology, etc.

Federal Motor Carrier Safety Regulations. US Dept of Transportation, Federal Highway Admin. Parts 383397, Jan., 1990.

Fonda, G: Bioptic Telescopic Spectacle Is A Hazard For Operating A Motor Vehicle.

Arch Ophthalmol 1983;101:1907-1908.

Fonda, G: Legal Blindness Can Be Compatible With Safe Driving. Ophthalmology 1989;96:1457-1459.

Fonda, G: Suggested Vision Standards For Drivers in the United States With Vision Ranging From $20 / 175$ (6/52) to $20 / 50(6 / 15)$. Ann Ophthalmol 1986; 18: 76-79.

Functional Ability Profiles in Driver Licensing. Madison H. Thomas. Proceedings of 24th Conference of the American Association for Automotive Medicine, Oct., 1980.

Functional Aspects of Driver Impairment: A Guide for State Medical Advisory Boards, Dept. of Transportation and American Association of Motor Vehicle Administrators, 1980.

Guidelines for Motor Vehicle Administrators: A Model State Classified Licensing Program. American Association of Motor Vehicle Administrators and NHTSA, Sept., 1978.

Hedin, A, Lovsund, P: Effects of Visual Field Defects on Driving Performance. From documenta Ophthalmologica roceedings, Series 49, Seventh International Visual Field Symposium, 541-547. Edited by E.L. Greve and A. Heijl. Amsterdam,

Martinus Nijhoff/Dr. W. Junk Publishers, 1986.

Johnson, CA, Keltner, JL: Incidence of Visual Field Loss in 20,000 Eyes and Its Relationship To Driving Performance. Arch Ophthalmol 1983;101:371-375.

Keltner, JL, Johnson, CA: Visual Function, Driving Safety, and the Elderly. Ophthalmology 1987;94:11801188.

Medical Aspects of Fitness to Drive. The Medical Commission on Accident Prevention. Editor: Andrew Raffie. London, England. (Third Ed.).

Medically Impaired Drivers: An Evaluation of California Policy. (Report to the California Legislature, Sept., 1978).

North Carolina Physicians's Guide for Determining Driver Limitation. North Carolina Department of Human Services. Raleigh, N.C., 1977.

Physician's Guide for Determining Driver Limitation. American Medical Association, 1973.

Qualification of Drivers; Waiver Applications; Vision. Federal Register Wed, Mar. 25, 1992; Vol.57, No. 58:10295-10297.

Report of National Commission for the Control of Epilepsy and Its Consequences. Vol. 1, page 107. 1977.

Report of Conference on Driver Licensing in Epilepsy: Epilepsy Foundation of America, American Neurologic Associan and American Academy of Neurology, January 1991.

Risks vs. Obligations When Your Patient is an Unfit Driver. Barnett et al. Patient Care. Feb., 1973.

Szlyk, JP: Peripheral Visual Field Loss and Driving Performance. AAA Foundation for Traffic Safety, 1992.

Appendix A. Guidelines and Standards 
The Role of Medical Advisory Boards in Driver Licensing. Department of Transportation, 1977.

Welner, AH: The Driving Environment and Visual Disability. American Journal of Physical Medicine 1987;66:133-137. 


\section{APPENDIX VI}

\section{9}

UTAH DRIVER LICENSE MEDICAL ADVISORY BOARD

\begin{tabular}{|l|l|}
\hline \multicolumn{2}{|c|}{ EXECUTIVE COMMITTEE MEMBERS } \\
\hline $\begin{array}{l}\text { DANA H. CLARKE, M.D., } \\
\text { CHAIR }\end{array}$ & ENDOCRINOLOGY \\
\hline ROBERT MISKA, M.D. & NEUROLOGY \\
\hline ALBERT L. UNGRICHT, M.D. & OPHTHALMOLOGY \\
\hline \multicolumn{2}{|c|}{ EXPERT PANEL MEMBERS } \\
\hline CHERIE P. BRUNKER, M.D. & GERIATRICS \\
\hline MADISON H. THOMAS, M.D. & NEUROLOGY \\
\hline TONI ROBERTS, O.D. & PHYSICAL REHABILITATION \\
\hline
\end{tabular}


Appendix B. General Screening Questionnaire and Health Care Professional Forms 
Utah Driver License Division

Abbreviated Health Questionnaire

Gast Name

First Name

Midde or Marden Naine

Date of Sirth

Onver Leenso Number

The Utah Driver License Medical Advisory Board has determined the following conditions may be directly related to driving safety. These questions must be answered by every applicant applying.for any Utah Driver License or Medical Certificate.

(Answer all questions) DO YOU HAVE, OR HAVE YOU HAD, ANY OF THE FOLLOWING IN THE LAST FIVE YEARS?

Yes $\square$ No

A. DIABETES: Diabetes (high blood sugar, sugar diabetes, you control with diet, medication or insulin) or hypoglycemia or other metabolic condition etc., which may interfere with driving safety? Is this a thyroid condition only? $\square$ Yes $\square$ No

$\square$ Yes $\square$ No

B. CARDIOVASCULAR: Heart condition, with or without symptoms, (heart attack, heart surgery, irregular rhythm. general heart disease) within the last five years; or hypertension (high blood pressurel currently requiring medication for control?

$\square$ Yes $\square$ No

C. PULMONARY: Pulmonary (lung) condition (asthma, emphysema, passing out from coughing, etc.), sleep apnea or shortness of breath which has required treatment? Is an inhaler the only medication prescribed for this condition? $\square$ Yes $\square$ No

Yes $\square$ No D. NEUROLOGIC: Neurological condition (stroke, head injury, narcolepsy, cerebral paisy, multiple sclerosis, muscular dystrophy, Parkinson's Disease, etc.) Which may interfere with driving safety?

Yes $\square$ No E. EPILEPSY: Epilepsy, seizures, other episodic conditions which include any recurrent loss of consciousness or control? [Commercial: anytime in life? $\square$ Yes $\square$ No]

Yes $\square$ No

F. LEARNING AND MEMORY: Learning and memory difficulties observed personally or reported to you by others?

Yes $\square$ No

G. PSYCHIATRIC: Psychological condition lanxiety, severe depression, behavioral mood conditions, schizophrenia, etc.), for which a physician has recommended that you take medication? List medications for this condition

$\square$ Yes $\square$ No H. ALCOHOL AND DRUGS: Excessive use of alcohol and7or prescription drugs, or use of any illegal drugs; or treatment or recommendation for treatment of alcohol use or chemical dependency?

$\square$ Yes $\square$ No
$\square$ Yes $\square$ No
$\square$ Yes $\square$ No

1. VISUAL ACUITY: Is your vision worse than $20 / 40$ in either eye, even with corrective lenses?

Are corrective lenses required for driving?

Have you experienced a decrease in peripheral (side) vision?

Do you have a degenerative or progressive eye condition?

Yes $\square$ No

J. MUSCULOSKELETAL/CHRONIC DEBILITIES: LoSS or paralysis of all or part of an extremity; or onset of a general debilitating illness requiring treatment? New or changed in the past 5 years? $\square$ Present longer than 5 years?

Yes $\square$ No K. FUNCTIONAL MOTOR IMPAIRMENT: Need for use of a brace, prosthesis or compensating accessories for driving? New or changed in the past 5 years? $\square$ Present longer than 5 years?

Yes $\square$ No L. HEARING: Have you experienced a loss of hearing? Please explain:

Are you currently wearing hearing aides? $\square$ Yes $\square$ No

Yes $\square$ No OTHER: Other health problems or use of medications which might interfere with driving ability or safety? Please explain:

I hereby certify under penalty of law that information contained in this health questionnaire is true to the best of my knowiedge.

Date: Signature: 


\section{GENERAL INFORMATION}

The Driver License Division has been authorized to extend the expiration date of licenses for persons who do not have: 11 More than 4 moving violations within five years; or, 2) A conviction for reckless driving within the last five years; or, 3) Any current suspension(s) or revocation(s) or any within the last five years, or, 4) Any medical impairment that could pose a threat to highway safety; or, 5) A Commercial Driver License.

Your driving record indicates that you are eligible; therefore, if you desire this extension, please follow the instructions below.

IMPORTANT: IF YOU WISH TO MAKE ANY CHANGES ON YOUR DRIVER LICENSE (Name Change, Address Change, Etc.) YOU MUST APPEAR AT A LOCAL ORIVER LICENSE EXAMINING OFFICE. If you change your name, you mUSt present a marriage certificate or related court documents.

\section{INSTRUCTIONS}

1. Complete the Abbreviated Health Questionnaire. (Answer each question on the reverse side of this form).

2. Complete the application. (Please do not fold or staple).

3. If you will be 65 or older on your next birchday, have a qualified ophthalmologist, optometrist, or other health care professional complete the vision exam below. The examination date must be within 6 months of the expiration date of your license, or you may appear at the most cenvenient Driver License Examining Office for a free vision check.

4. Prepare a check or money order, payable to the "Driver License Division", for the correct fee as stated on your application. PLEASE DO NOT MAIL CASH .- THANK YOU

5. Write your permanent Driver License Number on your check or money order.

6. Mail the application, medical questionnaire, eye statement if applicable, check or money order, NOT YOUR DRIVER LICENSE, in the enclosed self-addressed envelope to, Driver License Division, P.O. Box 30570, Salt Lake City, UT 84130-0570. We must receive your application before the expiration date of your driver license. When your application has been approved, a Certificate of Extension will be mailed to you within 8 weeks.

\section{AVOID WAITING IN LINE -- RETURN YOUR APPLICATION TODAY!}

NOTE: If you desire to apply at a local Driver License Examining Office, you will be required to have your vision checked and a photo taken, however, the written test will be waived if you present the enclosed application notice. IF THE APPLICATION IS MADE IN AN EXAMINING OFFICE. THERE WILL BE A FEE INCREASE AND A REGULAR APPLICATION FORM TO COMPLETE. If YOU aCt NOW, you will receive the Certificate of Extension before your current license expires. If you have already renewed your license, disregard this notice. General information telephone 965-4437.

COMPLETE THE ABBREVIATED HEALTH QUESTIONNAIRE ON REVERSE SIDE

IF YOU WILL BE 65 YEARS OR OLDER ON YOUR NEXT BIRTHDAY, YOU MUST HAVE YOUR VISION CHECKED IInsfructions bEIOW'

If you choose not to have a free vision check at a Driver License Office, then you must have a qualified ophthalmologist, optometrist. or other heaith care professional complete the following information and return this form with your application, and check or money order.

The date of the examination must be within six (6) months of the expiration date of your license.

Name

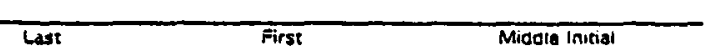

Oriver Lic. " Birth Date

\begin{tabular}{|c|c|c|c|c|}
\hline \multicolumn{2}{|c|}{ LENSES REQUIRED WHILE ORIVING: } & Q YES & \multicolumn{2}{|c|}{ ㅁ NO } \\
\hline Visual Acuity & Without Correction & With Correction & $\begin{array}{l}\text { Visual Fi } \\
120^{\circ} \\
\end{array}$ & eid at least \\
\hline RIGHT EYE & & & DYES & CNO \\
\hline LEFT EYE & & & DYES & C NO \\
\hline BOTH EYES & & & QYES & $\square$ NO \\
\hline $\begin{array}{l}\text { If visual fieids } \\
\text { Circle Profile }\end{array}$ & $\begin{array}{l}\text { e less than } 120^{\circ} \text {, } \\
\text { el: } 1234456\end{array}$ & $\begin{array}{l}\text { they at least } 90^{\circ} \text { ? } \\
89 \quad 10 \quad 11 \quad 12\end{array}$ & DYES & C NO \\
\hline
\end{tabular}




\title{
TOP PORTION MUST BE COMPLETED BY APPLICAVT
}

\begin{abstract}
Last Yame
First Name

Middle or Maiden Vame

Dase of Birth

Driver License : Yumber

As part of my applicssion for driving privileges. the following information about my physical. mienal and emotional heaith is submitted. PAST HISTORY: Report beiow anyehing which might affect driving. such as seizures. hean actacks. serious illnesses or injuries. use of alcohoi or other drugs. psychiarric conditions. accidents. visual loss, etc. Give date(s) of lass ocaurrence(s):
\end{abstract}

\section{PRESENT CONDITION: Give present starus of physical. mental or enocional problems. including medications beiag used limitalion of visual or movement functions:}

l authorize any health care protessional to reiease informacion pertaining to my physical. mencal and emocional healch for privale contidencial use in my evaluation for driving privileges. I expect the health care professional to advise me about my health as it relates to driving and to report aceurstely regarding my condicion. but I understand the Department of Public Safery is responsible for ail decisions about issuing driver licenses and medical cerrinicates. I further undersand it is my responsiöility to retrain from driving if I become aware of changes in my health which may affect diving safey and to report relevant changes in writing to the Driver License Division.

Date:

Applicant's Signanure:

\section{HEATT GABE PBOFESSIOMAL BEPQBT BELOW}

The following functional ability profile is for use in determining diving privileges. It is consistent wich Functional Ability in Driving: Guidelines and Standards For Henith Care Professionals. A summary tabulation of the Guidelines and Standards is shown on the back of this form for convenient reference. Details are found in your coov of the Guidelines and Standards. Please mark protile below with a horizontal line or an " $X$ " to show appropriate level for each caregory. In some caregories. final level may depend upon driving test. Please check the box below to indicate that a driving test should be taker.

\begin{tabular}{|c|c|c|c|c|c|c|c|c|c|c|c|c|}
\hline $\begin{array}{l}\text { Profile } \\
\text { Level }\end{array}$ & $\begin{array}{l}\text { A } \\
\text { Diabetes \& } \\
\text { Meta-bolic } \\
\text { Condition }\end{array}$ & $\begin{array}{l}\text { B } \\
\text { Cardia. } \\
\text { vascular }\end{array}$ & $\begin{array}{l}C \\
\text { Pul- } \\
\text { monary }\end{array}$ & $\begin{array}{l}\text { D } \\
\text { Neura } \\
\text { logic }\end{array}$ & $\begin{array}{l}\text { E } \\
\text { Epilepsy } \\
\text { (Episodic } \\
\text { Conditions) }\end{array}$ & $\begin{array}{l}\text { F } \\
\text { Learning } \\
\text { Memory }\end{array}$ & $\begin{array}{l}G \\
\text { Pychiatric } \\
\text { or } \\
\text { Emoxional } \\
\text { Condition }\end{array}$ & $\begin{array}{l}\text { H } \\
\text { Alcohol } \\
\text { \& Other } \\
\text { Drugs }\end{array}$ & $\begin{array}{l}! \\
\text { Visual } \\
\text { Acuity }\end{array}$ & $\begin{array}{l}\text { J } \\
\text { Musculo- } \\
\text { skeiecaly } \\
\text { Chronic } \\
\text { Debilitv }\end{array}$ & $\begin{array}{l}\text { K } \\
\text { Functional } \\
\text { Mocor } \\
\text { Imyaiment }\end{array}$ & L \\
\hline 1 & & & & & & & & & & & & \\
\hline 2 & & & & & & & & & & & & \\
\hline 3 & & & & & & & & & & & & \\
\hline 4 & & & & & & & & & & & & \\
\hline 5 & & & & & & & & & & & & \\
\hline 6 & & & & & & & & & & & & \\
\hline 7 & & & & & & & & & & & & \\
\hline 8 & & & & & & & & & & & & \\
\hline 9 & & & & & & & & & & & & \\
\hline 10 & & & & & & & & & & & & \\
\hline 11 & & & & & & & & & & & & \\
\hline 12 & & & & & & & & & & & & \\
\hline
\end{tabular}

Commercial drivers (Class A.B.CD Licenses) must be profiled in ALL categories by the examining health care professional.

If it is not possible to complete all coregories. please check one of the following:

$\square$ Profile entegories noo marked are nox relevant co driving ability in this case (e.g. visual problem onily)

口 Protile calegories not marked are retevant and should be completed by another health care professional who has more adequate information.

I t have noc examined this pacient recently or completely enough to have a valid judgment: piease refer to:

口Tere are special considerations I would like to discuss with a representative of the Department or the Medical Advisory Board

Q Other Comments:

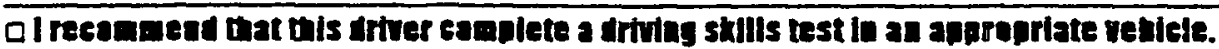

Standard intervals for medical re-evaluation for each category and profile level will apolv unless a different interval is shown under the agpropriale calegorr below.

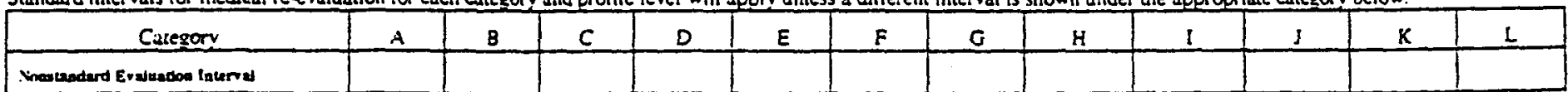

Street Address

Top Copy (pink): Health Care Professional
City

State
2nd Copy (white): Driver License Division

Telephone

3rd Copy (yellow): Applicant 


\begin{tabular}{|c|c|c|c|c|c|c|c|c|c|c|c|c|}
\hline I.evel & $\begin{array}{c}A \\
\text { Uinhetes \& } \\
\text { Alelnlunlie } \\
\text { Comditiuns }\end{array}$ & $\begin{array}{c}1 " \\
\text { Cinrillin. } \\
\text { vnsculnt }\end{array}$ & Pulmemary & $\begin{array}{c}1 " \\
\text { Neurulugical }\end{array}$ & $\begin{array}{c}\text { E } \\
\text { Eiplepsy } \\
\text { Eiplsoulic } \\
\text { Comulltions }\end{array}$ & $\begin{array}{c}r \\
\text { I.enrnluz, } \\
\text { Memiory, etc. }\end{array}$ & 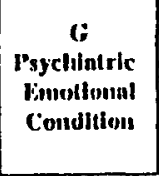 & $\begin{array}{c}\text { It } \\
\text { Nicoliut \& } \\
\text { Oflicer I)rugs }\end{array}$ & $\begin{array}{c}\text { I' } \\
\text { Visual Acuily } \\
\text { n. }\end{array}$ & $\begin{array}{c}\text { I } \\
\text { Musculoskeletul } \\
\text { or } \\
\text { Chirouic } \\
\text { Delillity } \\
\end{array}$ & $\begin{array}{c}K \\
\text { Functifusul } \\
\text { Motur } \\
\text { lompuirument } \\
\mathrm{n} . \\
\end{array}$ & $\begin{array}{c}\text { I. } \\
\text { Ilearling } \\
\text { b. }\end{array}$ \\
\hline 1 & \multicolumn{8}{|c|}{ 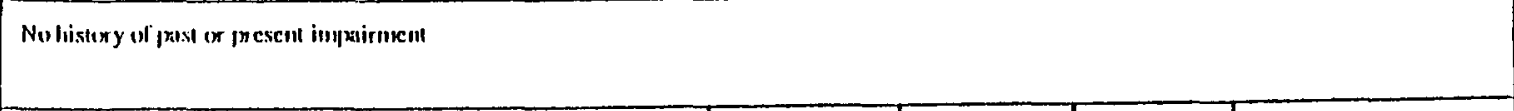 } & $\begin{array}{l}20 / 25 \text { in cacli cye. } 120^{\circ} \\
\text { visual lield in calch cyc. } \\
\text { Culor ok b. }\end{array}$ & \multicolumn{3}{|c|}{ No lisitury of past or present inpuirnent } \\
\hline 2 & \multicolumn{4}{|c|}{ I'nst innyininkent, full recovery, no necdiention } & $\begin{array}{l}\text { Free } 5 \text { years } \\
\text { wif meds } 5 \\
\text { yeurs }\end{array}$ & $\begin{array}{l}\text { I'nst impxir- } \\
\text { iment; full } \\
\text { recovery; } \\
\text { mo nucds. }\end{array}$ & $\begin{array}{l}\text { No } \\
\text { syninkeoms } \\
\text { S ycars: ofr } \\
\text { uncelicallion } \\
\end{array}$ & $\begin{array}{l}\text { No histery of nlatiol } \\
\text { ahuse No drug use in } \\
\text { bxist } 5 \text { yrs }\end{array}$ & $\begin{array}{l}20 / 41) \text { in catch cyc. } 120^{\circ} \\
\text { visuml lield in cucli cyc. } \\
\text { Color ok } \\
\text { b. }\end{array}$ & \multicolumn{3}{|c|}{ Past inyxirnxeir. full recovery, ino incedicalion } \\
\hline 1 & $\begin{array}{l}\text { biel k (nit) } \\
\text { ingent stibl)le }\end{array}$ & $\begin{array}{l}\text { Cliss 1 } \\
\text { Rlyythim } \\
\text { slabile } 5 \text { yrs } \\
\text { b. }\end{array}$ & 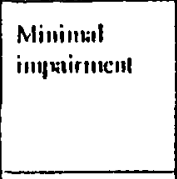 & $\begin{array}{l}\text { Very Mimiunal } \\
\text { inviairmemit }\end{array}$ & $\begin{array}{l}\text { litec } 5 \text { yrs ult } \\
\text { meds } 3 \text { yrs }\end{array}$ & $\begin{array}{l}\text { Alininat } \\
\text { impairneil }\end{array}$ & $\begin{array}{l}\text { Stable I gr; } \\
\text { on or off } \\
\text { nedicastion }\end{array}$ & $\begin{array}{l}\text { History of doug use or } \\
\text { rlcoluel abusc lut not int } \\
\text { paist } 5 \text { yrs }\end{array}$ & $\begin{array}{l}20190 \text { in lueter cyc. } \\
120^{n} \text { visual field in cach } \\
\text { cyc. Stable pathulogy. } \\
\text { Color ok. } \\
\text { b. } \\
\end{array}$ & $\begin{array}{l}\text { Mininat residual } \\
\text { luss } \\
\text { of function }\end{array}$ & $\begin{array}{l}\text { Nolimit in } \\
\text { driving }\end{array}$ & $\begin{array}{l}\text { Able to hear } \\
\text { forced } \\
\text { whisper ut } 5 \\
\text { feet w/o aid }\end{array}$ \\
\hline 4 & $\begin{array}{l}\text { Slably|c I } \\
\text { year }\end{array}$ & $\begin{array}{l}\text { Alis Clisss I } \\
\text { h. }\end{array}$ & $\begin{array}{l}\text { Mild } \\
\text { innprirnkent }\end{array}$ & $\begin{array}{l}\text { Miniuntal } \\
\text { impxirunem! }\end{array}$ & $\begin{array}{l}\text { I yeir frec - on } \\
\text { or off } \\
\text { medicution }\end{array}$ & $\begin{array}{l}\text { Benderline } \\
\text { Cognitive } \\
\text { innquiruncul }\end{array}$ & $\begin{array}{l}\text { Stahlic } 3 \\
\text { momths; on } \\
\text { or off } \\
\text { nnedicntion }\end{array}$ & $\begin{array}{l}\text { Ilisteny or arug use or } \\
\text { alcolwol abuse but not in } \\
\text { paist } 2 \text { grs }\end{array}$ & $\begin{array}{l}20 / 40 \text { in theller cyc. } \\
120^{\circ} \text { total visual ficld. } \\
\text { Stallic pathiology. Color } \\
\text { ok } \\
1 . \\
\end{array}$ & $\begin{array}{l}\text { Mild residual loss } \\
\text { of function }\end{array}$ & \multirow{5}{*}{$\begin{array}{l}\text { Denkmstrated } \\
\text { nbility lo } \\
\text { liandle velicies } \\
\text { lo le driven, } \\
\text { witl or without } \\
\text { coinnensaleny } \\
\text { aids }\end{array}$} & $\begin{array}{l}\text { Able lu hens } \\
\text { forced } \\
\text { whisper at } 5 \\
\text { reet will aid }\end{array}$ \\
\hline 5 & $\begin{array}{l}\text { Stulle G } \\
\text { Inumul|s }\end{array}$ & $\begin{array}{l}\text { AlIA Class II } \\
\text { b. }\end{array}$ & $\begin{array}{l}\text { Oyspmen with } \\
\text { unustual } \\
\text { uctivity }\end{array}$ & $\begin{array}{l}\text { Mtild } \\
\text { innpuirment }\end{array}$ & $\begin{array}{l}6 \text { montl frec; } \\
\text { on an otr } \\
\text { modication }\end{array}$ & $\begin{array}{l}\text { Mild } \\
\text { intellcctual } \\
\text { impairment } \\
\end{array}$ & $\begin{array}{l}\text { Stally } 1 \\
\text { mombli: (un } \\
\text { unedication }\end{array}$ & $\begin{array}{l}\text { Ilistory or drug use ur } \\
\text { nlcohul aluse but not in } \\
\text { past } 6 \text { unths }\end{array}$ & $\begin{array}{l}20 / 40 \text { in betler cye. } \\
120)^{\circ} \text { tulal visual ficld. } \\
\text { Uistrable pantholugy }\end{array}$ & $\begin{array}{l}\text { Moxlerule } \\
\text { residual loss or } \\
\text { function } \\
\end{array}$ & & $\begin{array}{l}\text { Unable lo } \\
\text { liear foreed } \\
\text { whisper }\end{array}$ \\
\hline 6 & $\begin{array}{l}\text { Stithle } 3 \\
\text { memillos }\end{array}$ & $\begin{array}{l}\text { AlIA Cliass III } \\
\text { Ulislialibe } \\
\text { Iliythin. }\end{array}$ & Nor Used & $\begin{array}{l}\text { Menkerste } \\
\text { impairmeent }\end{array}$ & 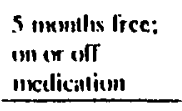 & Nex Used & $\begin{array}{l}\text { Siatile. Min. } \\
\text { uncel clicets }\end{array}$ & 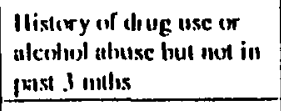 & 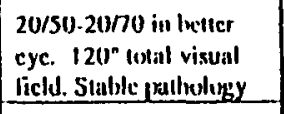 & $\begin{array}{l}\text { Mexlerale } \\
\text { innztirunem }\end{array}$ & & $\begin{array}{l}\text { Mure than } \\
\text { 65 dec loss } \\
\text { I'riv. Only } \\
\end{array}$ \\
\hline 7 & \multirow[t]{3}{*}{ 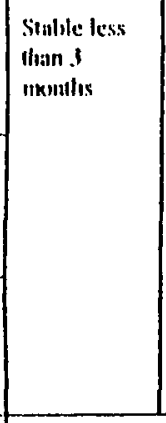 } & ctc. & $\begin{array}{l}\text { Minflerilc } \\
\text { dyspuca; i' }{ }^{\prime} \\
\text { ever 5i) }\end{array}$ & $\begin{array}{l}\text { Mexlecinte will } \\
\text { inprairnent \& } \\
\text { lmigue }\end{array}$ & $\begin{array}{l}4 \text { monitis free: } \\
\text { ow or ofl } \\
\text { medication }\end{array}$ & & Nol used & $\begin{array}{l}\text { llistery of drug use or } \\
\text { alecthol ahesse but not in } \\
\text { paist nomblh }\end{array}$ & $\begin{array}{l}20 / 50-20 / 70 \text { in heller } \\
\text { eye. } 120^{\circ} \text { lotil visual } \\
\text { ficld. Unstalle } \\
\text { palliolugy }\end{array}$ & & & \\
\hline 8 & & & $\begin{array}{l}\text { Mexlermete } \\
\text { dyspmed }\end{array}$ & Not uscd & $\begin{array}{l}3 \text { unoniths frec; } \\
\text { on er off } \\
\text { medication }\end{array}$ & & & Intcrusillenll prallersus & $\begin{array}{l}20 / 80-20 / 100 \text { in beller } \\
\text { cye. } 90^{\circ} \text { Iotal visual } \\
\text { field. Stable pathulogy }\end{array}$ & & & \\
\hline 9 & & & $\begin{array}{l}\text { Unynedicl- } \\
\text { athle } \\
\text { syminnoms }\end{array}$ & $\begin{array}{l}\text { Tempxorny } \\
\text { inquirusent }\end{array}$ & Not used & & $\begin{array}{l}\text { Variuble } \\
\text { symmouns }\end{array}$ & $\begin{array}{l}\text { Inlermintaun usc: driving } \\
\text { only with } \\
\text { licenscd driver } \\
\text { icsirictions alply }\end{array}$ & $\begin{array}{l}20 / 80-20 / 100 \text { in better } \\
\text { eye. } 900^{\circ} \text { lotal visual } \\
\text { lield. Unstoble } \\
\text { gaullough }\end{array}$ & $\begin{array}{l}\text { Reçuiring } \\
\text { assistance }\end{array}$ & $\begin{array}{l}\text { Accounyanied } \\
\text { by licensed } \\
\text { driver }\end{array}$ & \\
\hline 10 & \multicolumn{11}{|c|}{ Special cincunsianecs - Sec Guidelines and Stiundards fen canch calegeny } & \\
\hline 11 & \multicolumn{12}{|c|}{ Under cvalualion c. } \\
\hline 12 & \multicolumn{11}{|l|}{ Nos driving } & \\
\hline
\end{tabular}

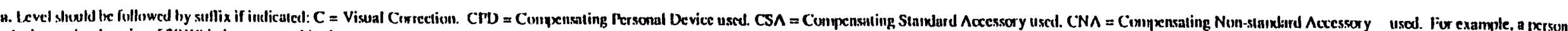

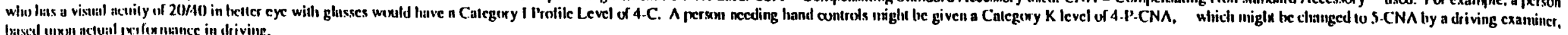

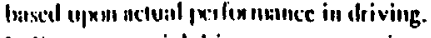

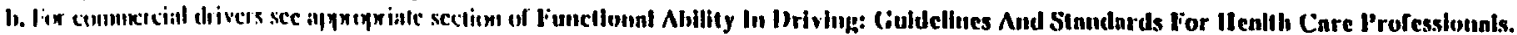

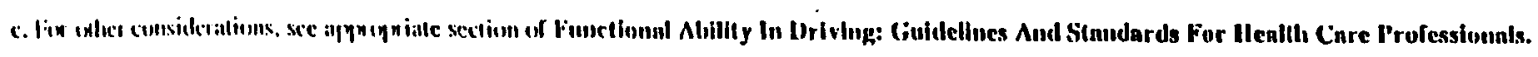

FOR USL AS AN OVERVULW ONLY 
Appendix C. Executive Summary From the First Report, "Evaluating Drivers Licensed with Medical Conditions in Utah, 1992-1996" 


\section{Executive Summary}

The Utah Driver License Division operates a specialized licensing program for drivers who have medical conditions. The program was developed by the division under the guidance of the Utah Medical Advisory Board. The program's guideline describes the physical, mental and emotional capabilities appropriate for various types of driving and determines license eligibility by medical condition or functional ability category, and functional ability level (1-12). The intent of the board was to create the least restrictive program possible that was consistent with public safety. Drivers who are licensed with medical conditions may receive a full unrestricted or restricted license depending on their functional ability level. Restricted licenses may include speed, area and/or time of day limitations. The functional ability or medical condition categories include:

1. diabetes mellitus and other metabolic conditions,

2. cardiovascular,

3. pulmonary,

4. neurologic,

5. epilepsy and other episodic conditions,

6. learning/memory/communications,

7. psychiatric or emotional conditions,

8. alcohol and other drugs,

9. visual acuity, musculoskelatal abnormalities/chronic medical debilities,

10. functional motor ability, and

11. hearing

Utah CODES was funded to evaluate the effect of the existing medical condition licensing program on public safety. The project was funded in part by NHTSA, with the support of the Utah Driver License Division in the Utah Department of Public Safety, and the Utah Department of Transportation.

In order to determine the effects of this public safety program, we compared the citation, crash and at-fault crash rates of drivers licensed with medical conditions to those of similar drivers matched on age group, gender and county of residence. Comparison drivers were obtained randomly from the general driving population and rates of adverse driving events were examined over a five year period, 1992-1996. A two-to-one matching strategy was used. Sampling was performed with replacement.

Analyses were conducted for each functional ability or medical condition category by restriction status. Analyses for drivers licensed with multiple medical conditions were conducted separately, by restriction status. The previous analyses were also conducted separately for drivers who maintained one restriction status during the study period, and drivers whose restriction status fluctuated during the study period. We used probabilistic linkage to link data elements relating to the same driver from several different databases in order to combine the elements needed for the study (i.e., crash, violation and driver license databases).

The rates of citation, crash and at-fault crash varied between the populations and events of interest. Overall, unrestricted drivers licensed with single medical conditions had higher rates of citation, crash and at-fault crashes than the chosen comparison drivers. The differences were 
statistically significant, but of small magnitude. Restricted drivers licensed with single medical conditions during the study period had higher rates of crash and at-fault crash than unrestricted program drivers, but similar rates of citation. Analysis by individual functional ability categories (medical conditions), showed great variation. Of interest, the citation risk for unrestricted drivers licensed in the categories "cardiovascular" and "pulmonary" had significantly lower rates of citation than their chosen comparison drivers, but similar rates of crash and at-fault crash. The greatest citation risks were found in the restricted categories "learning, memory and communication disorders" and "alcohol and other drugs" where the rates were 11.63 and 5.83 times higher respectively than of the selected comparison drivers. However, these populations were extremely small $(\mathrm{N}=6$ and $\mathrm{N}=24$ respectively) so their impact on public safety was negligible. Similarly, the greatest risks for all crash and at-fault crash occurred in small, restricted driving populations licensed in the "musculoskelatal abnormalities" and "alcohol and other drugs" categories ( $\mathrm{N}=32$ and $\mathrm{N}=24$ respectively).

Drivers who were licensed with more than one medical condition during the study period were analyzed separately. The risks for crash and at-fault crash were higher than those of the chosen comparison drivers for both restricted and unrestricted drivers. The magnitude of risk was highest for at-fault crash for drivers who had restrictions imposed on their driver licenses; the rate was 1.76 times higher than those of the chosen comparison drivers $(95 \% \mathrm{CI} 1.40,2.28)$. The rates of citation for unrestricted drivers were similar and citation rates for restricted drivers were significantly lower than those of their respective comparison groups:

The results of this study provide contextual information on the effects of the medical conditions licensing program on public safety. Specifically, we found that the overall rates of adverse driving events varied between medical condition or category type, and restriction status. Of interest, in the largest functional ability category, cardiovascular $(N=18,990)$, the rates for all adverse events were similar to those of their comparison groups for both restricted and unrestricted drivers; however, unrestricted drivers in this category had a slight but significantly lower rate of citation. For unrestricted drivers, the highest risk of at-fault crash was found in the learning, memory and communications category where the risk of at-fault crash was 3.63 times higher than their respective comparison group $(95 \%$ CI $2.00,6.60)$. The greatest differences in at-fault crash rates were found in restricted license categories. Restricted drivers in the musculoskelatal abnormality or chronic medical disability group had a rate 11.29 times higher than their comparison drivers $(95 \%$ CI $2.39,53.25)$.

As with any injury control intervention, evaluation is an essential component of the program in order to identify areas of increased risk and to provide feedback to the administering agency. Further research should be performed to evaluate the rates of adverse driving events by individual functional ability levels in order to determine if there are distinct levels for which risk increases or decreases, and to describe the effects of co-existing medical conditions for large categories. This information will help to identify areas where the program could be improved, as well as, help to identify functional ability categories where unnecessary restrictions could be eliminated. 
DOT HS 809211

February 2001

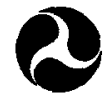

U.S. Department of Transportation

National Highway 